(N)

Cite as

Nano-Micro Lett.

(2020) 12:118

Received: 22 March 2020

Accepted: 22 April 2020

Published online: 30 May 2020

(C) The Author(s) 2020

\section{A Review on Nano-/Microstructured Materials Constructed by Electrochemical Technologies for Supercapacitors}

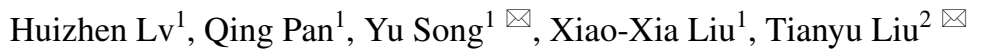 \\ Huizhen Lv and Qing Pan have contributed equally to this work. \\ $\bowtie$ Yu Song, songyu@mail.neu.edu.cn; Tianyu Liu, tliu23@vt.edu \\ 1 Department of Chemistry, Northeastern University, Shenyang 110819, People's Republic of China \\ 2 Department of Chemistry, Virginia Polytechnic Institute and State University, Blacksburg, VA 24061, USA
}

\title{
HIGHLIGHTS
}

- Recent progress of active materials in supercapacitors synthesized by electrochemical techniques is reviewed.

- Electrochemically synthesized nanostructures of various dimensions, compositions, and electrochemical properties are discussed.

- The advantages and challenges of electrochemical technologies in preparing nano-/microstructured materials for electrochemical energy storage devices are summarized.

ABSTRACT The article reviews the recent progress of electrochemical techniques on synthesizing nano-/microstructures as supercapacitor electrodes. With a history of more than a century, electrochemical techniques have evolved from metal plating since their inception to versatile synthesis tools for electrochemically active materials of diverse morphologies, compositions, and functions. The review begins with tutorials on the operating mechanisms of five commonly used electrochemical techniques, including cyclic voltammetry, potentiostatic deposition, galvanostatic deposition, pulse deposition, and electrophoretic deposition, followed by thorough surveys of the nano-/microstructured materials synthesized electrochemically. Specifically, representative synthesis mechanisms and the state-of-the-art electrochemical performances of exfoliated graphene, conducting polymers, metal oxides, metal

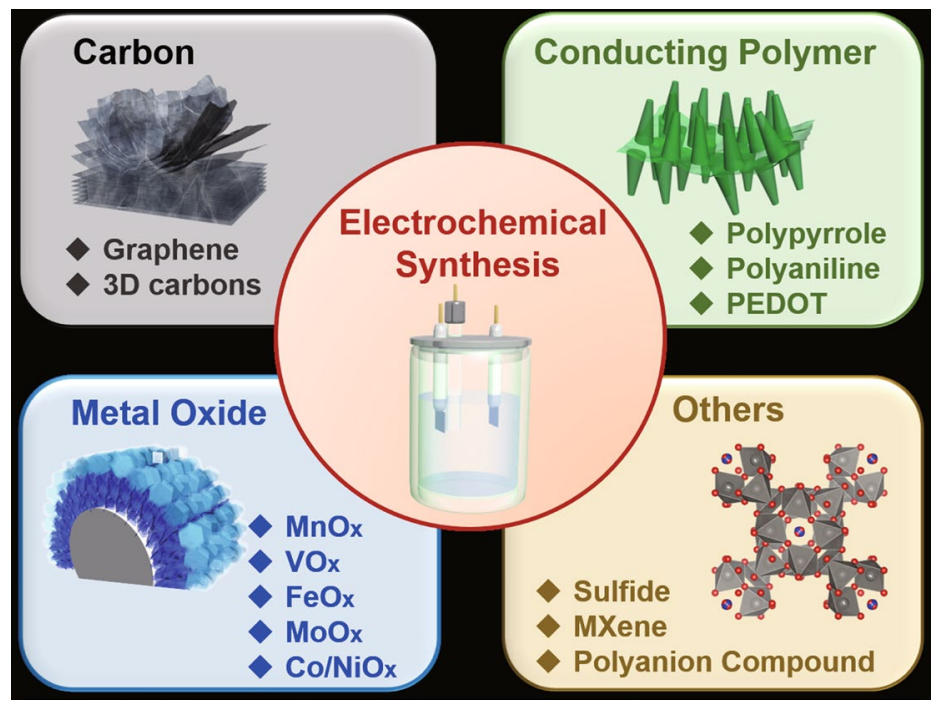
sulfides, and their composites are surveyed. The article concludes with summaries of the unique merits, potential challenges, and associated opportunities of electrochemical synthesis techniques for electrode materials in supercapacitors.

KEYWORDS Nanostructure; Microstructure; Electrochemical; Synthesis; Supercapacitor 


\section{Introduction}

The rapidly expanding markets of mobile electronics, electrified transportation, wireless networks (e.g., the Internet of Things), and sustainable energy utilization have substantially fueled the development of electrochemical energy storage systems [1-4]. Supercapacitors, including electrochemical capacitors and pseudocapacitors, stand out among diverse arrays of energy storage devices due to their ultrahigh power density and ultralong life spans [5-9]. Since the first introduction in 1957 by Howard Becker of American General Electric [10], supercapacitors have pervaded in applications demanding energy input and output with high power, e.g., the power source to the emergency doors of Airbus A380 aircraft $[11,12]$. Therefore, elevating the capacitance and energy density of supercapacitors at ultrafast charging rates has remained a central topic [13-16]. Extensive research efforts have been devoted to developing high-performance electrode materials [13, 15-17], since electrodes primarily determine the capacitance, energy density, and power density of supercapacitors.

Supercapacitors are classified into two categories: electric double-layer capacitors (EDLCs) and pseudocapacitors. EDLCs store charges through adsorption and desorption of ions in electrolytes at the electrolyte/electrode interfaces. Carbon materials are conventional electrode materials in EDLCs. Pseudocapacitors store charges through kinetically fast Faradaic reactions. Surface redox pseudocapacitance, intercalation pseudocapacitance, and underpotential deposition are examples of pseudocapacitance [13]. Redox pseudocapacitance occurs when electrolyte ions adsorbed on or near the electrode surfaces and involves interfacial charge transfer. Intercalation pseudocapacitance comes from reversible insertion and desertion of electrolyte ions in layered or tunneled electrode materials without phase transitions. Underpotential deposition will be elaborated in Sect. 2.2, but it is not used for charge storage due to its limited capacity. Pseudocapacitance has its electrochemical features, such as quasi-rectangular cyclic voltammetry curves, linear galvanostatic charge/discharge profiles, as well as a near-linear response between current and scan rate in cyclic voltammograms. These characteristics must be clearly distinguished from battery-type behaviors (Sect. 5.6).

Electrochemical techniques are a group of synthesis methods of versatile active materials in supercapacitors. These methods have a history of more than 150 years [18], and their first application is to plate metals for jewelry decoration, surface protection, and electronic-circuit manufacturing [19]. Along with the boom of electrochemical energy storage, the role of electrochemical techniques has been enriched by synthesizing nano-/microstructured materials for electrochemical energy storage $[2,20]$. The syntheses involve electrochemical processes including reduction, oxidation, gas evolution, ion intercalation, and combinations of these methods thereof. Chemical reactions, such as the electrolysis of electrolytes (e.g., $\mathrm{H}_{2}$ and $\mathrm{O}_{2}$ evolution in aqueous electrolytes), redox reactions of electrolyte ions, as well as modifications of the structures and compositions of electrode materials, are typically accompanying phenomena.

Compared to other synthesis strategies, electrochemical techniques have their unique advantages. First, they are facile and mild. Room temperature, ambient pressure, and aqueous solutions are sufficient for performing electrochemical techniques. Second, the experimental setups, such as electrolytic cells and electrochemical workstations, are often readily available in electrochemistry laboratories. This availability allows electrochemists to prepare active materials without delicate instruments and sophisticated protocols. Perhaps the most striking feature of electrochemical techniques is their high tunability toward the structure, composition, property, and morphology of products [2, 20]. Magnitudes of applied current or voltage, types and concentrations of salts in electrolytes, reaction durations, solution temperatures, as well as substrate morphologies are all tunable parameters that result in versatile materials. Benefited from these merits, electrochemical techniques have been extensively studied and rapidly developed in the past decades. The materials that have been prepared electrochemically include exfoliated graphene [21], metal oxides [22-24], conducting polymers $[25,26]$, and their composites [27-29].

This review article presents a thorough survey of electrochemically synthesized nano-/microstructured materials for supercapacitors. It starts with introduction of the operating mechanisms, characteristics of input and output signals, strengths, and weaknesses of cyclic voltammetry, potentiostatic (constant voltage) and galvanostatic (constant current) depositions, pulse electrodeposition, and electrophoretic deposition. Afterward, the article reviews the recent progress of the active materials synthesized by electrochemical techniques. This part is segmented based on the compositions of 
materials, including carbon-based materials, metal oxides, conducting polymers, composites, and other materials. Each subsection starts with typical synthesis mechanisms and is exemplified with one or more representative examples in the literature. At last, the article comments on the merits, challenges, and opportunities of electrochemical technologies in terms of synthesizing nano-/microstructured materials for electrochemical energy storage.

\section{Fundamentals of Electrochemical Synthesis Techniques}

Cyclic voltammetry, galvanostatic deposition, potentiostatic deposition, pulse deposition, and electrophoretic deposition constitute the most widely and extensively investigated and practiced electrochemical synthesis techniques for nano-/ microstructured materials as supercapacitor electrodes. These processes are typically carried out in electrolytic cells powered by electrochemical workstations. Based on the number of electrodes involved, the setup for electrochemical synthesis is categorized into two types: two-electrode (Fig. 1a) and three-electrode (Fig. 1b) configurations
[30]. The two-electrode configuration contains a positive electrode and a negative electrode that are both immersed in electrolytes. An electrochemical workstation or power source provides voltage across the two electrodes. Therefore, the measured voltage in this scenario is the overall cell voltage. The three-electrode system comprises a working electrode (WE), a counter electrode (CE), and a reference electrode (RE). Ideally, current flows only between WE and CE, and the voltage of WE is referenced to that of RE. Saturated calomel electrode (SCE), $\mathrm{Ag} / \mathrm{AgCl}$, and $\mathrm{Hg} / \mathrm{HgO}$ electrodes with their nearly constant half-reaction potentials are common REs. REs are placed in vicinity to WEs to minimize $i R$ drop and voltage fluctuation due to electrolyte resistance [31]. The measured voltage in three-electrode configurations is the real-time potential of WEs.

\subsection{Cyclic Voltammetry (CV)}

Besides a conventional electrochemical technique for probing electrochemically redox activities [32], CV serves as a synthetic tool. It linearly scans potential within a range, termed potential window, and simultaneously records (a)

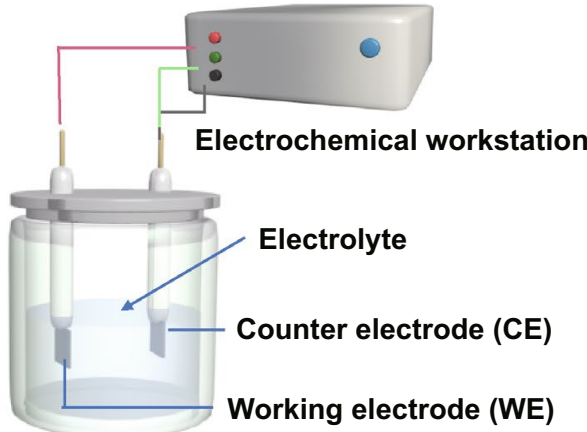

(b)

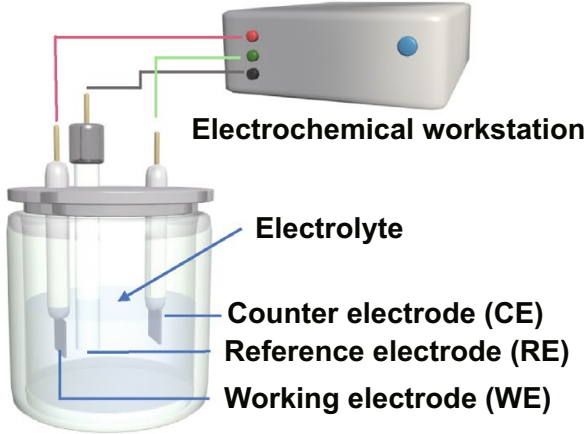

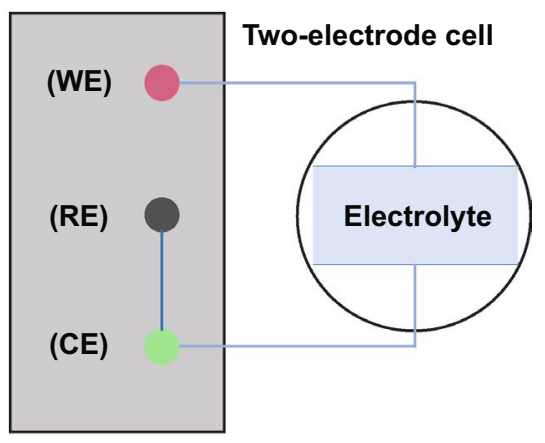

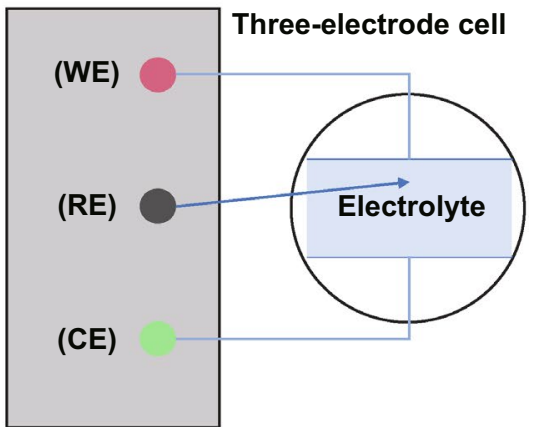

Fig. 1 Schemes illustrating the experimental setups of a two-electrode and $\mathbf{b}$ three-electrode electrolytic cells for electrochemical syntheses 
current as a response [33]. Increasing the applied potential, the forward scan oxidizes species in electrolytes or on electrodes and produces anodic current. Conversely, the backward scan decreases the applied potential, reduces active components, and generates a cathodic current.

$\mathrm{CV}$ has three main advantages as a synthetic approach. First, it allows for determining the onset potential of an electrodeposition reaction. Oxidation or reduction reactions involving charge transfer across the electrolyte-electrode interfaces will display sharp increases or well-defined peaks in the current. Since the onset potential is the minimum voltage needed to initiate electrodeposition reactions, $\mathrm{CV}$ is useful for developing experimental protocols. Second, the potential linear scan of $\mathrm{CV}$ is beneficial for growing uniform and conformal films. This characteristic provides a gradient driving force for deposition: Deposition will only begin until the potential is scanned above the onset potential, and the driving force of deposition scales linearly with the potential gradually elevated away from the onset potential. This gradient driving force of $\mathrm{CV}$ adjusts the deposition rate and avoids consistently high deposition voltages that can lead to overgrowth of materials, rapid clogging of pores, and/or uneven deposition of films. Third, CV is suitable for synthesizing materials with multiple valence states, e.g., transition metal oxides. For example, deposited by $\mathrm{CV}$ within a potential range between -1.5 and $1.5 \mathrm{~V}$ vs. SCE in a $0.1 \mathrm{M}$ $\mathrm{VOSO}_{4}$ aqueous electrolyte, vanadium oxide nanorods contained $\sim 50 \% \mathrm{~V}_{5} \mathrm{O}_{12}$ (a mixture of $\mathrm{V}^{5+}$ and $\mathrm{V}^{4+}$ ) and $\sim 50 \%$ $\mathrm{VO}_{2}$ [34]. The high valence state, $\mathrm{V}^{5+}$, formed during the anodic or forward scan, while the as-deposited $\mathrm{V}_{5} \mathrm{O}_{12}$ was partially reduced to $\mathrm{VO}_{2}$ in the subsequent cathodic or backward scan. These redox processes were documented by the broad peaks in the corresponding CV curve (Fig. 2). Compounds with multivalent species reportedly possess augmented capacitance [35], improved rate capability [34, 36], as well as enhanced cycling stability $[37,38]$ compared to their monovalent counterparts.

\subsection{Potentiostatic (Constant Voltage) Deposition}

Potentiostatic deposition synthesizes materials by applying a constant potential across the positive and negative electrodes (two-electrode system) or between the working and counter electrodes (three-electrode system). The deposition potential is maintained constant by an electrochemical workstation

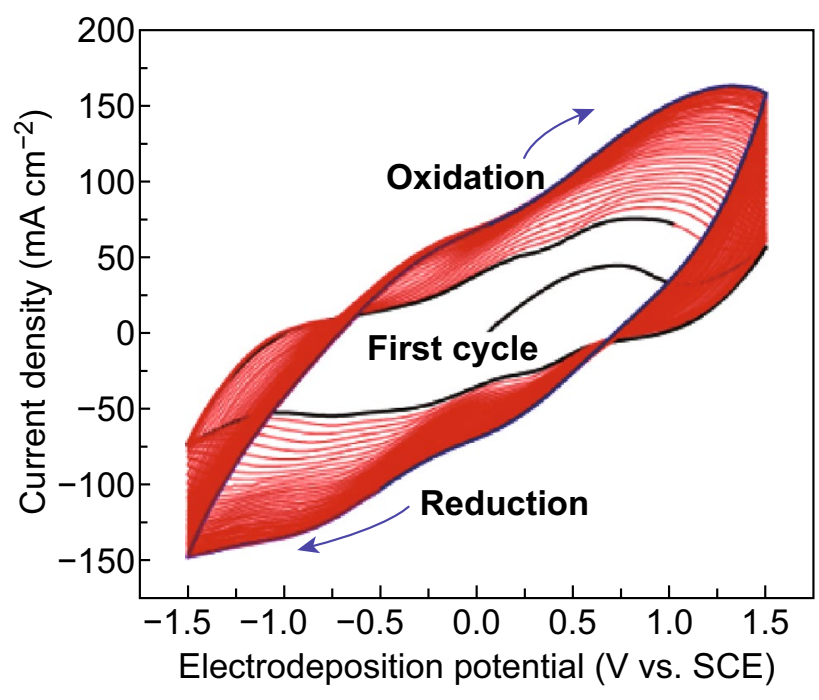

Fig. $2 \mathrm{CV}$ curves of the deposition of mixed-valence vanadium oxide nanorods

(Fig. 3a), and the current is recorded as a function of time (Fig. 3b) [39]. Based on the difference between applied and thermodynamic equilibrium potentials, potentiostatic deposition is categorized into underpotential deposition (UPD) and overpotential deposition (OPD) [40, 41].

UPD happens at potentials below thermodynamic equilibrium potentials. For example, metal deposition can initiate at potentials smaller than the corresponding equilibrium reduction potentials, due to the lower work function of the deposited metal than that of the substrate metal, as described by the Kolb-Gerischer equation [42]:

$\Delta E=0.5 \Delta \phi$

where $\Delta E$ is the downshift of deposition potential (in $\mathrm{V}$ ) and $\Delta \phi$ is the difference in the work functions between the deposited and substrate metals (in $\mathrm{eV}$ ). The coefficient 0.5 (in $\mathrm{V} \mathrm{eV}^{-1}$ ) comes from a linear fitting involving 21 metal-metal couples [42]. UPD involves adsorption, nucleation, and growth processes determined by surface characteristics of substrates (e.g., chemical composition, crystal structure, morphology, and electrolyte wettability) and ion-substrate interactions. Besides, the types of cations in electrolytes and anions strongly influence the structure and properties of the deposited materials, as well as deposition kinetics [43-45]. One example is the UPD of $\mathrm{Cu}$ on $\mathrm{Au}(111)$ facets in aqueous sulfuric acid solutions [46]. The deposition was much slower under $\mathrm{pH}=2$ than $\mathrm{pH}=4$. This discrepancy in the deposition rate was correlated with the different anions under different $\mathrm{pH}$ values. Increasing the solution 
(a)

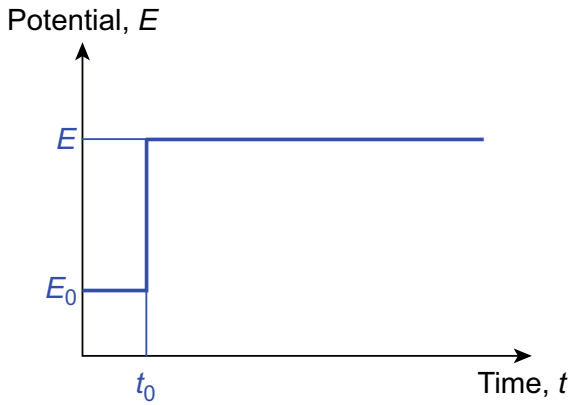

(b)

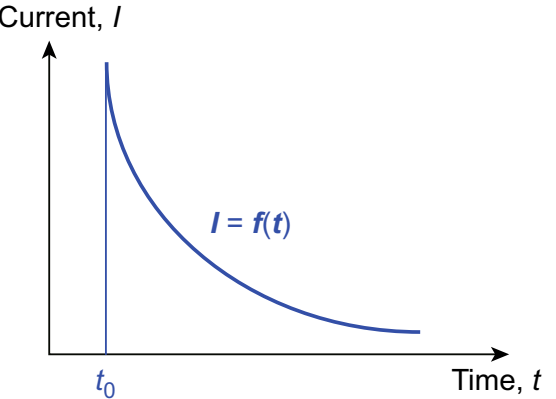

Fig. 3 a Constant potential applied in potentiostatic deposition; $E_{0}$ and $E$ are the open-circuit potential and the applied potential; $t_{0}$ marks the starting time of deposition. b Corresponding current as a function of time

acidity converted bisulfate ions to sulfate ions. The latter adsorbed much more strongly than the former on the gold substrate, which blocked some active sites for deposition and hence decelerated the UPD.

OPD occurs in potentials above thermodynamic equilibrium potentials [39, 47]. The structure and properties of the OPD deposits highly depend on various factors, including overpotential (the difference between applied and equilibrium potentials), electrolyte concentration, growth mechanism and deposit-substrate interactions [41]. Notably, diffusion-controlled nucleation is often the rate-determining step of OPD, while that of UPD is the deposit lattice incorporation into substrate [46].

\subsection{Galvanostatic (Constant Current) Deposition}

Galvanostatic deposition refers to electrodeposition with constant currents between the positive and negative electrodes in a two-electrode system, or between the working electrode and counter electrode in a three-electrode setup (Fig. 4a) [39]. The recorded response is the time-dependent potential of the cell (two-electrode) or the working electrode (threeelectrode). The $V-t$ curves (Fig. $4 \mathrm{~b}$ ) sometimes are called polarization curves. Unlike potentiostatic deposition that can start the moment when potentials are applied, galvanostatic deposition needs a short period to begin [48, 49]. It is because that some applied current needs to charge electrical double layers (EDLs) first. After potential reaches certain thresholds (usually equilibrium potentials plus overpotentials), electrochemical reactions occur. Therefore, the applied constant current $(I)$ is contributed from two components:

$I=I_{\mathrm{DL}}+I_{\mathrm{ct}}$ where $I_{\mathrm{DL}}$ is capacitive current for charging EDLs and $I_{\mathrm{ct}}$ is charge transfer current for electrodeposition. $I_{\mathrm{DL}}$ rapidly approaches zero when electrodeposition starts.

$V-t$ curves of galvanostatic deposition contain essential information on electrodeposition chemistries. Since EDL charging time is on the order of milliseconds, $V-t$ curves collected on the timescale of minutes or hours are almost contributed from electrodeposition. For example, the $V-t$ curves of manganese dioxide $\left(\mathrm{MnO}_{2}\right)$ deposition processes at different temperatures qualitatively elucidate the nucleation kinetics (Fig. 4d) [50]. The increased potentials at the beginning of the electrodeposition corresponded to the nucleation of $\mathrm{MnO}_{2}$ as nucleation demanded more energy than its growth to surmount the activation energy barrier. Increasing temperature from 25 to $60{ }^{\circ} \mathrm{C}$ offered the additional electrodeposition energy to enable the $\mathrm{MnO}_{2}$ deposition at the reduced deposition potentials. The prolonged nucleation process at $25{ }^{\circ} \mathrm{C}$ results in dense manganese oxide nanosheets.

\subsection{Pulse Electrodeposition}

Pulse electrodeposition technique deposits materials by applying pulses of potential or current, i.e., a series of pulses with equal polarization, amplitude, and duration, separated by periodic zero current or open-circuit potentials (Fig. 5) $[39,51]$. Each pulse has "on" periods when the current or potential is applied and "off" periods with no current or potential (Fig. 5) [52-54]. During the "off" periods, ions in electrolytes diffuse into electric double layers along the surfaces of the deposition substrates, which is beneficial to obtain the uniform deposition of fine-grained deposits during "on" periods [55-57]. 
Current, I

(a)

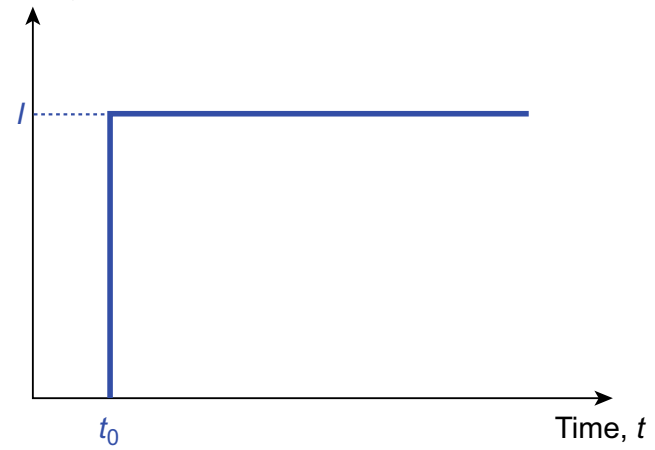

(c)

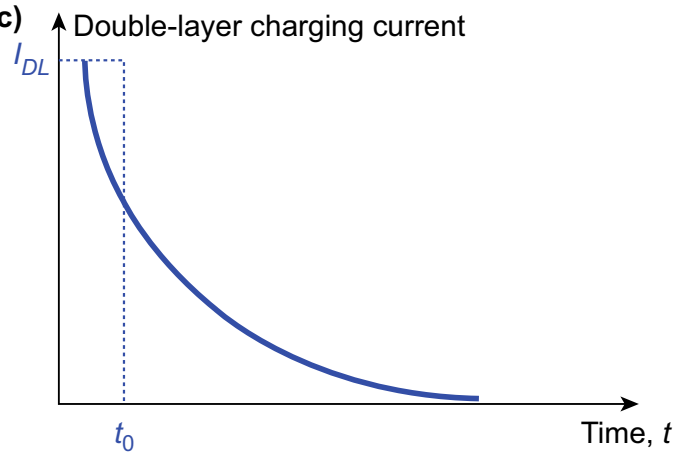

\section{Potential, E}

(b)
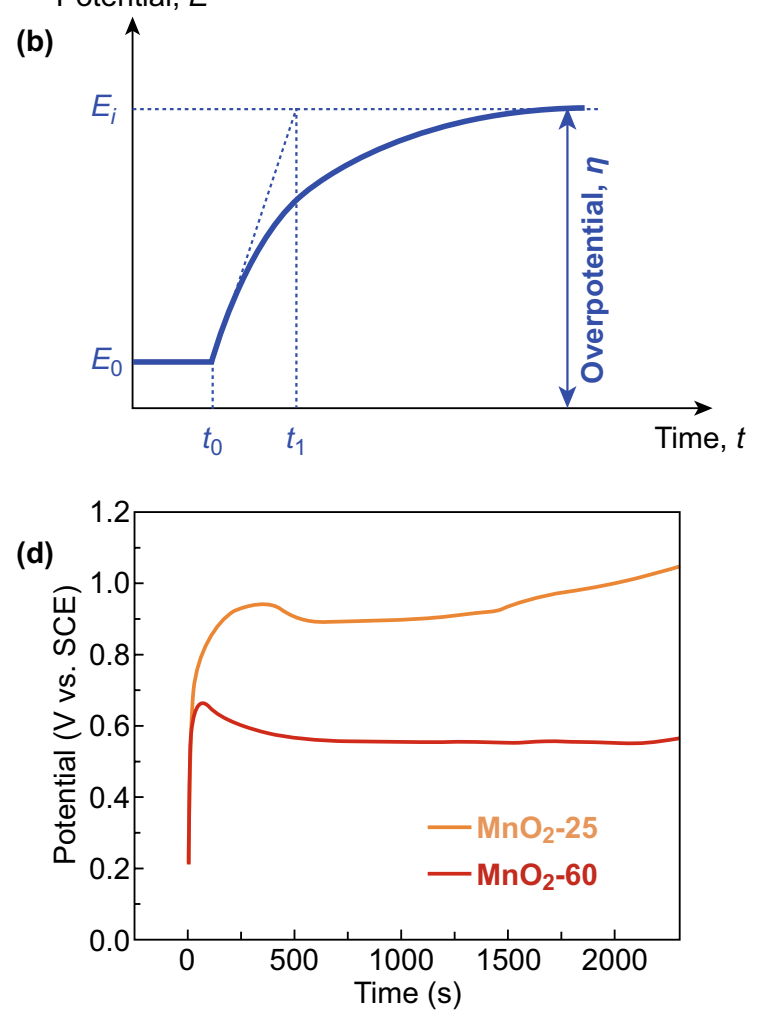

Fig. 4 a Constant current applied during a galvanostatic deposition; $t_{0}$ represents the moment when current is applied. b Potential response as a function of time in a galvanostatic deposition; $E_{0}$ and $E_{\mathrm{i}}$ are the equilibrium potential and maximal potential of a working electrode during galvanostatic deposition, respectively. $\mathbf{c}$ Double-layer charging current $\left(I_{\mathrm{DL}}\right)$ decays exponentially with time. $\mathbf{d}$ Time evolutions of the potential during galvanostatic depositions of $\mathrm{MnO}_{2}$ at temperatures of $25{ }^{\circ} \mathrm{C}$ (orange) and $60{ }^{\circ} \mathrm{C}$ (red). Adapted from Ref. [50] with permission. (Color figure online)

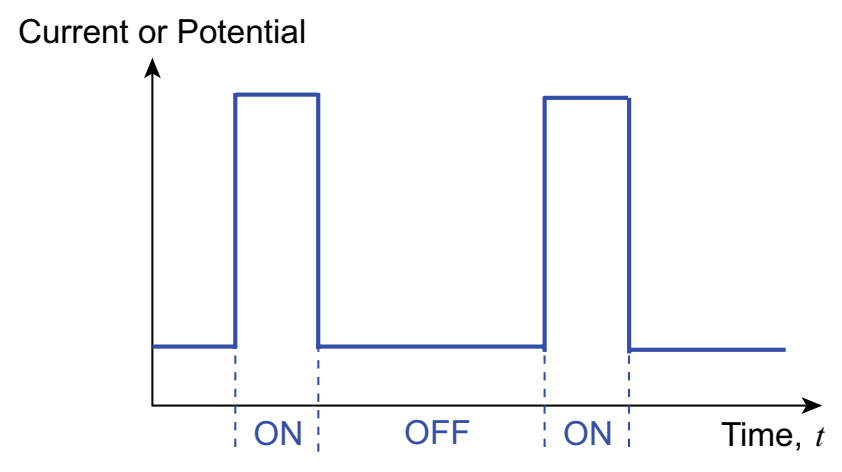

Fig. 5 Current or potential signals applied in pulse electrodeposition

Using pulsed electrodeposition, Yu et al. synthesized flexible graphene/polypyrrole composite films as pseudocapacitor electrodes [57]. The "off" period allowed pyrrole monomers to diffuse into the intersheet spaces of graphene and then electropolymerized into uniform polypyrrole coatings over the "on" periods. By contrast, the continuous, unpulsed electrodeposition triggered the fast polymerization of pyrrole near the graphene sheets. Since there are no "off" periods to replenish pyrrole monomers near graphene surfaces, the lowered reactant concentration led to scattered polypyrrole particles on the graphene surface. This work highlights the suitability of pulse electrodeposition in coating uniform films onto irregularly shaped substrates.

\subsection{Electrophoretic Deposition}

Electrophoretic deposition (EPD) differs from all the abovediscussed techniques. First, the charge carriers in EPD are suspending, charged colloidal particles, not ions. Second, EPD involves electrostatic attractions between the particles and substrates, but no charge transfer. Third, unlike electrodeposition that demands electrolytes to conduct ions, EPD can perform in poorly conductive media, e.g., water [58, 59].

Depending on charges carried by the colloidal particles, EPD is classified into cathodic and anodic EPD. The 
cathodic EPD refers to the deposition of positively charged particles onto negatively charged substrates (Fig. 6a), whereas anodic EPD proceeds in a reverse manner (Fig. 6b) [58]. The structures of the deposits are tailorable by varying parameters of applied potential, particle concentration, and deposition duration [60-65]. Notably, the stoichiometry of the electrosorbed particles directly determines the stoichiometry of the deposit [59].

\section{Electrochemically Synthesized Carbon Materials}

Carbon materials, including activated carbon, carbon fibers, carbon aerogels, carbon nanotubes, and graphene, are conventional materials in electrical double-layer capacitors [17]. Their high electrical conductivity, large surface areas, cost-effectiveness, chemical inertness, and tailorable porous structures make them suitable electrode candidates [66, 67]. The two outstanding advantages of carbon electrodes are their exceptional rate capability and ultralong lifetimes. Electrochemical approaches have been widely used to produce carbon materials [68-70]. The following sections first present the recent progress in syntheses of graphene (Sect. 3.1) and 3D carbons (Sect. 3.2), the two carbon materials that have been prepared by electrochemical technologies. Their applications in supercapacitors are highlighted separately in Sect. 3.3.

\subsection{Graphene}

Electrochemical exfoliation is a facile method for synthesizing graphene. Compared with chemical exfoliation, electrochemical exfoliation avoids chemical treatments that can introduce unwanted species, simplifying product purification $[66,71]$. Electrochemically exfoliated graphene often maintains more $s p^{2}$-hybridized carbon networks than that made by chemical oxidation. Additionally, the graphene surface functionalization often accompanies with exfoliation $[72,73]$, and the heteroatom doping level is highly controllable. Another strength of electrochemical exfoliation is its high efficiency. It only needs minutes or hours, depending on applied potentials, electrolyte compositions, and graphite sources, to produce grams of graphene sheets in laboratories $[74,75]$.

According to the potential polarity, electrochemical exfoliation is classified into (1) anodic exfoliations performed in aqueous electrolytes containing inorganic salts [76], mineral acids [77, 78], ionic liquids [79], or their mixtures [67, 80]; and (2) cathodic exfoliations in organic electrolytes having lithium or alkylammonium salts [21, 67, 81-83].

\subsubsection{Anodic Exfoliation}

Anodic exfoliation separates graphite into graphene by anion intercalation [73, 76]. It is the most used electrochemical approach for graphene production due to its high exfoliation efficiency. With inorganic acids (e.g., $\mathrm{H}_{2} \mathrm{SO}_{4}[78,84]$, $\mathrm{HNO}_{3}[85,86]$, and $\mathrm{H}_{3} \mathrm{PO}_{4}$ [87]) or salts (e.g., $\mathrm{KNO}_{3}$ [88] and $\left.\left(\mathrm{NH}_{4}\right)_{2} \mathrm{SO}_{4}[89]\right)$ as supporting electrolytes, a high exfoliation potential (e.g., 3-10 V) can generate single-layer or multilayer graphene sheets from graphite. For example, Parvez et al. exfoliated graphite foils in sulfuric acid aqueous solutions with concentrations of $0.1,1$, and $5 \mathrm{M}$ [84]. (a)

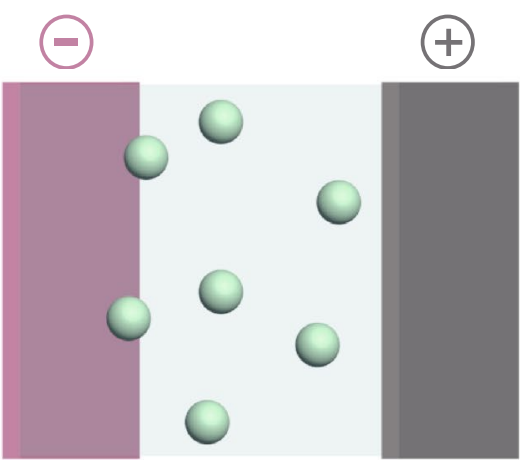

(b)

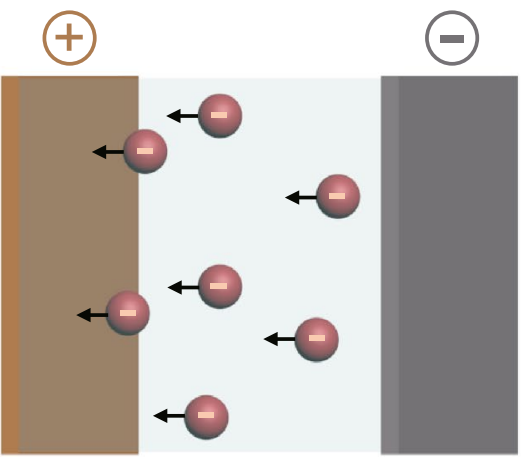

Fig. 6 Schematic illustrations of a cathodic and $\mathbf{b}$ anodic electrophoretic deposition. Only ions of interest are shown for brevity 
The synthesis procedures involved multiple steps (Fig. 7a). First, a high potential of $10 \mathrm{~V}$ was applied across a graphite positive electrode and a Pt negative electrode (Fig. 7b), splitting water into hydroxyl $(\mathrm{OH} \cdot)$ and oxygen radicals $(\mathrm{O} \cdot)$. These radicals preferentially oxidized the boundaries and defects of graphite, opening its edges. Second, driven by the applied electrical field, sulfate ions $\left(\mathrm{SO}_{4}{ }^{2-}\right)$, together with water molecules, intercalated into graphite layers through the open edges and expanded graphite layers. Meanwhile, oxygen gas evolution in between graphite layers further torn apart graphite sheets and dispersed exfoliated graphene layers into electrolytes (Fig. 7c-e). Water in the electrolytes was critical for electrochemically exfoliation, as it both generated $\mathrm{OH} \cdot$ and $\mathrm{O} \cdot$ (the exfoliation initiators) and served as an intercalant. The exfoliation efficiency in the $0.1 \mathrm{M} \mathrm{H}_{2} \mathrm{SO}_{4}$ electrolyte reached the highest, since the $5 \mathrm{M} \mathrm{H}_{2} \mathrm{SO}_{4}$ electrolyte overexfoliated graphite into graphitic particles, while the $0.1 \mathrm{M} \mathrm{H}_{2} \mathrm{SO}_{4}$ electrolyte led to incomplete exfoliation due to insufficient sulfate ions. The obtained graphene sheets in $0.1 \mathrm{M} \mathrm{H}_{2} \mathrm{SO}_{4}$ had a high yield of $>80 \%$, less than three layers, a high $\mathrm{C} / \mathrm{O}$ ratio of 12.3 , and good electrical conductivity (sheet resistance of $\sim 4.8 \mathrm{k} \Omega / \square$ ), all of which are comparable to those of high-quality graphene sheets synthesized by chemical vapor deposition.

Changing the water content of non-aqueous electrolytes can yield graphene-based materials with different surface areas and morphologies. Specifically, Lu et al. found that the morphologies of the exfoliation products in 1-methyl3-butylimidazolium tetrafluoroborate, an ionic liquid (IL), depended on the water-to-IL ratio [79]. Identical to

(a)
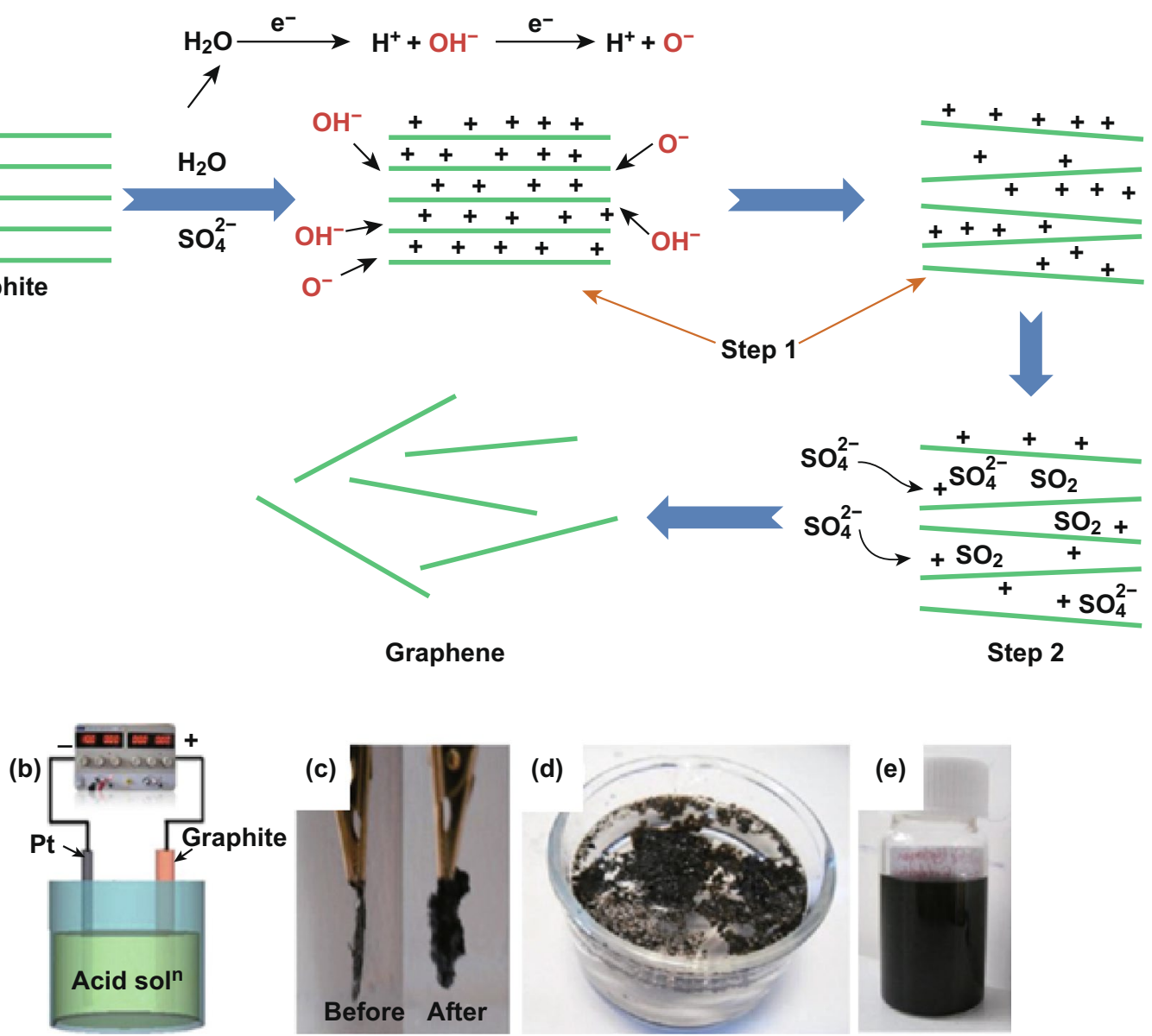

Fig. 7 a Schemes of the microscopic processes of graphite exfoliation in $\mathrm{H}_{2} \mathrm{SO}_{4}$ aqueous electrolytes. Step 1: edge opening by waterborne radicals; Step 2: $\mathrm{SO}_{4}{ }^{2-}$ intercalation and exfoliation. b Experimental setup for the graphite exfoliation. $\mathbf{c}$ Photographs of the exfoliated electrodes before and after exfoliation. d Exfoliated graphene floating on an electrolyte. e Dispersed graphene sheets in dimethylformamide solution. Adapted from Ref. [84] with permission 
electrochemical exfoliations in aqueous solutions, water in the IL produced $\mathrm{OH}$ and $\mathrm{O} \cdot$ to drive the exfoliation process, while subsequent intercalation of $\mathrm{BF}_{4}{ }^{-}$promoted complete exfoliation. Decreasing the water/IL ratio favored $\mathrm{BF}_{4}{ }^{-}$intercalation that significantly expanded graphite into graphene nanoribbons. Increasing the water/IL ratio increased the populations of $\mathrm{OH} \cdot$ and $\mathrm{O} \cdot$, which substantially oxidized and broke graphite into hydroxylated carbon particles. In this case, the oxygen-containing radicals acted as electrochemical "scissors" that cut the graphite plates into nanoribbons or nanoparticles.

Graphite exfoliation in aqueous solutions often yields oxygenated graphene with reduced electrical conductivity, a property unfavorable for rapid charge storage [36, 80, 90-94]. To circumvent this shortcoming, a variety of additives, including reducing agents [95] and oxygen radical scavengers [76], have been introduced into electrolytes to prevent overoxidation of exfoliated graphene. For example, Yang et al. demonstrated that (2,2,6,6-tetramethylpiperidin1-yl)oxyl (TEMPO), ascorbic acid, and sodium borohydride could consume radicals. This characteristic kept oxygen content at low levels (3.8 atom\% O of TEMPO-added exfoliated graphene vs. 11 atom\% O of TEMPO-free exfoliated graphene) [95]. Besides, Ejigu et al. reported that transition metal ions (e.g., $\mathrm{Co}^{2+}, \mathrm{Ni}^{2+}, \mathrm{Fe}^{3+}, \mathrm{Mn}^{2+}, \mathrm{Ru}^{3+}, \mathrm{Ir}^{3+}$, and $\mathrm{V}^{3+}$ ) as electrolyte additives were conducive to acquiring high-quality graphene because they scavenged oxygen radicals [76]. Among all these ions, $\mathrm{Co}^{2+}$ was the most promising one because it converted to an oxygen evolution reaction catalyst. During anodic exfoliation, $\mathrm{Co}^{2+}$ was first oxidized to $\mathrm{Co}^{4+}$, an active species for oxygen evolution. The $\mathrm{Co}^{4+}$ adsorbed on graphite facilitated oxygen evolution from water, bypassing the formation of oxygen radicals that oxidized exfoliated graphene. The lowest oxygen content was $2.6 \%$.

\subsubsection{Cathodic Exfoliation}

Cathodic exfoliation, which produces graphene by applying negative biases to graphite, is a method free of oxidation concerns. Though this technique is not as developed as anodic exfoliation, it has successes in graphite exfoliation in organic-based electrolytes [21, 67, 81, 83] and molten salts [82]. For example, Wang et al. deployed a cathodic exfoliation method that acquired highly conductive, less than five layers of graphene nanosheets from graphite with yields of $>70 \%$ [21]. At a high cathodic potential of $-15 \pm 5 \mathrm{~V}$, $\mathrm{Li}^{+}$-propylene carbonate ( $\mathrm{PC}$, a solvent) complexes intercalated into graphite and expanded graphite layers. Subsequently, the reduction of PC molecules liberated gas bubbles in between graphite layers, eventually exfoliating graphite into graphene sheets (Fig. 8a-c). Because the exfoliation involved no oxidation, the resultant graphene contained little defects, as evidenced by the small $I_{\mathrm{D}} / I_{\mathrm{G}}$ ratio of 0.1 revealed by Raman spectroscopy (Fig. 8d).

In addition to liquid electrolytes, quasi-solid molten salts were potent electrolytes for graphite exfoliation. For instance, Huang et al. successfully exfoliated graphite in molten LiOH with a high cathodic current of $15 \mathrm{~A}$ [82]. This process was based on intercalation, expansion, and micro-explosion. First, $\mathrm{Li}^{+}$ions in the molten $\mathrm{LiOH}$ intercalated into graphite layers and widened the interlayer gap of graphite, forming graphite intercalation compound $\left(\mathrm{Li}_{x} \mathrm{C}_{y}\right)$. Afterward, the $\mathrm{Li}^{+}$-intercalated graphite was soaked in water. $\mathrm{Li}_{x} \mathrm{C}_{y}$ and metallic $\mathrm{Li}$ reacted violently with water (micro-explosion), creating hydrogen gas bubbles that further exfoliated graphite into graphene. The conversion efficiency was $\sim 80 \%$.

\subsection{Three-Dimensional Carbons}

As supercapacitor electrodes, three-dimensional (3D) carbon materials have advantages over other conventional carbon powders (e.g., activated carbon) and graphene. First, their self-standing nature requires no binder blending for preparing electrodes, which eases fabrication and reduces the negative impact of the binders on electron transport. Second, their tailorable structures offer opportunities to achieve both high surface areas and hierarchical porous networks known to facilitate ion diffusion [4, 96-102].

Electrochemical partial exfoliation of graphitic materials is the most common synthesis method of electrochemically synthesizing 3D carbon materials. As indicated by its name, electrochemical partial exfoliation only partially exfoliates graphitic precursors, e.g., carbon fibers [37, 85, 97, 99], graphene aerogels [99], and graphite foils [88, 103, 104], leading to graphene sheets anchored on the exposed surfaces. For example, Song et al. demonstrated a two-step electrochemical partial exfoliation method to prepare oxygenfunctionalized, partially exfoliated graphite foils (Fig. 9a) 

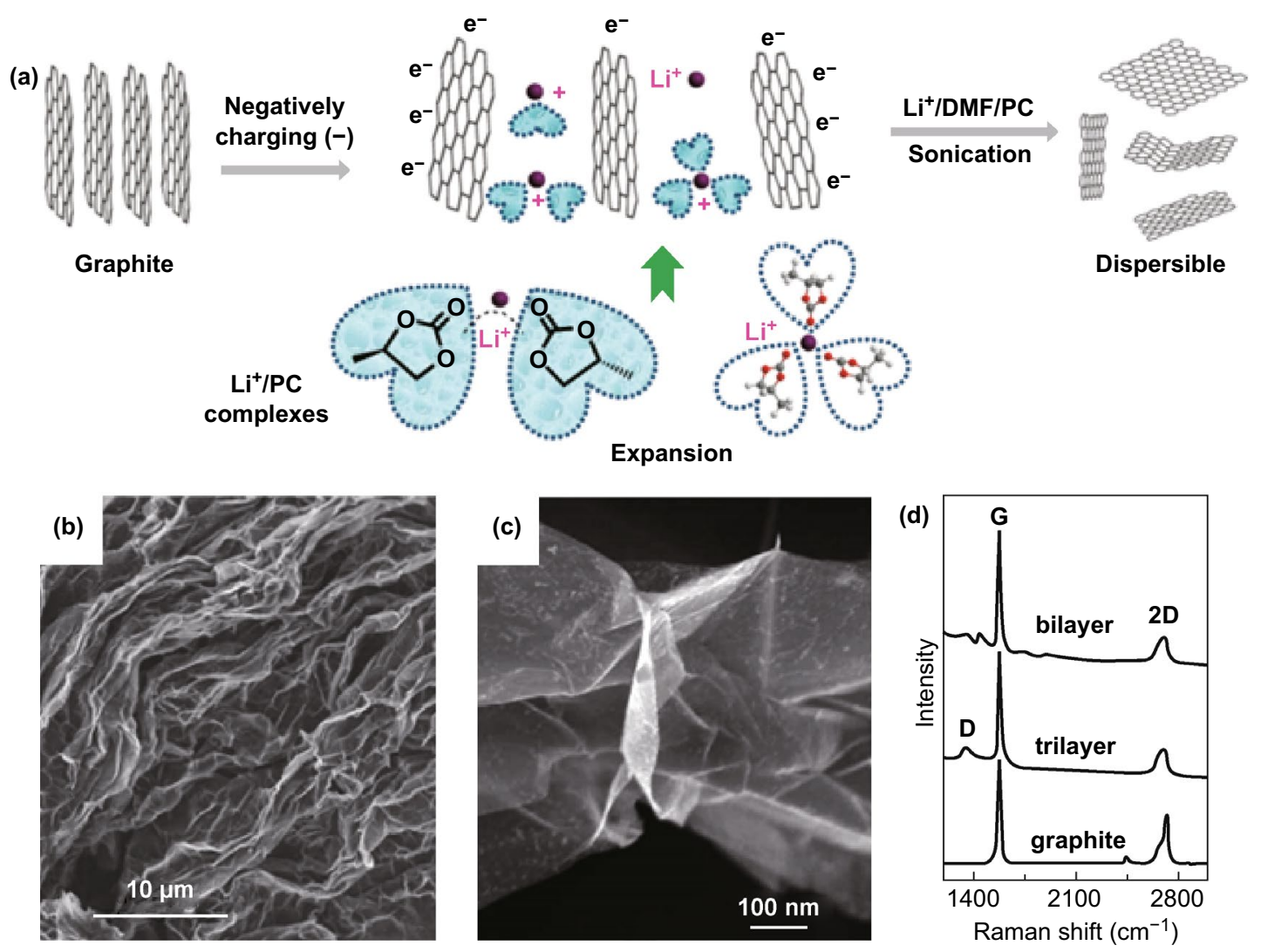

Fig. 8 a Schematic illustration of cathodic exfoliation of graphite by intercalation of $\mathrm{Li}^{+}$complexes. b, $\mathbf{c}$ SEM images of the cathodically exfoliated graphene plates. d Raman spectra of the cathodically exfoliated graphene with bilayers and trilayers, in comparison with that of pristine graphite. Adapted from Ref. [21] with permission

[88]. The authors first scanned a piece of graphite foil (EG in Fig. 9b) in aqueous $\mathrm{K}_{2} \mathrm{CO}_{3}$ electrolytes by cyclic voltammetry. This step partially exfoliated the graphite layers on and near the outer surface of EG through vigorous gas evolution from water splitting (Fig. 9c). The secondary exfoliation process intercalated $\mathrm{NO}_{3}{ }^{-}$into $\mathrm{EG}$ through the open edges and defects formed during the first step, forming graphite intercalation compounds $\left(\mathrm{C}-\mathrm{NO}_{3}\right)$. These compounds, when placed in water, hydrolyzed and released oxygen gas. The gas evolution further exfoliated and oxygenated the top layers of EG (Fig. 9d). The introduced oxygen functionalities rendered the foil superhydrophilicity as reflected from the zero contact angle (Fig. 9d inset). The potential applied in the second step controlled the degrees of the exfoliation and oxygenation. The functionalized, exfoliated EG possessed a 3D network consisting of oxygenated graphene sheets integrated onto graphite foil. The seamless integration between the top layer and the graphite bottom ensured fast electron conduction pathways. Besides improving electrolyte wettability, the oxygen moieties served as anchoring sites for depositing guest materials for polyaniline [27], polypyrrole [105], manganese oxides [86], vanadium oxides [37], iron oxides [35, 106], nickel-cobalt double hydroxides [106], and molybdenum-based materials [28].

In addition to graphite, carbon fibers can also be partially electroexfoliated. For example, Wang et al. synthesized electrochemically activated carbon fiber cloth electrodes by applying a voltage of $3 \mathrm{~V}$ in $\mathrm{HNO}_{3} / \mathrm{H}_{2} \mathrm{SO}_{4}$ mixed aqueous electrolytes [85]. The high voltage, together with the highly oxidative and corrosive acids, roughened the carbon fiber surfaces and introduced functionalities of $\mathrm{C}-\mathrm{OH},-\mathrm{C}=\mathrm{O}$, and $-\mathrm{COOH}$. This activated carbon cloth electrode exhibited a high areal capacitance of $756 \mathrm{mF} \mathrm{cm}^{-2}$ at $6 \mathrm{~mA} \mathrm{~cm}^{-2}$. Song et al. demonstrated an acid-free method to exfoliate carbon fiber cloth partially [37]. First, $\mathrm{NO}_{3}{ }^{-}$anions intercalated into carbon fibers, exfoliating and oxidizing the outer surface (Fig. 9e). To recover the electrical conductivity of carbon fibers, the researchers immersed the oxidized carbon 

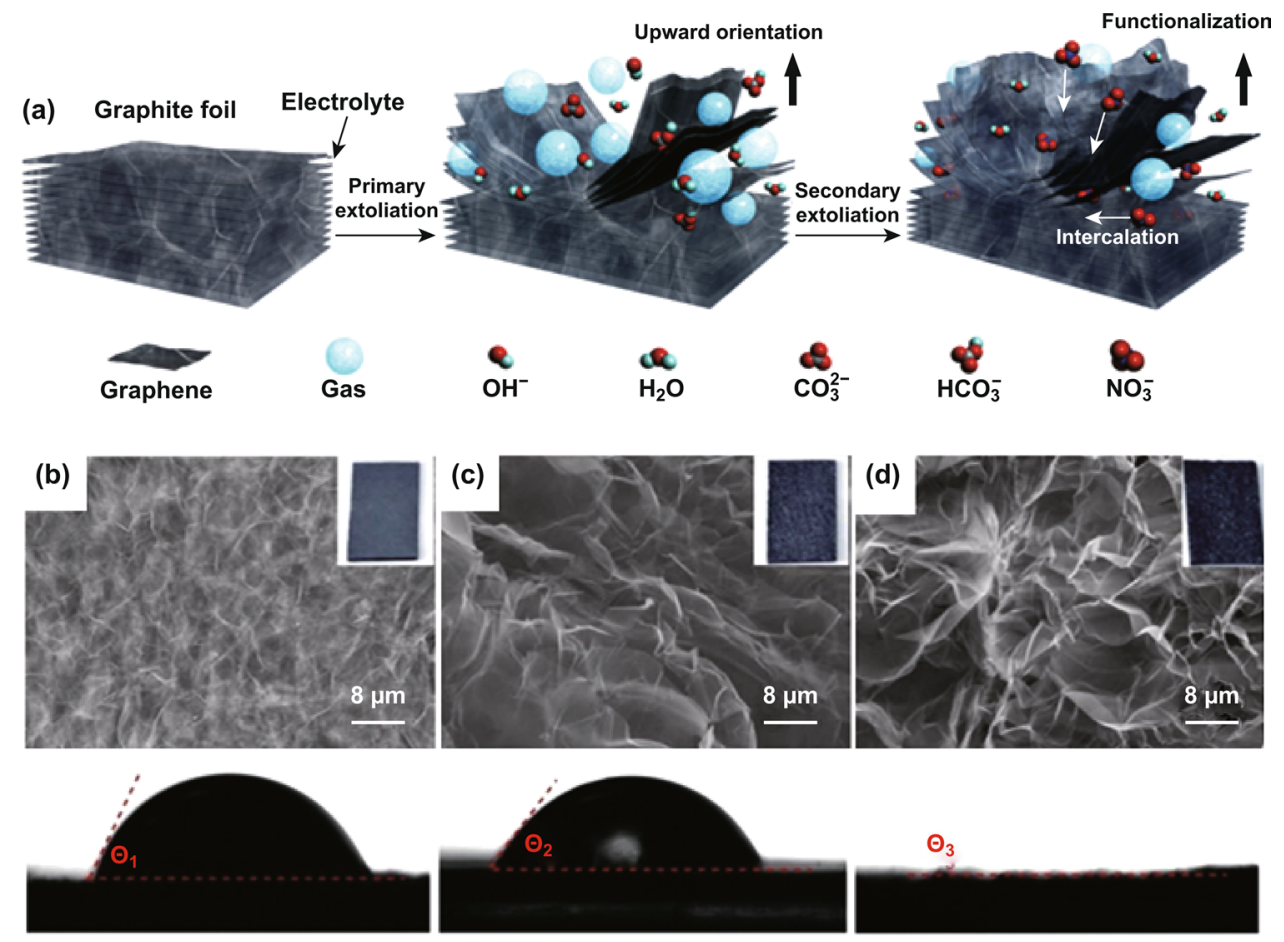

$\Theta_{3}$
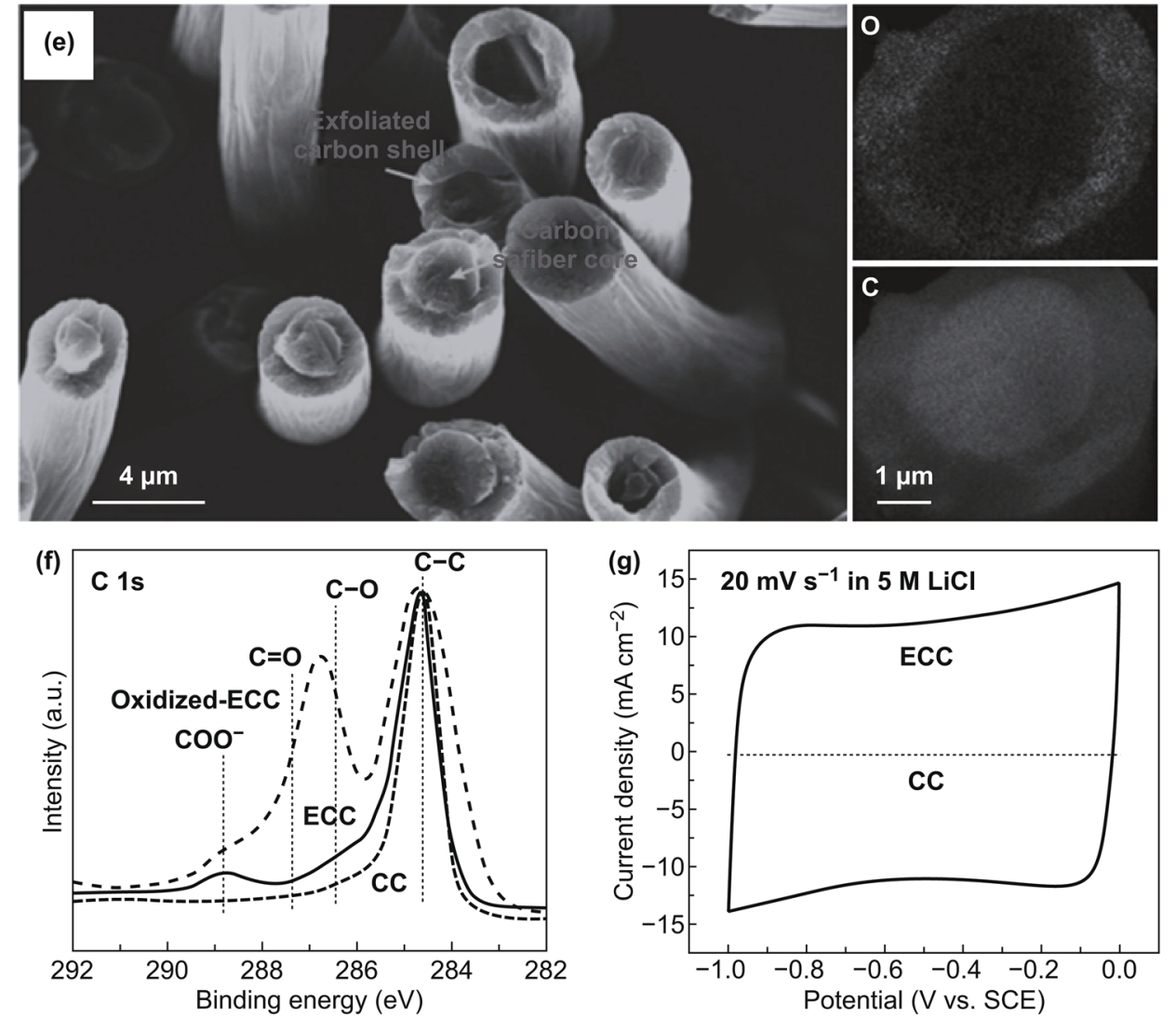

Fig. 9 a Schemes of the two-step partial exfoliation of graphite foil. b-d SEM images and contact angles of $\mathbf{b}$ graphite foil, $\mathbf{c}$ graphite foil after primary exfoliation, and $\mathbf{d}$ graphite foil after secondary exfoliation. Insets: photographs of graphite foil at different treatment stages. e SEM image and EDS element mappings $(\mathrm{C}$ and $\mathrm{O})$ of the cross sections of exfoliated carbon cloth fibers. $\mathrm{f}$ XPS $\mathrm{C} 1 s$ spectra of pristine carbon cloth (CC) and exfoliated carbon cloth (ECC). $\mathbf{g}$ CV curves of CC and ECC. Adapted from a-d Ref. [88] and e-g Ref. [37] with permission 
cloth in a $0.1 \%$ hydrazine hydrate aqueous solution to reduce the oxygen content. This reduction process removed most of the oxygen functionalities (Fig. 9f) and resulted in enhanced capacitive performance (Fig. 9g). The partially exfoliated carbon cloth electrode exhibited a high areal capacitance of $\sim 500 \mathrm{mF} \mathrm{cm}^{-2}$ at $20 \mathrm{~mA} \mathrm{~cm}^{-2}$.

\subsection{Application for Supercapacitors}

Owing to the enhanced surface areas and high electrical conductivity, electrochemically exfoliated graphene-based materials or activated carbon fibers have functioned as either electrode materials or current collectors in supercapacitors. Liu et al. fabricated an in-plane micro-supercapacitor through directly printing electrochemically exfoliated graphene on patterned microelectrodes. This micro-supercapacitor delivered an areal capacitance of $800 \mu \mathrm{F} \mathrm{cm}^{-2}$ at $1 \mathrm{mV} \mathrm{s}^{-1}$ [107]. Wu et al. used electrochemically exfoliated graphene to prepare graphene paper and 3D graphene foams as supercapacitor electrodes [75]. The specific capacitance of the 3D graphene electrode reached $113.2 \mathrm{~F} \mathrm{~g}^{-1}$ and $58.9 \mathrm{~F} \mathrm{~g}^{-1}$ at $0.5 \mathrm{~A} \mathrm{~g}^{-1}$ in $6 \mathrm{M} \mathrm{KOH}$ aqueous and $1 \mathrm{M}$ triethylmethylammonium tetrafluoroborate acetonitrile $\left(\mathrm{TEMABF}_{4} / \mathrm{AN}\right)$, respectively.

Besides reporting the outstanding electrochemical performance, some researchers devoted to revealing the interplays between exfoliation conditions and electrochemical properties. Ambrosi et al. compared the capacitive performances of electrochemically exfoliated graphene synthesized in different aqueous electrolytes, i.e., $0.5 \mathrm{M} \mathrm{H}_{2} \mathrm{SO}_{4}, \mathrm{Na}_{2} \mathrm{SO}_{4}$, and $\mathrm{LiClO}_{4}$ [71]. The results showed that the graphene prepared in $\mathrm{H}_{2} \mathrm{SO}_{4}$ and $\mathrm{Na}_{2} \mathrm{SO}_{4}$ exhibited relatively high specific capacitance of 78 and $106 \mathrm{~F} \mathrm{~g}^{-1}$, respectively. $\mathrm{LiClO}_{4}$ introduced a large amount of oxygen functional groups on the exfoliated graphene, which could be anchoring sites for growing other materials to form graphene-based composites. Notably, the specific capacitances of the electrochemically exfoliated graphene often fall in the range of $50-100 \mathrm{~F} \mathrm{~g}^{-1}$, which are slightly lower than those of graphene obtained through chemical oxidation. The underlying reason was revealed by Xia et al., who studied the different graphite exfoliation routes via chemical oxidation and electrochemical exfoliation [66]. The authors discovered that the surface area of the electrochemically exfoliated graphite was only $6.6 \mathrm{~m}^{2} \mathrm{~g}^{-1}$, which was three orders of magnitude lower than that of the theoretical value $\left(2600 \mathrm{~m}^{2} \mathrm{~g}^{-1}\right)$ of a graphene monolayer achieved by chemical exfoliation. Therefore, electrochemical exfoliation is challenging to fully separate graphite into monolayer graphene, resulting in the relatively low gravimetric capacitance due to the small surface area (Table 1). This limitation has motivated the introduction of pseudocapacitive functional groups to boost capacitance [85, 99, 101].

Compared with fully exfoliated graphene sheets, partial exfoliated graphite and carbon electrodes have the main advantage that the whole electrodes remain structurally and electrically connected, enabling them to function as current collectors for loading pseudocapacitive materials. The resultant composite materials possess both high capacitance from the incorporated pseudocapacitive materials and the excellent rate capability characteristic of carbon-based materials. In this regard, the mass loadings of the pseudocapacitive materials must be meticulously tuned to ensure the highest specific capacitance without significantly compromising the rate capability.

\section{Conducting Polymers}

Conducting polymers, or conjugated polymers, are organic polymers that conduct electricity in their electron conjugated networks in the polymer backbones [116-118]. Polyaniline (PANI) [119-122], polypyrrole (PPy) [105, 123], polythiophene (PTh) [124, 125], and poly(3,4-ethylene dioxythiophene) (PEDOT) [126-129] are common supercapacitor electrode materials. In terms of electrochemical synthesis, electrochemical polymerization of monomers is typical to prepare these conducting polymers. It grows conducting polymers onto electrically conductive substrates (current collectors), eliminating the need for blending powdered materials with binders and conductive additives when preparing electrodes. Potentiostatic deposition [130], galvanostatic deposition [131, 132], and cyclic voltammetry [105] are synthesis techniques of conducting polymers. The thicknesses and mass loadings of conducting polymers are controllable by tuning deposition duration. The compositions of electrolytes mainly influence their electrical conductivity. This section summarizes the mechanisms of electrochemical polymerization, recent progress of the electrochemically synthesized conducting polymers, and their electrochemical performance as supercapacitor electrodes. 
Table 1 Synthesis conditions and specific capacitance of electrochemically exfoliated graphene-based electrodes

\begin{tabular}{|c|c|c|c|c|}
\hline Material $^{\mathrm{a}}$ & Method & Exfoliation electrolyte $^{\mathrm{b}}$ & Specific capacitance & Current density/scan rate \\
\hline Exfoliated carbon cloth [85] & Anodic exfoliation & $\mathrm{HNO}_{3} / \mathrm{H}_{2} \mathrm{SO}_{4}$ & $756 \mathrm{mF} \mathrm{cm}^{-2}$ & $6 \mathrm{~mA} \mathrm{~cm}^{-2}$ \\
\hline Exfoliated carbon fibers [102] & Cathodic exfoliation & $0.1 \mathrm{M} \mathrm{TMAClO}_{4} / \mathrm{NMP}$ & $64.5 \mathrm{mF} \mathrm{cm}^{-2}$ & $10 \mathrm{mV} \mathrm{s}^{-1}$ \\
\hline $\begin{array}{l}\text { Partial exfoliation of HOPG } \\
\text { [104] }\end{array}$ & Anodic exfoliation & $1 \mathrm{M} \mathrm{H}_{2} \mathrm{SO}_{4}$ & $750 \mathrm{mF} \mathrm{cm}^{-2}$ & $20 \mathrm{mV} \mathrm{s}^{-1}$ \\
\hline Exfoliated carbon paper [86] & Anodic exfoliation & $0.5 \mathrm{M} \mathrm{KOH}$ & $400 \mathrm{mF} \mathrm{cm}^{-2}$ & $1 \mathrm{~mA} \mathrm{~cm}^{-2}$ \\
\hline Trilayer graphite foil [101] & Anodic exfoliation & $\begin{array}{c}0.5 \mathrm{M} \mathrm{K}_{2} \mathrm{CO}_{3} / 0.5 \mathrm{M} \\
\mathrm{KNO}_{3} / 3 \mathrm{M} \mathrm{KCl}\end{array}$ & $820 \mathrm{mF} \mathrm{cm}^{-2}$ & $5 \mathrm{~mA} \mathrm{~cm}^{-2}$ \\
\hline Exfoliated carbon cloth [97] & Anodic exfoliation & $2 \mathrm{M} \mathrm{H}_{2} \mathrm{SO}_{4}$ & $12 \mathrm{mF} \mathrm{cm}^{-2}$ & $1 \mathrm{~mA} \mathrm{~cm}^{-2}$ \\
\hline $\begin{array}{l}\text { Exfoliated graphitic paper } \\
\text { [99] }\end{array}$ & $\begin{array}{l}\text { Cathodic and anodic exfolia- } \\
\text { tion }\end{array}$ & $\begin{array}{l}1 \mathrm{M} \mathrm{LiClO}_{4} / \text { propylene carbon- } \\
\text { ate }\end{array}$ & $108.8 \mathrm{mF} \mathrm{cm}^{-2}$ & $0.5 \mathrm{~mA} \mathrm{~cm}^{-2}$ \\
\hline $\begin{array}{l}\text { Exfoliated 3D printed gra- } \\
\text { phene aerogel [99] }\end{array}$ & $\begin{array}{l}\text { Cathodic and anodic exfolia- } \\
\text { tion }\end{array}$ & $\begin{array}{l}1 \mathrm{M} \mathrm{LiClO}_{4} / \text { propylene carbon- } \\
\text { ate }\end{array}$ & $101.7 \mathrm{~F} \mathrm{~g}^{-1}$ & $10 \mathrm{~A} \mathrm{~g}^{-1}$ \\
\hline $\begin{array}{l}\text { Vertically oriented graphene } \\
\text { nanosheets [98] }\end{array}$ & Anodic exfoliation & $0.5 \mathrm{M} \mathrm{H}_{2} \mathrm{SO}_{4}$ & $3.9 \mathrm{~F} \mathrm{~cm}^{-3}$ & $7.5 \mathrm{~mA} \mathrm{~cm}^{-3}$ \\
\hline Exfoliated graphite foils [88] & Anodic exfoliation & $\begin{array}{l}0.5 \mathrm{M} \mathrm{K}_{2} \mathrm{CO}_{3} / 1 \mathrm{M} \mathrm{KNO}_{3} \text { in } \\
\quad \operatorname{PBS}(\mathrm{pH}=6.7)\end{array}$ & $60 \mathrm{mF} \mathrm{cm}^{-2}$ & $0.23 \mathrm{~mA} \mathrm{~cm}^{-2}$ \\
\hline Exfoliated carbon cloth [37] & Anodic exfoliation & $0.5 \mathrm{M} \mathrm{KNO}_{3}$ & $560 \mathrm{mF} \mathrm{cm}^{-2}$ & $2 \mathrm{~mA} \mathrm{~cm}^{-2}$ \\
\hline Graphene [108] & Anodic exfoliation & $0.1 \mathrm{M} \mathrm{NaI}$ & $50 \mathrm{~F} \mathrm{~g}^{-1}$ & $0.1 \mathrm{~A} \mathrm{~g}^{-1}$ \\
\hline Graphene [107] & Anodic exfoliation & $0.1 \mathrm{M} \mathrm{H}_{2} \mathrm{SO}_{4}$ & $5.4 \mathrm{mF} \mathrm{cm}^{-2}$ & $1 \mathrm{mV} \mathrm{s}^{-1}$ \\
\hline Graphene [92] & Anodic exfoliation & $0.1 \mathrm{M}\left(\mathrm{NH}_{4}\right)_{2} \mathrm{SO}_{4}$ & $56.6 \mathrm{~F} \mathrm{~g}^{-1}$ & $1 \mathrm{Ag}^{-1}$ \\
\hline Graphene [95] & Anodic exfoliation & $\begin{array}{l}0.05 \mathrm{M} \\
\quad\left(\mathrm{NH}_{4}\right)_{2} \mathrm{SO}_{4}+\mathrm{TEMPO}+\mathrm{H}_{2} \mathrm{O}\end{array}$ & $11.5 \mathrm{mF} \mathrm{cm}^{-2}$ & $2 \mathrm{mV} \mathrm{s}^{-1}$ \\
\hline Graphene [89] & Anodic exfoliation & $0.1 \mathrm{M}\left(\mathrm{NH}_{4}\right)_{2} \mathrm{SO}_{4}$ & $11.3 \mathrm{mF} \mathrm{cm}^{-2}$ & $1 \mathrm{mV} \mathrm{s}^{-1}$ \\
\hline S-doped graphene [109] & Anodic exfoliation & $\mathrm{Na}_{2} \mathrm{~S}_{2} \mathrm{O}_{3}+\mathrm{H}_{2} \mathrm{SO}_{4}$ & $320 \mathrm{~F} \mathrm{~g}^{-1}$ & $3 \mathrm{~A} \mathrm{~g}^{-1}$ \\
\hline Graphene film [110] & Anodic exfoliation & $\begin{array}{c}0.15 \mathrm{M} \mathrm{Na}_{2} \mathrm{SO}_{4}+0.01 \mathrm{M} \\
\text { sodium dodecyl sulfate }\end{array}$ & $900 \mu \mathrm{F} \mathrm{cm}^{-2}$ & $10 \mathrm{mV} \mathrm{s}^{-1}$ \\
\hline Graphene aerogel [111] & Cathodic/Anodic exfoliation & $0.2 \mathrm{M} \mathrm{H}_{2} \mathrm{SO}_{4}+\mathrm{KOH}$ & $325 \mathrm{~F} \mathrm{~g}^{-1}$ & $1 \mathrm{~A} \mathrm{~g}^{-1}$ \\
\hline 3D graphene [75] & Anodic exfoliation & $10 \mathrm{M} \mathrm{H}_{2} \mathrm{SO}_{4}$ & $113.2 \mathrm{Fg}^{-1}$ & $0.5 \mathrm{~A} \mathrm{~g}^{-1}$ \\
\hline 3D N-doped graphene [112] & Anodic exfoliation & $\mathrm{CH}_{3} \mathrm{COOH} / \mathrm{H}_{2} \mathrm{SO}_{4}(\mathrm{~V} / \mathrm{V}=4: 6)$ & $170.5 \mathrm{Fg}^{-1}$ & $10 \mathrm{mV} \mathrm{s}^{-1}$ \\
\hline Acid modified graphene [113] & Anodic exfoliation & $\begin{array}{l}\text { 9-anthracene carboxylic acid } \\
\quad\left(1 \mathrm{mg} \mathrm{mL}^{-1}\right)\end{array}$ & $577 \mathrm{~F} \mathrm{~g}^{-1}$ & $7 \mathrm{~A} \mathrm{~g}^{-1}$ \\
\hline Graphene film [114] & Electrophoretic deposition & $\begin{array}{l}\text { Graphene oxide suspension } \\
\left(0.6 \mathrm{mg} \mathrm{mL}^{-1}\right)\end{array}$ & $156 \mathrm{~F} \mathrm{~g}^{-1}$ & $0.15 \mathrm{~A} \mathrm{~g}^{-1}$ \\
\hline P-doped graphene [115] & Anodic exfoliation & $\mathrm{H}_{3} \mathrm{PO}_{4}$ & $290 \mathrm{~F} \mathrm{~g}^{-1}$ & $1 \mathrm{Ag}^{-1}$ \\
\hline Graphene [71] & Anodic exfoliation & $0.5 \mathrm{M} \mathrm{Na}_{2} \mathrm{SO}_{4}$ & $106 \mathrm{~F} \mathrm{~g}^{-1}$ & $0.1 \mathrm{~A} \mathrm{~g}^{-1}$ \\
\hline Graphene [71] & Anodic exfoliation & $0.5 \mathrm{M} \mathrm{LiClO}_{4}$ & $78 \mathrm{~F} \mathrm{~g}^{-1}$ & $0.1 \mathrm{~A} \mathrm{~g}^{-1}$ \\
\hline Graphene [71] & Anodic exfoliation & $0.5 \mathrm{M} \mathrm{H}_{2} \mathrm{SO}_{4}$ & $21 \mathrm{Fg}^{-1}$ & $0.1 \mathrm{~A} \mathrm{~g}^{-1}$ \\
\hline
\end{tabular}

${ }^{\mathrm{a}} \mathrm{TMAClO}_{4}$ : tetramethylammonium perchlorate; NMP: $N$-methyl pyrrolidone; PBS: phosphate-buffered saline; TEMPO: (2,2,6,6-tetramethylpiperidin-1-yl)oxyl

${ }^{\mathrm{b}}$ Unless specifically stated, solutions are aqueous-based

\subsection{Mechanism of Electrochemical Polymerization of Conducting Polymer Materials}

Electrochemical technologies are time- and cost-efficient in preparing conducting polymers. Electrochemical polymerization begins with oxidizing monomers possessing five-membered aromatic heterocycles (e.g., pyrrole or thiophene) $[133,134]$ or cyclic aromatic amines (e.g., aniline) [116]. The oxidation involves generating and dimerizing radical cations, followed by polymer chain growth. Electrochemical polymerization initiates polymer growth on the surfaces of conductive substrates. 
Diaz proposed the widely accepted electrochemical polymerization mechanism of five-membered aromatic monomers in 1983 (Fig. 10a) [133]. Taking polypyrrole (PPy) as an example, pyrrole (Py) monomers are first oxidized to radical cations under an anodic potential. Subsequently, the radical cations dimerize through radical-radical coupling reactions at $\alpha$-positions and deprotonated into neutral dimers. The as-formed dimers further combine and eventually extend to PPy.

The polymerization of another conducting polymer, polyaniline, follows a similar path as that of PPy (Fig. 10b) [135]. Its monomers are first oxidized to radical cations, then coupled, and deprotonated to dimers. Unlike PPy, whose chain propagation is driven by continuous dimer combination, aniline dimers undergo further oxidation and couple with one aniline radical cation at a time. The coupling extends to polyaniline. For both cases, anions (or counterions in general) will dope into the as-formed conducting polymers to balance the charges carried by the positively charged sites on the polymer backbones. Note that the concept of doping in the context of conducting polymers is fundamentally different from that in conventional solid-state semiconductors. Doping semiconductors means to incorporate dopants into the crystal lattices of the host materials [136].
This counterion doping process maintains the electroneutrality of conducting polymer and affects the electrical conductivity of conducting polymers [137]:

$\mathrm{Pol}^{*}+n \mathrm{~A}^{-}+m \mathrm{~S} \leftrightarrow \mathrm{Pol}^{\mathrm{n}+} \mathrm{A}^{-} \mathrm{S}+n e^{-}$

where $\mathrm{Pol}^{*}$ is the positively charged sites in a conducting polymer, $\mathrm{A}^{-}$stands for counterion, and $\mathrm{S}$ represents a solvent molecule. When electrons enter in conducting polymers, doping of $\mathrm{A}^{-}$and concurrently co-insertion of solvent molecules lead to volumetric expansion of the host polymers. Conversely, electron extraction causes de-doping of $\mathrm{A}^{-}$and de-solvation of conducting polymers, resulting in volumetric contraction. The irreversible volumetric deformation is a typical culprit for the structural instability that causes unsatisfactory cycling stability of conducting polymers [138, 139].

\subsection{Electrochemically Synthesized Conducting Polymers for Supercapacitors}

\subsubsection{Films}

Conformal films are the most common morphologies of electrochemically polymerized conducting polymer electrodes [97, 140, 141]. Parameters associated with

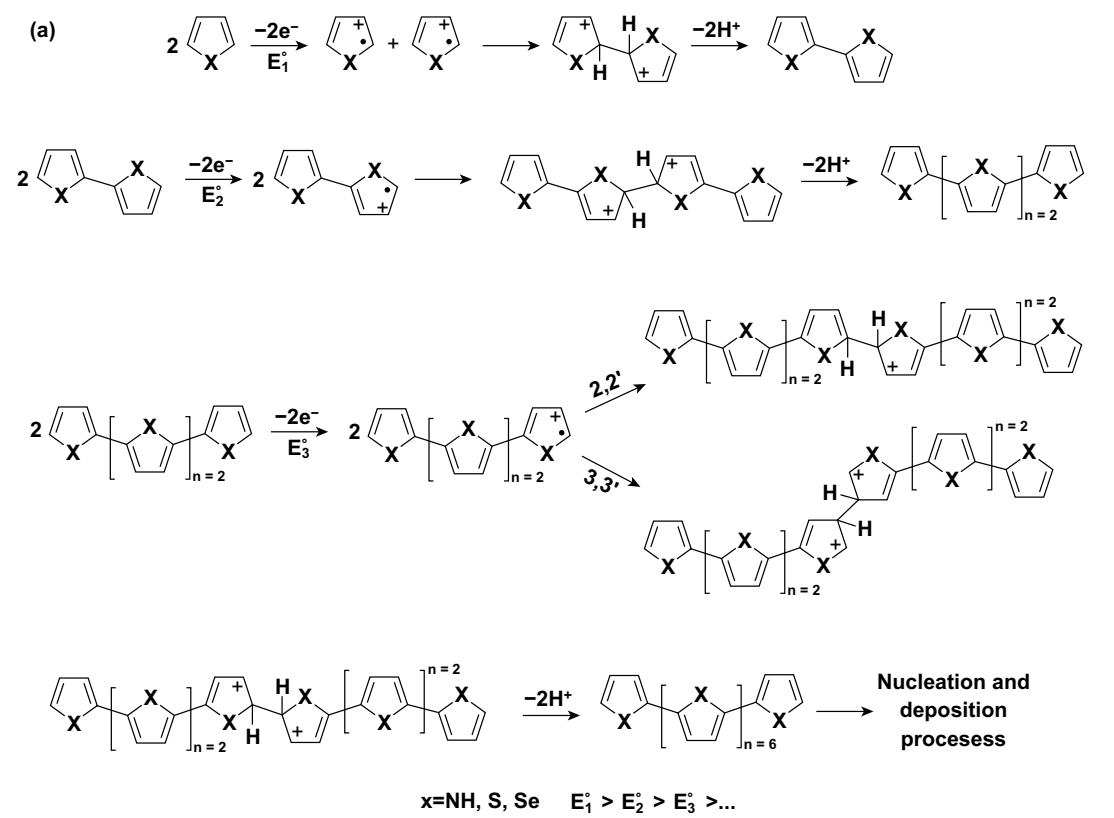

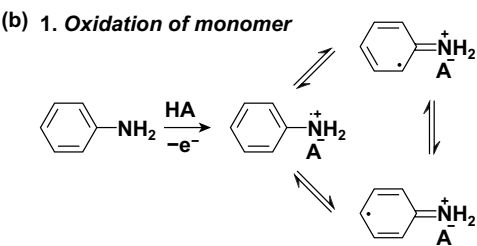

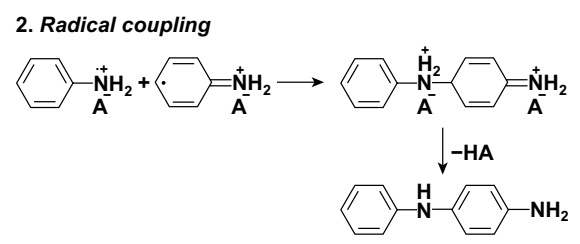

3. Chain propagation

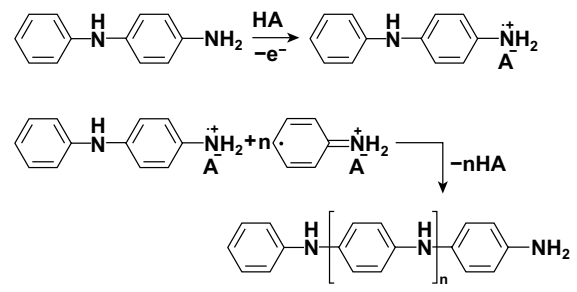

Fig. 10 a Electrochemical polymerization mechanism of pyrrole. Adapted from Ref. [133] with permission. b Electrochemical polymerization mechanism of polyaniline. Adapted from Ref. [135] with permission 
electropolymerization have profound influences on the chemical compositions, morphologies, and electrochemical properties of the deposited polymer films [130, 142].

The surface properties of the substrates influence the adhesion strength and chemical compositions of the polymer films. For example, Feng et al. electrochemically deposited a thin PPy layer on oxygen-functionalized carbon cloth (FCC) [97]. Compared with PPy deposited on pristine carbon cloth (CC), PPy/FCC exhibited enhanced dopant concentrations and electrical conductivity, because the oxygen functional groups on FCC could dope into PPy and reinforced the adhesion of PPy onto FCC. Consequently, PPy/FCC displayed an areal capacitance of $341 \mathrm{mF} \mathrm{cm}^{-2}$ at $1 \mathrm{~mA} \mathrm{~cm} \mathrm{~cm}^{-2}$, about $40 \mathrm{mF} \mathrm{cm}^{-2}$ higher than that of PPy/CC at the same current density.

Electrochemically polymerized conducting polymer films have different molecular structures from those prepared by chemical polymerization. Huang et al. reported that PPy film deposited via galvanostatic electrodeposition exhibited higher molecular order than that made by chemical oxidation (Fig. 11a) [143]. During electrochemical polymerization, the $\alpha-\alpha$ coupled PPy chains stacked layer by layer with an interlayer spacing of $3.45 \AA$, as evident from the pronounced $\mathrm{X}$-ray diffraction peak (Fig. 11b, c). This layered molecular structure facilitated ion transport within the electrode and induced a homogeneous stress distribution in the polymer films, both of which improved the cycling stability of PPy.

Coating conducting polymer films onto flexible substrates is a strategy of making flexible electrodes for wearable supercapacitors. Huang et al. demonstrated a stretchable stainless steel mesh as an electrically conductive substrate to endow the deposited PPy film excellent stretchability (Fig. 11d) [132]. The PPy-coated stainless steel mesh delivered a specific capacitance of $170 \mathrm{~F} \mathrm{~g}^{-1}$ at $0.5 \mathrm{~A} \mathrm{~g}^{-1}$, and the capacitance augmented to $214 \mathrm{~F} \mathrm{~g}^{-1}$ when the electrode was applied a $20 \%$ strain. The strain improved the contact between PPy and stainless steel and reduced the contact resistance, which augmented the specific capacitance (Fig. 11e).

It should be noted that thin films are usually obtained at the early stage of electrode polymerization, and prolonging deposition time may modify the film morphology due to overgrowth. For instance, Song et al. observed that instead of thin films, PPy cauliflowers formed (Fig. 11f) after 10 cycles scanning from 0 to $0.8 \mathrm{~V}$ vs. SCE at $50 \mathrm{mV} \mathrm{s}^{-1}$ [105].

Soft templates (e.g., surfactant) can introduce porosity in electrodeposited conducting polymer films. Kurra et al. used a potentiostatic method to deposit a thin layer of PEDOT on an Au-coated, interdigitated electrode (Fig. 12a,
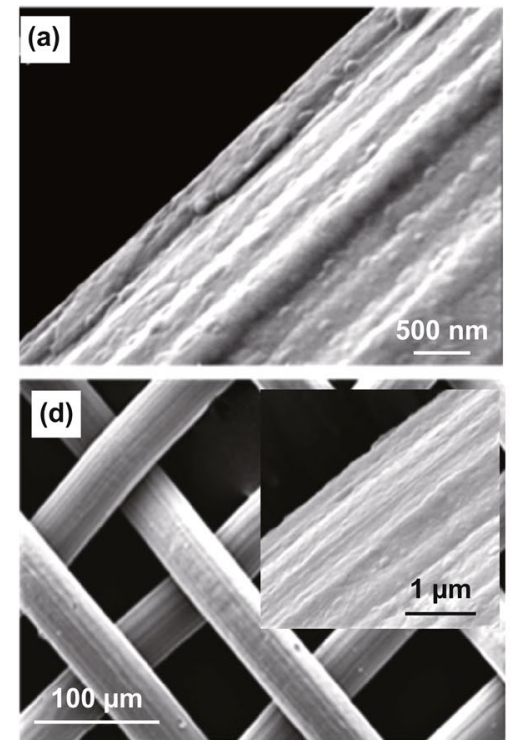

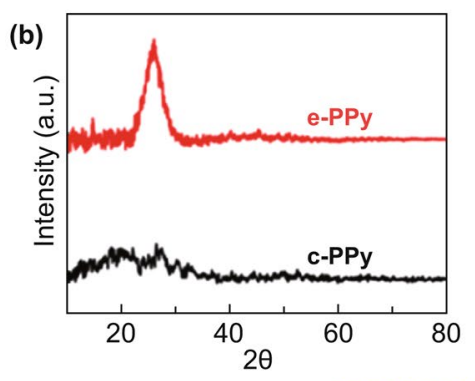

(e)

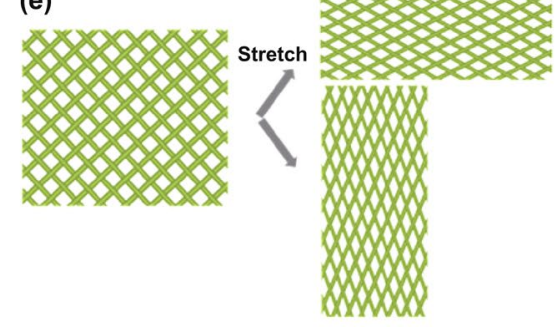

(c)
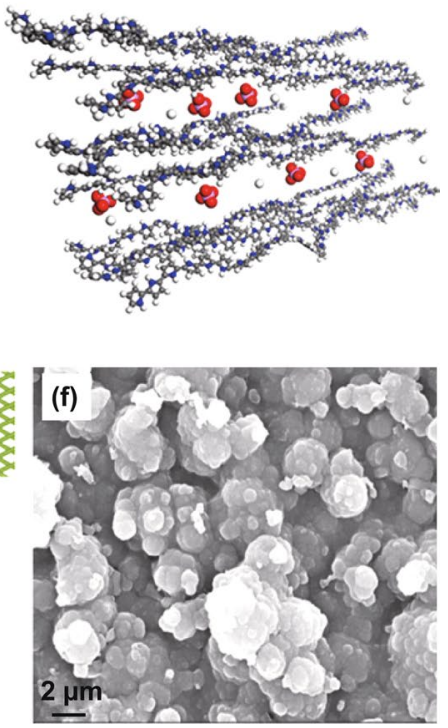

Fig. 11 a SEM image of electrodeposited PPy film on an oxygen-functionalized carbon fiber. b XRD patterns of electrochemically and chemically deposited PPy. c A possible molecular structure of electrodeposited PPy. d PPy film electrochemically deposited on a flexible stainless steel mesh. e Schematic illustration of the stretched mesh structure. f Cauliflower-like PPy film. Adapted from a-c Ref. [143], d, e Ref. [132], f Ref. [105] with permission 
b) [144]. Sodium dodecyl sulfate, an anionic surfactant, was used to increase the solubility of 3,4-ethylenedioxythiophene (EDOT) in water and thus decreased the polymerization potential of EDOT. The surfactant molecules also served as soft templates that created cracks in the PEDOT film (Fig. 12c, d). These cracks provided electrolyte ion percolation pathways and benefited rate capability at high frequencies. A symmetric micro-supercapacitor consisting of two identical interdigitated electrodes displayed a typical capacitive behavior as reflected from the plateau-free galvanostatic charge-discharge profiles (Fig. 12e). This micro-supercapacitor exhibited a positive trend between its areal capacitance and the electropolymerization time, but the volumetric capacitance peaked after 15 min polymerization (Fig. 12f). The drop in the volumetric capacitance was attributed to the increased PEDOT thickness that impeded ion diffusion.

\subsubsection{Nanowires and Nanorods}

One-dimensional (1D) conducting polymers, such as polyaniline nanofibers [145-147] and polypyrrole nanorods
[148-150], are popular morphologies of pseudocapacitor electrodes. Their merits include the wide-open interfiber space that facilitates electrolyte infiltration and ion diffusion, as well as minimizes dead volumes (materials that are unusable for charge storage).

In the absence of any structure-directing agents, polyaniline preferentially forms randomly intertwined nanofibers [151]. Liu et al. electrodeposited polyaniline (PANI) nanowires on carbon cloth using cyclic voltammetry within a potential window between -0.2 and $0.8 \mathrm{~V}$ in aqueous electrolytes containing $0.1 \mathrm{M}$ aniline and $1 \mathrm{M} \mathrm{H}_{2} \mathrm{SO}_{4}$ [25]. PANI nanowires were uniformly grown on carbon cloth fibers (Fig. 13a). To address the intrinsic cycling instability of PANI, the researchers conformally coated the deposited PANI nanowires with 5-nm-thick carbonaceous shells by hydrothermally decomposing glucose. The coated PANI electrode exhibited a high theoretical areal capacitance of $787.4 \mathrm{mF} \mathrm{cm}^{-2}$ (estimated by the Trasatti method) and excellent cycling stability of $\sim 95 \%$ after 10,000 charge-discharge cycles. SEM revealed that the carbonaceous shell mitigated the volumetric deformation-induced structural pulverization of PANI.
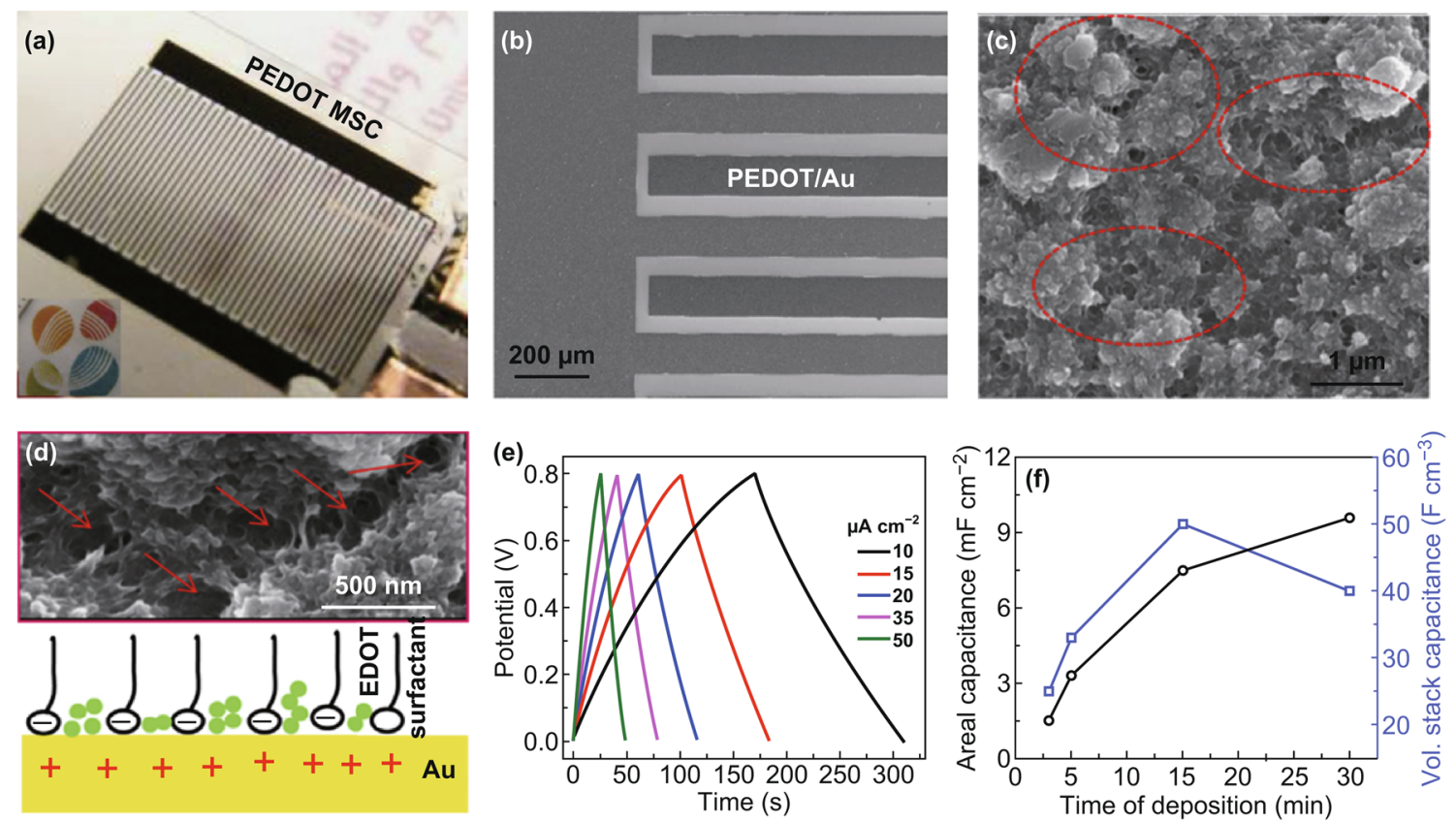

Fig. 12 a Photograph and b SEM image of PEDOT-coated interdigitated electrode. c Magnified view SEM image of the electrodeposited PEDOT film. The red circles highlight the cracks formed by soft templates. d Scheme illustrating the surfactant-induced crack formation. e Galvanostatic charge-discharge profiles of a symmetric micro-supercapacitor consisting of two PEDOT-coated interdigitated electrodes. Electrolyte: $1 \mathrm{M} \mathrm{H}_{2} \mathrm{SO}_{4}$ aqueous solutions. f Areal and volumetric capacitances of the symmetric micro-supercapacitor as a function of polymer deposition time. Adapted from Ref. [144] with permission 

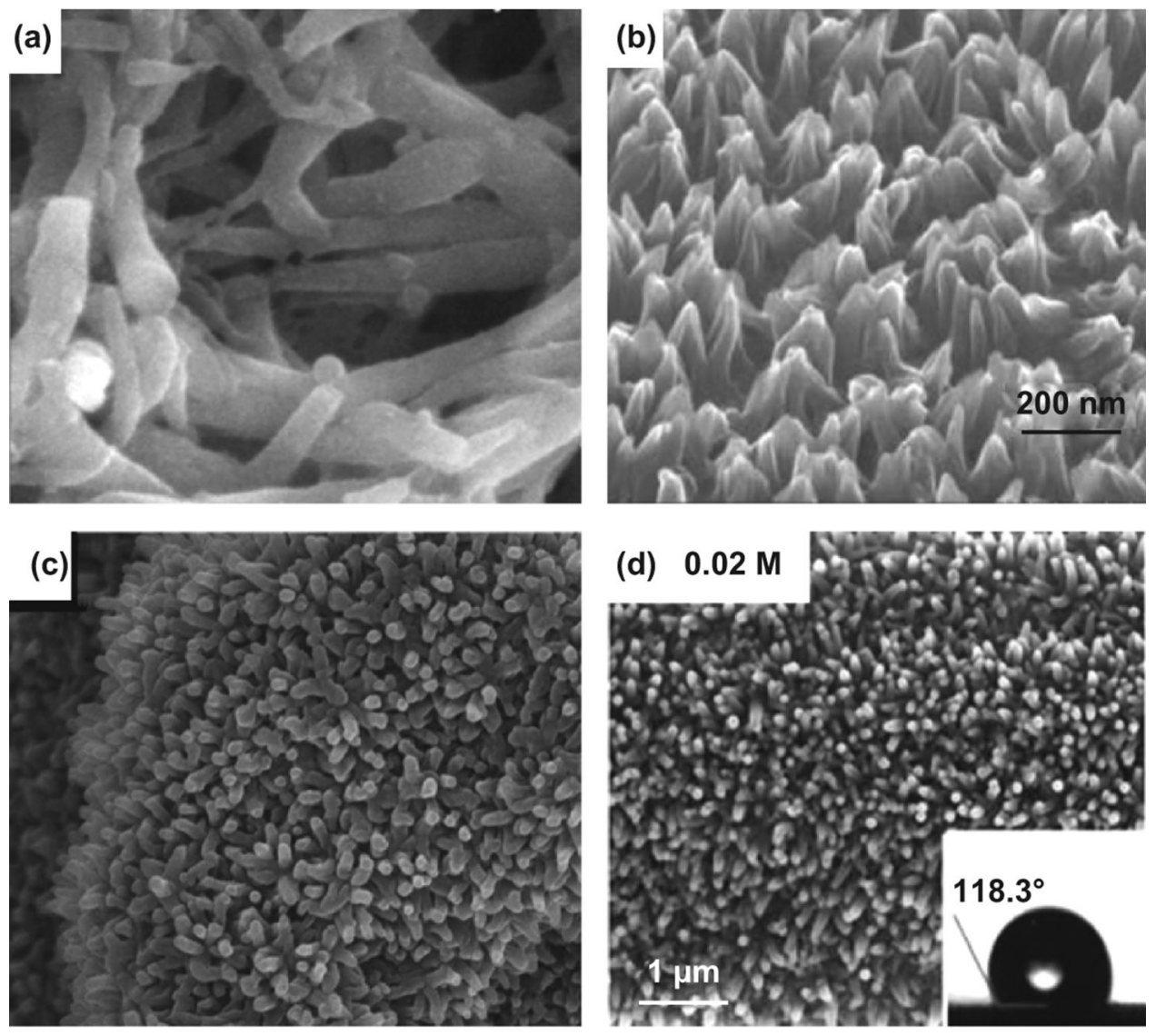

Fig. 13 Electrochemically deposited 1D polymer structures. a PANI nanofibers on carbon cloth; b PANI nanorod arrays on Au plates; c PANI nanorod arrays on carbon nanotube paper; d PPy nanorod arrays on carbon cloth. Adapted from a Ref. [25], b Ref. [153], c Ref. [145], d Ref. [149] with permission

Confining the growth of conducting polymers from current collector surfaces is a prerequisite to obtaining binderfree supercapacitor electrodes. To suppress electropolymerization of monomers in bulk electrolytes, small current, low potential, and dilute monomer solutions are preferred. Once polymer nucleates on substrate surfaces, they minimize the energy barrier for the subsequent growth of conducting polymer nanostructures [152, 153]. For example, PANI nanorod arrays were grown on a gold plate using a galvanostatic method with a small current density of $0.01 \mathrm{~mA} \mathrm{~cm}^{-2}$ (Fig. 13b) [153]. The formation mechanism followed the nucleation-initiated growth process. The electrodeposited PANI nanorod array electrode exhibited a high specific capacitance of $950 \mathrm{~F} \mathrm{~g}^{-1}$ at $1 \mathrm{~A} \mathrm{~g}^{-1}$. Following the same protocol, PANI nanorod arrays were grown on other conductive substrates, such as carbon nanotubes (Fig. 13c) [145], exfoliated graphene sheets [154], as well as graphene papers $[155,156]$. The generality of substrates indicated that the nucleation growth process is independent of substrate properties.

In addition to PANI, electrochemical technology also produces polypyrrole (PPy) nanorod arrays on conductive substrates. Huang et al. fabricated PPy nanorod arrays via a one-step galvanostatic deposition at $1 \mathrm{~mA} \mathrm{~cm}^{-2}$ with $p$-toluenesulfonate acid (TsOH) as a soft template (Fig. 13d) [149]. The TsOH anions prevented the as-formed PPy oligomers from growing in random directions, promoting the growth of PPy nanorods on carbon cloth. Significantly, the PPy nanorods exhibited capacitance of $699 \mathrm{~F} \mathrm{~g}^{-1}$ at $1 \mathrm{~A} \mathrm{~g}^{-1}$. When the current density increased from 1 to $20 \mathrm{~A} \mathrm{~g}^{-1}$, $81.5 \%$ capacitance retained, indicating its excellent rate capability.

The use of hard templates enables the growth of sophisticated 1D nanostructures, such as nanotubes. Using nickel nanotube array (NiNTA) hard templates, Chen et al. made perchlorate-doped PPy nanotubes (Fig. 14) [157]. First, Ni 
nanoparticles were dispersed on $\mathrm{ZnO}$ nanorod arrays to form ZnO@NiNRAs, followed by dissolving the $\mathrm{ZnO}$ templates to produce NiNTAs. Second, the electropolymerization of PPy on NiNTAs generated NiNTAs@PPy (Fig. 14a, b). Highresolution TEM showed abundant mesopores throughout the PPy layer (Fig. 14c, d). Possibly, the mesopores formed during the polymerization process when the anions were inserted into PPy, and the cations were extracted. The highly porous hollow nanotube arrays in NiNTAs@PPy acted as ion reservoirs that shortened ion diffusion distance.
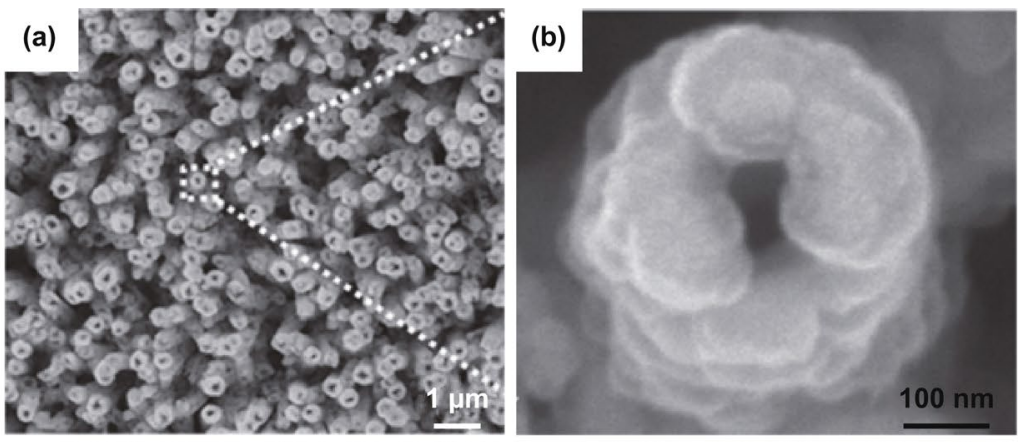

(c)
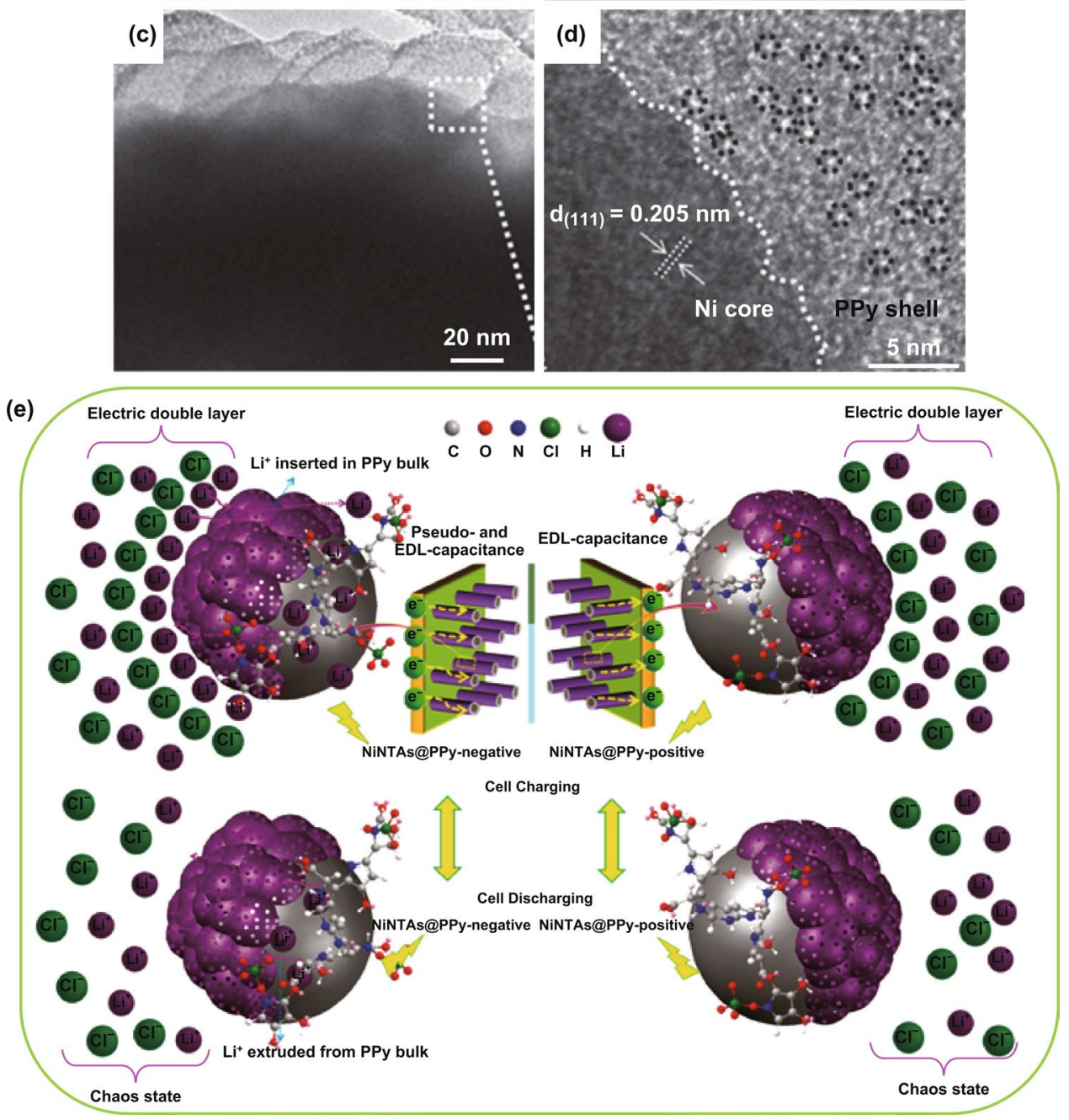

Fig. 14 a, b SEM and c, d TEM images of NiNTAs@PPy. The black dotted circles in $\mathbf{d}$ highlight micropores in PPy. e Schemes showing the charge storage mechanism of NiNTAs@PPy in supercapacitors during (top) charging and (bottom) discharging. Adapted from Ref. [157] with permission 
Therefore, NiNTAs@PPy electrode displayed a high specific capacitance of $474.4 \mathrm{~F} \mathrm{~g}^{-1}$ at $5 \mathrm{mV} \mathrm{s}^{-1}$. The PPy nanotubes also had excellent electrochemical stability with $75.3 \%$ capacitance retention after 10,000 charge-discharge cycles. The nanotube morphology and many pores and voids in PPy buffered the volumetric change of PPy and facilitated ion diffusion (Fig. 14e), which ensured excellent cycling stability.

\subsubsection{Nanoplates}

Electrochemically synthesized two-dimensional (2D) conducting polymers are rare because conducting polymers intrinsically prefer to grow into fibers or films. One typical example of 2D conducting polymer made by electropolymerization is pyrene nanosheets (Fig. 15a). They were grown in a mixed electrolyte containing boron trifluoride diethyl etherate (BFEE), trifluoroacetic acid (TFA), and polyethylene glycol (PEG), using a potentiostatic technique (1.2 V vs. SCE) [158]. Spectroscopy revealed that the formation of nanosheets was due to oligomer growth via $\alpha-\alpha$ coupling of pyrene rings. Besides pyrene, PPy nanosheets (Fig. 15b) were synthesized using cyclic voltammetry at a high scan rate of $200 \mathrm{mV} \mathrm{s}^{-1}$ in an aqueous electrolyte containing 0.05 $\mathrm{M}$ pyrrole and 0.1 $\mathrm{M} \mathrm{KNO}_{3}$ [159]. These PPy nanosheets interconnected with each other and assembled into a macroporous structure. It had a specific surface area of $37.1 \mathrm{~m}^{2} \mathrm{~g}^{-1}$ and a specific capacitance of $584 \mathrm{~F} \mathrm{~g} \mathrm{~g}^{-1}$ at $5 \mathrm{~mA} \mathrm{~cm}^{-2}$

Hard template methods can also synthesize 2D polymer materials (Fig. 15c, d). These 2D templates (e.g., graphene sheets [160] and layered double hydroxides [161]) are structural scaffolds to direct the growth of conducting polymers in 2D fashion, endowing fast ion diffusion pathways in the electrode materials that results in excellent rate capability.
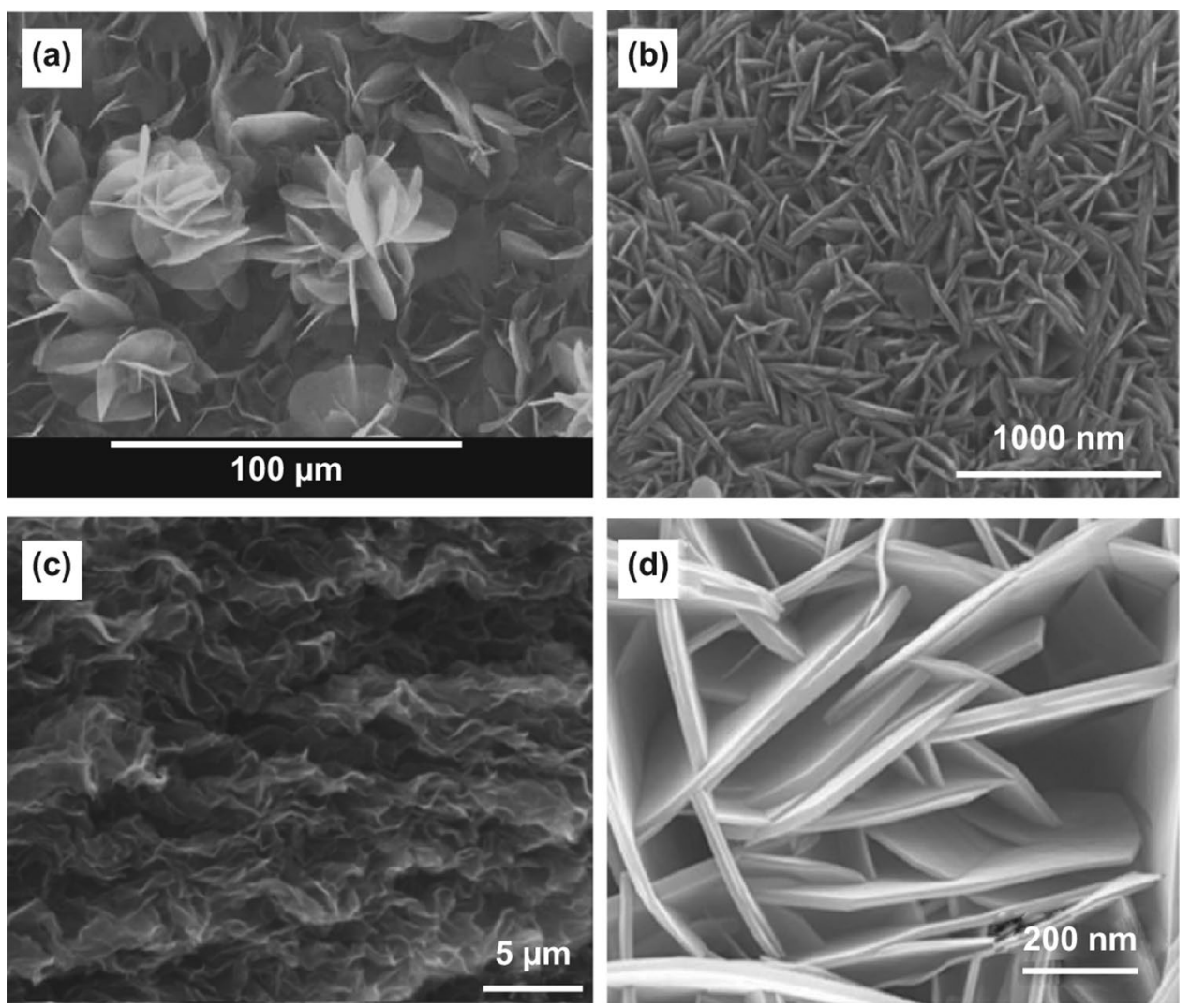

Fig. 15 Electrodeposited two-dimensional conducting polymers. a Oligopyrene nanosheets; b PPy nanosheets; $\mathbf{c}$ PANI nanosheets on graphene sheets; d PEDOT thin films on CoAl layered double hydroxide nanoplates. Adapted from a Ref. [162], b Ref. [159], c Ref. [160], d Ref. [161] with permission 


\subsubsection{D Networks}

Three-dimensional (3D) conductive structures provide large ion-accessible surface areas and abundant pores compared to $2 \mathrm{D}$ architectures and, thus, are increasingly popular morphologies of electrochemically deposited conducting polymers. High surface area can effectively reduce the local current density and polarization in bulk electrodes and thus improve the electrodes' charge storage kinetics. Unfortunately, ideal 3D structures composed merely of conducting polymers are challenging to acquire, due to their preferably random growth into films or fibers during electropolymerizations.

To circumvent this challenge, researchers adopt templates to construct 3D conducting polymers. Demonstrated templates, including carbon nanotube foam [163] (Fig. 16a, b), graphene foam [164] (Fig. 18c), partial exfoliated graphite [26] (Fig. 16d), as well as Ni foam [165] (Fig. 16e-g), have been used to construct 3D polymer-based electrodes. For example, Park et al. deposited a PPy film on graphene foam (Fig. 16c) [164]. The high surface area of graphene foam and the pseudocapacitance of PPy synergistically improved the performance of the electrode. Wang et al. reported a PPy foam using a sacrificial Ni foam template (Fig. 16e) [165]. PPy was first electrodeposited on a Ni foam (Fig. 16f), and subsequently, the Ni foam was etched away, leaving a freestanding 3D PPy foam (Fig. 16g). This as-prepared 3D PPy foam was mechanically strong and highly flexible, making it a multifunctional 3D material in sensors, supercapacitors, and supports for graphene. Moreover, the freestanding 3D PPy exhibited a capacitance of $316.2 \mathrm{~F} \mathrm{~g}^{-1}$ at $2 \mathrm{mV} \mathrm{s}^{-1}$, and the graphene-coated 3D PPy achieved a higher capacitance of $702.9 \mathrm{~F} \mathrm{~g}^{-1}$ at the same scan rate. The incorporation of graphene created highly conductive surface coatings as well as increasing specific surface area from 72 to $113.4 \mathrm{~m}^{2} \mathrm{~g}^{-1}$.

\section{Metal Oxides and Hydroxides}

\subsection{Manganese Oxides}

Manganese oxides, particularly manganese dioxide $\left(\mathrm{MnO}_{2}\right)$, have attracted immense interest as one of the most commercially promising pseudocapacitive materials, due to its high theoretical capacitance $\left(\sim 1000 \mathrm{~F} \mathrm{~g}^{-1}\right)$, cost efficiency, source abundance, and environmental friendliness [166, 167]. A variety of chemical and electrochemical techniques
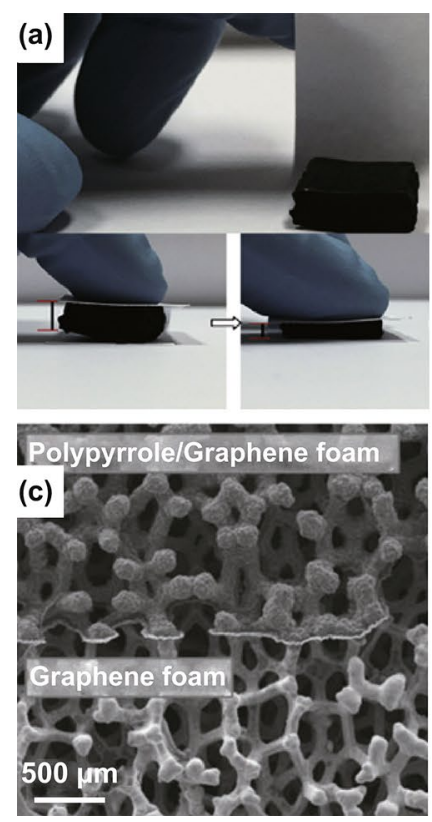
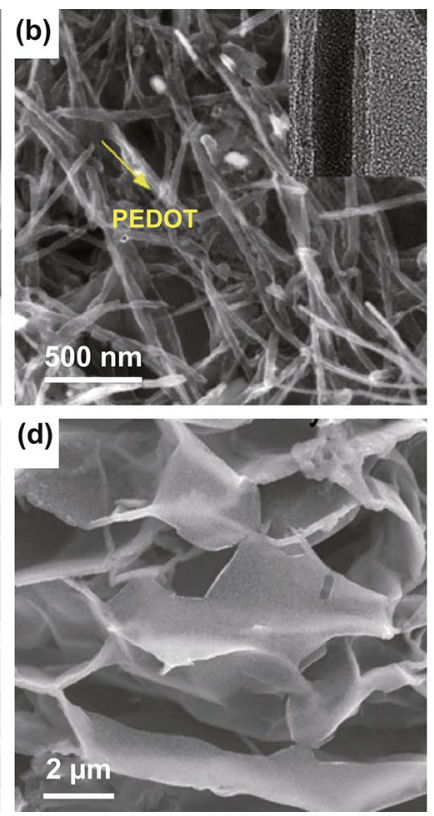

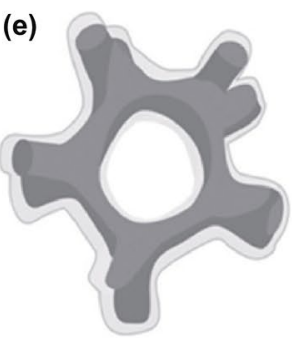

PPy@NF

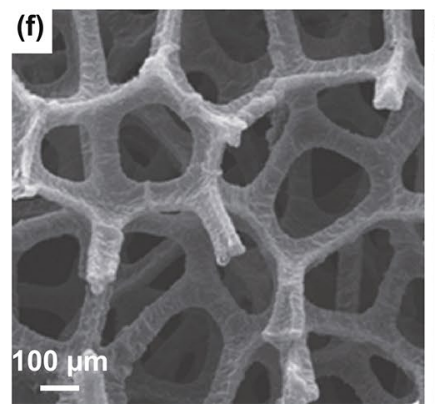

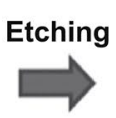

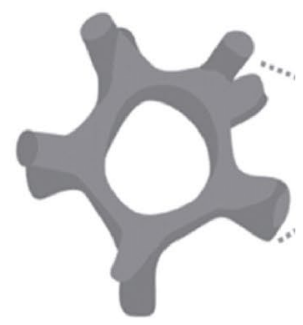

PPy Lattice

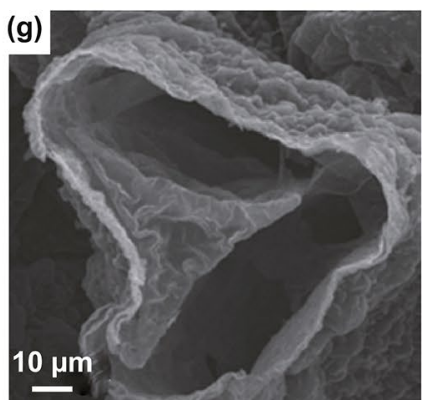

Fig. 16 a Photographs and b SEM and TEM (inset) images of a compressible, PEDOT-coated carbon nanotube sponge. c SEM image of PPycoated graphene (top) and bare graphene (bottom) foams. d PPy film deposited on electrochemically exfoliated graphite foil. e Scheme of the fabrication process of 3D PPy foam. f, g SEM images of 3D PPy foam at different magnifications. Adapted from a, b Ref. [163], c Ref. [164], d Ref. [26], e-g Ref. [165] with permission 
have synthesized manganese oxides. Among them, anodic electrodeposition is the most time-efficient. This technique deposited $\mathrm{MnO}_{x}$ by consecutive oxidation of $\mathrm{Mn}^{2+}$, as illustrated in the following equations $[168,169]$ :

$\mathrm{Mn}^{2+} \rightarrow \mathrm{Mn}^{3+}+e^{-}$

$\mathrm{Mn}^{3+}+2 \mathrm{H}_{2} \mathrm{O} \rightarrow \mathrm{MnOOH}+3 \mathrm{H}^{+}$

$\mathrm{MnOOH} \rightarrow \mathrm{MnO}_{2}+e^{-}$

The nanostructures of electrodeposited $\mathrm{MnO}_{x}$ are tunable by varying the electrolyte composition, temperature, potential, and current density. For example, Feng et al. demonstrated that complexing agents such as $\mathrm{CH}_{3} \mathrm{COO}^{-}$and $\mathrm{NH}_{4}{ }^{+}$ significantly reduced the charge transfer resistance of the electrooxidation of $\mathrm{Mn}^{2+}$ [166], changing the morphology of $\mathrm{MnO}_{x}$ from 2D nanosheets to 1D nanoneedles. These observations indicate that diminishing charge transfer resistance of $\mathrm{MnO}_{x}$ electrodeposition impedes its lateral growth.
Wei et al. proposed a theory of the supersaturation ratio of $\mathrm{Mn}^{2+}$ to rationalize the diverse morphologies of anodically electrodeposited $\mathrm{MnO}_{x}$ (Fig. 17a) [170]. Supersaturation ratio is defined as the ratio of the actual concentrations (or more vigorously speaking, activities) of all the ions associated with electrodeposition to the equilibrium concentrations of the same set of ions. The authors observed that high concentrations of $\mathrm{Mn}\left(\mathrm{NO}_{3}\right)_{2}$ and large current densities induced high supersaturation ratios that led to uniform coatings. In contrast, low concentrations of $\mathrm{Mn}\left(\mathrm{NO}_{3}\right)_{2}$ and small current densities favored epitaxial growth into interconnected nanosheets (Fig. 17b-f). These different morphologies were associated with the number of nucleates formed at the beginning of electrodeposition. High supersaturation ratios yielded abundant nucleation sites that suppressed epitaxial growth. Parameters that lowered the supersaturation ratio decreased the number of nucleation sites and favored the formation of nanostructures.

(a)
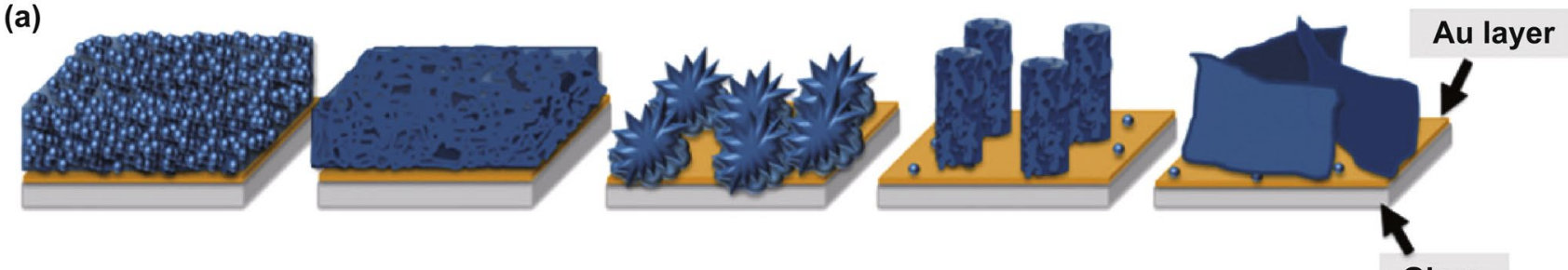

Concentration, temperature, current density and $\mathrm{pH}$ value

Supersaturation ratio decreases
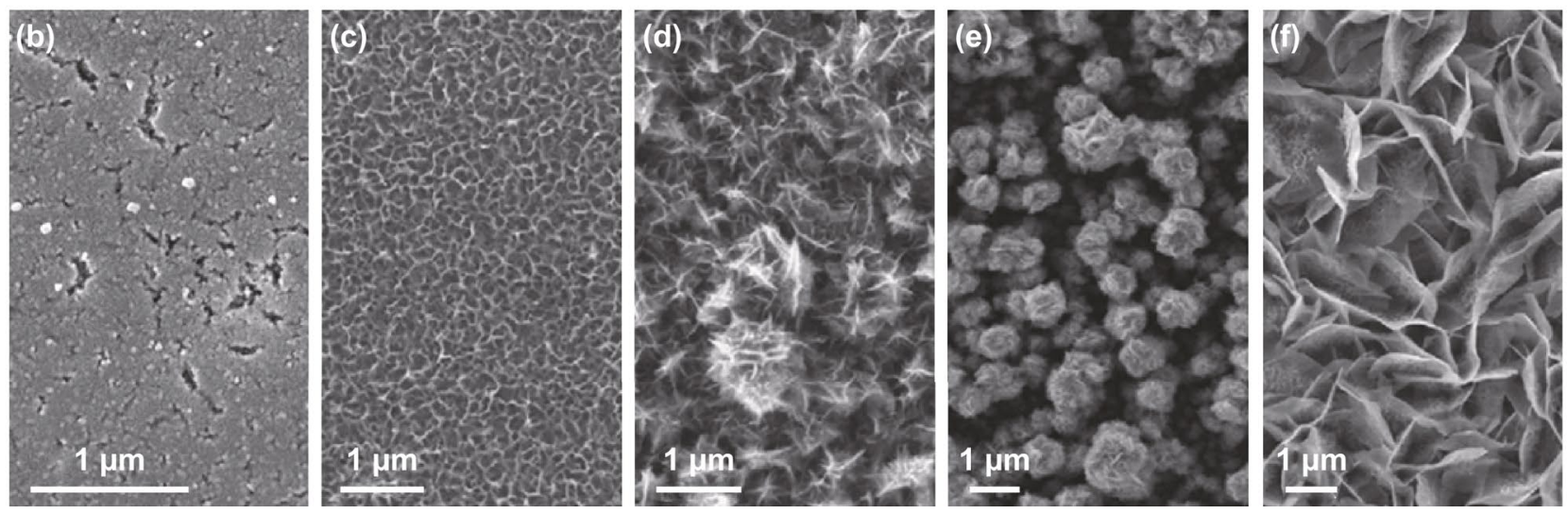

Fig. 17 a Schemes of the morphological evolution of $\mathrm{MnO}_{x}$ across different electrodeposition supersaturation ratios. b-d Top-view SEM images of $\mathrm{MnO}_{x}$ electrodeposited in $0.1 \mathrm{M} \mathrm{Mn}\left(\mathrm{NO}_{3}\right)_{2}$ aqueous solutions at various current densities: b $20 \mathrm{~mA} \mathrm{~cm} \mathrm{~cm}^{-2}, \mathbf{c} 1 \mathrm{~mA} \mathrm{~cm} \mathrm{~cm}^{-2}$, and d $0.1 \mathrm{~mA} \mathrm{~cm}^{-2}$. e-f SEM images of $\mathrm{MnO}_{x}$ prepared in $0.0025 \mathrm{M} \mathrm{Mn}\left(\mathrm{NO}_{3}\right)_{2}$ at $\mathbf{e} 0.1 \mathrm{~mA} \mathrm{~cm}{ }^{-2}$ and $\mathbf{f} 0.05 \mathrm{~mA} \mathrm{~cm}^{-2}$. Adapted from Ref. [170] with permission 


\subsubsection{Nanorods and Nanotubes}

Templating is a typical strategy to prepare $1 \mathrm{D} \mathrm{MnO}_{x}$ nanostructures [171, 172]. ZnO nanorods [173], anodized alumina [174, 175], hydrogenated $\mathrm{TiO}_{2}$ nanorods [176], and silicon square pillars [177] are reported templates for electrodepositing $\mathrm{MnO}_{x}$ nanorod or nanotube arrays. For example, Li and coworkers synthesized double-walled carbon/ $\mathrm{MnO}_{2}$ nanotube arrays using $\mathrm{ZnO}$ nanorods as sacrificial templates [173] (Fig. 18a). First, $\mathrm{ZnO}$ nanorod arrays were grown on Ti plates via electrodeposition, and thin layers of carbon were coated on the nanorods to render the $\mathrm{ZnO}$ nanorods electrically conductive. Afterward, a uniform $\mathrm{MnO}_{2}$ film was electrodeposited on the carbon-coated $\mathrm{ZnO}$ nanorod arrays (Fig. 18b). Finally, dissolving the $\mathrm{ZnO}$ nanorod arrays using $0.5 \mathrm{M} \mathrm{NaOH}$ solution generated the double-walled carbon/ $\mathrm{MnO}_{2}$ nanotube arrays (Fig. 18c). These double-walled nanotubes displayed a high specific capacitance of $793 \mathrm{~F} \mathrm{~g} \mathrm{~g}^{-1}$ at $1.5 \mathrm{~A} \mathrm{~g}^{-1}$, and a rate capability of $83 \%$ when the scan rate increased from 5 to $50 \mathrm{mV} \mathrm{s}^{-1}$. The excellent electrochemical performances were ascribed to factors including: (1) the hollow structure of the nanotube arrays exposed plentiful active sites of $\mathrm{MnO}_{2}$ and provided ions with fast diffusion pathways; (2) the conformal carbon coating served as electron transport expressways, minimizing capacitance loss at elevated scan rates; and (3) the high weight fraction of $\mathrm{MnO}_{2}(\sim 98.94 \mathrm{wt} \%)$ in the electrodes was beneficial to achieve high specific capacitance and energy density.

Besides templating, template-free methods could also synthesize 1D nanostructured $\mathrm{MnO}_{x}$. These methods are time-efficient and can synthesize products of high purity because they lift the needs for template incorporation and removal $[178,179]$. For example, Lu and coworkers demonstrated that adding dimethyl sulfoxide (DMSO) in the deposition solution of $\mathrm{MnO}_{2}$ led to $\mathrm{MnO}_{2}$ nanorod arrays without any templates [180]. They applied a constant anodic current of $0.2 \mathrm{~mA} \mathrm{~cm}^{-2}$ at $70{ }^{\circ} \mathrm{C}$ and used aqueous electrolytes containing $0.01 \mathrm{M}$ manganese(II) acetate, $0.02 \mathrm{M}$ ammonium acetate, and $10 \mathrm{wt} \%$ DMSO. The resultant $\mathrm{MnO}_{2}$ nanorods had diameters between 70 and $100 \mathrm{~nm}$, and lengths up to $\sim 1.5 \mu \mathrm{m}$ (Fig. 18d). Electrodeposition without DMSO only yielded $\mathrm{MnO}_{2}$ herringbones (Fig. 18e). Though the authors did not justify how DMSO changed the deposit morphology, we hypothesized that the addition of DMSO reduced the supersaturation ratio of $\mathrm{Mn}^{2+}$, and thus promoted epitaxial (a)
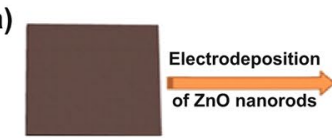

Ti substrate

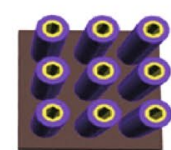

Carbon/ $/ \mathrm{MnO}_{2}$ DNTAs

(NRAs: nanorod arrays: DNTAs: double-walled nanotube arrays)
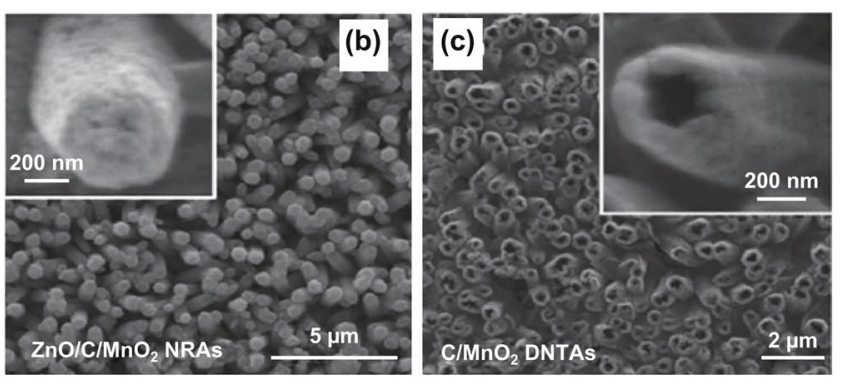

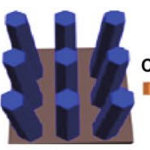

Carbon coating

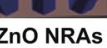

ZnO dissolving

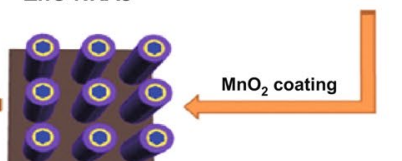

$$
\text { Znolcas }
$$$$
\text { O } 00
$$

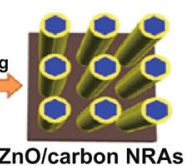

(d)
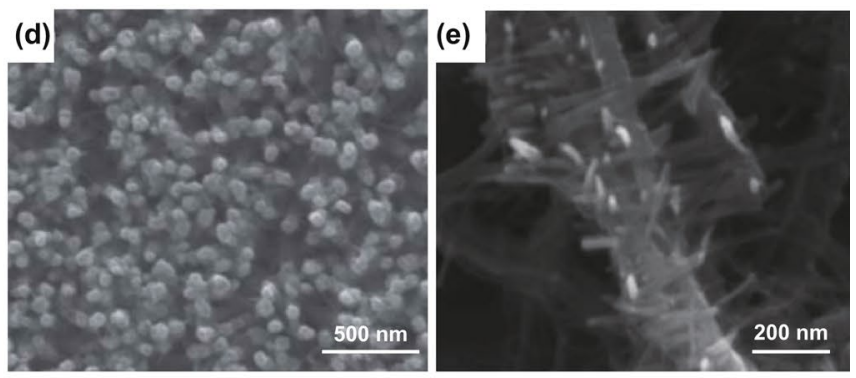

(f)

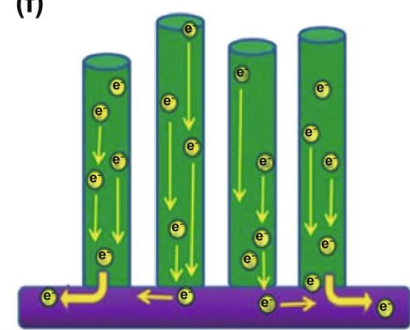

FTO Substrates

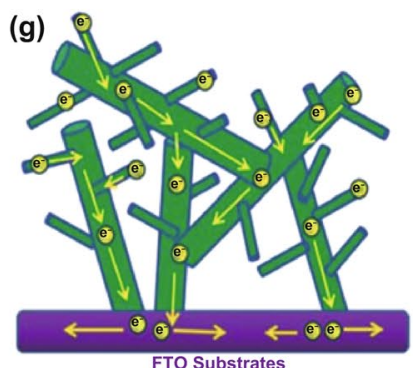

(g)

FTO Substrates

Fig. 18 a Schemes of the synthesis procedures of double-walled $\mathrm{MnO}_{2}$ nanotube arrays on carbon cloth. b $\mathrm{SEM}$ image of $\mathrm{ZnO} / \mathrm{C} / \mathrm{MnO}{ }_{2}$ nanorod arrays. Inset: Magnified view of a single nanorod. c SEM image of C-coated $\mathrm{MnO}_{2}$ double-walled nanotubes. Inset: Magnified view showing a C-coated $\mathrm{MnO}_{2}$ nanotube. d, e SEM images of $\mathrm{MnO}_{x} \mathbf{d}$ nanorods and e herringbones. $\mathbf{f}, \mathbf{g}$ Schemes of the charge transfer pathways in f $\mathrm{MnO}_{x}$ nanorod arrays and $\mathbf{g} \mathrm{MnO}_{x}$ herringbones. Adapted from a-c Ref. [173] and $\mathbf{d}-\mathbf{g}$ Ref. [180] with permission 
growth of $\mathrm{MnO}_{2}$ into nanorods. The specific capacitance of the $\mathrm{MnO}_{2}$ nanorod array was $660.7 \mathrm{~F} \mathrm{~g}^{-1}$ at $10 \mathrm{mV} \mathrm{s}^{-1}$, which was $\sim 100 \mathrm{~F} \mathrm{~g}^{-1}$ higher than that of the herringbone structured $\mathrm{MnO}_{2}\left(564.3 \mathrm{~F} \mathrm{~g}^{-1}\right)$. This capacitance discrepancy was associated with the morphology: The ordered vertically aligned nanorods, compared with the herringbones, reduced the tortuosity and distances for electron transport, which boosted capacitance (Fig. 18f, g).

\subsubsection{Nanosheets and Nanoplates}

Ultrathin 2D $\mathrm{MnO}_{x}$ nanosheets were other common morphologies of electrodeposited $\mathrm{MnO}_{x}$ [181-185]. Anodic deposition is widely demonstrated to prepare $\mathrm{MnO}_{x}$ nanosheets [186-195]. For example, Yao et al. deposited
$\mathrm{MnO}_{2}$ nanosheets onto 3D printed graphene aerogel lattices through an anodic galvanostatic deposition at $10 \mathrm{~mA} \mathrm{~cm}^{-2}$ (Fig. 19a) [196]. The outstanding property of these 3D printed $\mathrm{MnO}_{2}$ /graphene composite electrodes was their uncompromised electrochemical performance at $\mathrm{MnO}_{2}$ mass loadings as high as $182.2 \mathrm{mg} \mathrm{cm}^{-2}$. The areal capacitance scaled linearly with the thickness of the electrode, reaching $44.13 \mathrm{~F} \mathrm{~cm}^{-2}$ at $0.5 \mathrm{~mA} \mathrm{~cm}{ }^{-2}$ in $3 \mathrm{M} \mathrm{LiCl}$ aqueous electrolytes at a thickness of $4.0 \mathrm{~mm}\left(\mathrm{MnO}_{2}\right.$ mass loading $182.2 \mathrm{mg} \mathrm{cm}^{-2}$ ). This linear relationship indicated that the charge storage process of the electrode was not under diffusion control or limited by ion percolation even at ultrahigh mass loadings and thicknesses. This merit was attributed to the 3D-printed graphene lattices with macropores of 5-50 $\mu \mathrm{m}$ pores (Fig. 19b, c), which promoted the uniform

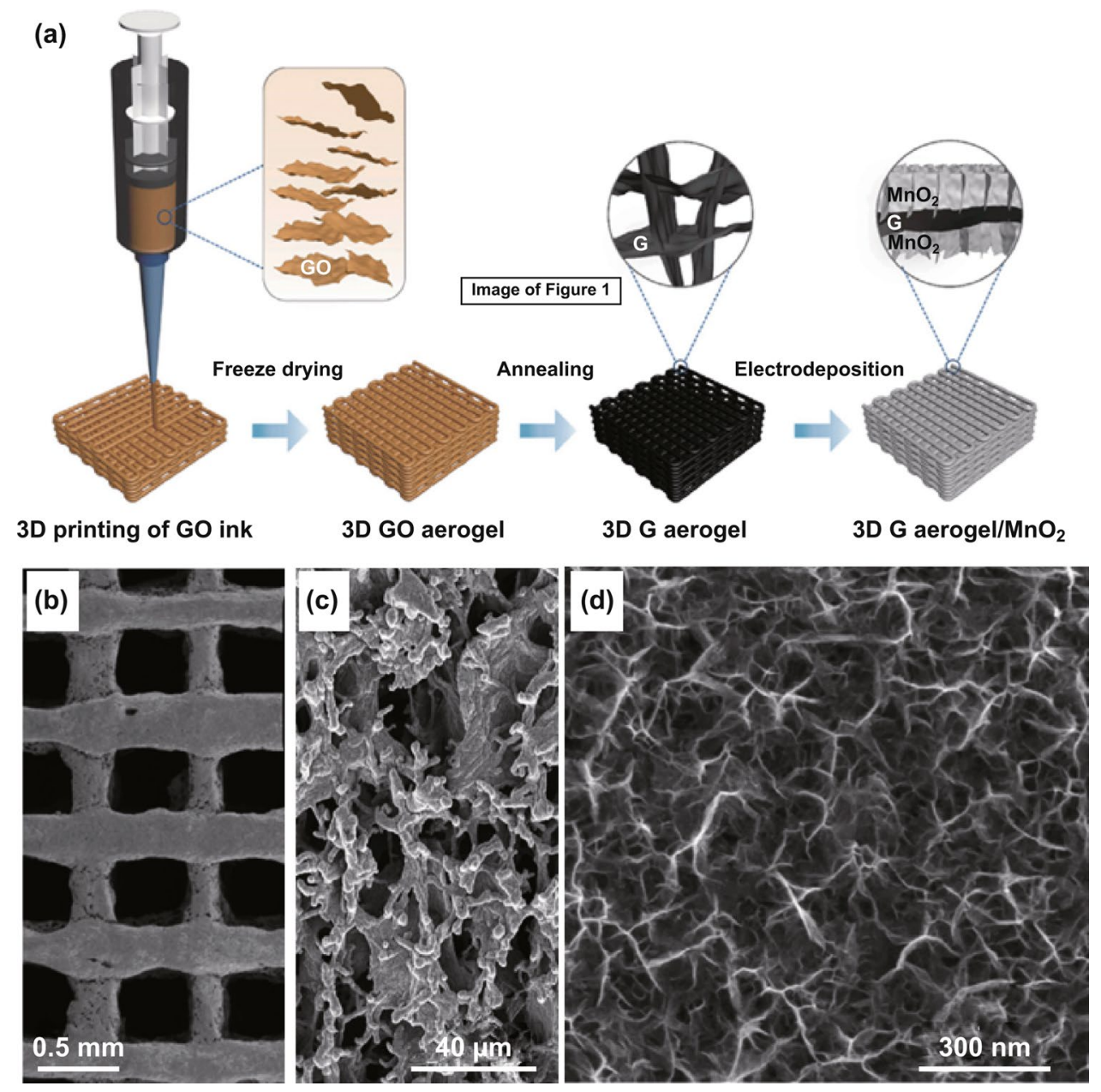

Fig. 19 a Schemes of the synthesis procedures of $\mathrm{MnO}_{2}$ nanosheets deposited on 3D printed graphene aerogel lattices. b A top-view SEM image of $\mathrm{MnO}_{2}$-coated 3D printed graphene aerogel. c, $\mathbf{d}$ SEM images of the deposited $\mathrm{MnO}_{2}$ nanosheets at two magnifications. Adapted from Ref. [196] with permission 
deposition of $\mathrm{MnO}_{2}$ and opened up wide ion diffusion pathways throughout the entire electrodes.

In addition to anodic electrodeposition, cathodic electrodeposition also synthesizes $2 \mathrm{D} \mathrm{MnO}_{x}$ nanosheets. For example, Beyazay et al. used a chronoamperometry technique to deposit $\mathrm{Mn}_{3} \mathrm{O}_{4}$ hexagonal nanosheets on graphene paper. This electrode delivered a maximal specific capacitance of $546 \mathrm{~F} \mathrm{~g}^{-1}$ at $0.5 \mathrm{~A} \mathrm{~g}^{-1}$. Interestingly, the capacitance increased about 1.5 times after being charged and discharged for 10,000 times. XPS analysis after the stability test found that the average valence of $\mathrm{Mn}$ raised from 2.7 to 3.2, indicating that part of $\mathrm{Mn}_{3} \mathrm{O}_{4}$ was oxidized to $\mathrm{MnO}_{2}$. Besides the valence change, some hexagonal nanosheets transformed into particles and needles. These results suggested that the hexagonal $\mathrm{Mn}_{3} \mathrm{O}_{4}$ nanosheets were both chemically and structurally unstable during long-term cycling tests.

\subsubsection{Hierarchical Structures}

Hierarchical $\mathrm{MnO}_{x}$ integrates nanostructures of different dimensions, e.g., 1D nanorod, 2D nanosheet, and 2D nanoplate. Electrodepositing hierarchical structures often begins with one specific structure. For example, Jabeen et al. synthesized $\mathrm{Mn}_{3} \mathrm{O}_{4}$ nanosheet-on-nanowall arrays via a cathodic potentiostatic method $(-1.8 \mathrm{~V}$ vs. $\mathrm{Ag} / \mathrm{AgCl})$ in an aqueous solution containing $0.1 \mathrm{M}$ manganese acetate and $0.1 \mathrm{M}$ sodium sulfate. High-resolution scanning electron microscopy revealed that these nanowalls were composed of interconnected nanoparticles (Fig. 20a) [14]. After 500 cycles of electrochemical oxidation in $10 \mathrm{M}$ sodium sulfate aqueous solutions, the nanoparticles disappeared, and nanosheets appeared on the surface of the nanowalls, assembling the nanosheet-on-nanowall hierarchical structure (Fig. 20b, c). Meanwhile, the composition of the electrode changed from $\mathrm{Mn}_{3} \mathrm{O}_{4}$ to $\mathrm{Na}_{0.5} \mathrm{MnO}_{2}$. The hierarchically structured $\mathrm{Na}_{0.5} \mathrm{MnO}_{2}$ exhibited a specific capacitance of $366 \mathrm{~F} \mathrm{~g}^{-1}$ at $1 \mathrm{~A} \mathrm{~g}^{-1}$. Besides, the redox peak of $\mathrm{Na}_{0.5} \mathrm{MnO}_{2}$ at $\sim 0.96 \mathrm{~V}$ vs. $\mathrm{Ag} / \mathrm{AgCl}$ extended the upper limit potential to approximately $1.3 \mathrm{~V}$ vs. $\mathrm{Ag} / \mathrm{AgCl}$, enabling the development of aqueous-based supercapacitors with high voltages and energy densities.

The most significant characteristic of hierarchical structures is their capability to maintain excellent electrochemical performance at $\mathrm{MnO}_{x}$ mass loadings exceeding $10 \mathrm{mg} \mathrm{cm}^{-2}$. Increasing the mass loadings of $\mathrm{MnO}_{x}$ (and other pseudocapacitive materials) has become a trend in recent years, due to the consideration of practicality. Unfortunately, the capacitances of poorly conductive pseudocapacitive materials, including $\mathrm{MnO}_{x}$, are greatly compromised when enhancing their mass loadings, particularly under fast charge and discharge rates. Hierarchical structures could resolve this challenge. For example, Song et al. developed an Ostwald ripening strategy that improved the rate capability of electrodeposited $\mathrm{MnO}_{x}$ thick films with a high mass loading of $\sim 10 \mathrm{mg} \mathrm{cm}^{-2}$ (Fig. 20d-f) [197]. The authors first coated carbon fibers with $\mathrm{MnO}_{x}$ films of $\sim 4.5 \mu \mathrm{m}$ thick using a constant current of $10 \mathrm{~mA} \mathrm{~cm}{ }^{-2}$ in $0.1 \mathrm{M}$ manganese acetate aqueous solutions (Fig. 20d). They then hydrothermally treated the electrodeposited $\mathrm{MnO}_{x}$ at $90^{\circ} \mathrm{C}$, which appreciably altered the morphology of the $\mathrm{MnO}_{x}$ films. First, many crystalline $\mathrm{MnO}_{x}$ nanosheets formed on the surface. Second, the porosity of the $\mathrm{MnO}_{x}$ core increased (Fig. 20e, f). The porous $\mathrm{MnO}_{x}$ core and oxide shell together constituted a core-shell hierarchical structure. The crystalline surface ensured good electrical conductivity, and the porous $\mathrm{MnO}_{x}$ core sped up ion diffusion. Therefore, the electrode exhibited improved rate performance even at a high mass loading of $10 \mathrm{mg} \mathrm{cm}^{-2}$. Recently, Huang et al. have demonstrated a facile electrochemical technology that synthesized a nanorodon-nanosheet hierarchical structure. The structure consisted of primary two-dimensional $\varepsilon-\mathrm{MnO}_{2}$ nanosheets and secondary one-dimensional $\alpha-\mathrm{MnO}_{2}$ nanorod arrays (Fig. 20g-i) [50]. Morphology studies indicated that elevating the deposition temperature to $60{ }^{\circ} \mathrm{C}$ and $80{ }^{\circ} \mathrm{C}$ added nucleation sites on the as-formed nanorods, which favored the secondary growth of nanorods. This hierarchical electrode had a high $\mathrm{MnO}_{2}$ mass loading of $10 \mathrm{mg} \mathrm{cm}^{-2}$ and delivered a high areal capacitance of $3.04 \mathrm{~F} \mathrm{~cm}^{-2}$ at $3 \mathrm{~mA} \mathrm{~cm}^{-2}$. Significantly, the areal capacitance maintained at $1.9 \mathrm{~F} \mathrm{~cm}^{-2}$ at $30 \mathrm{~mA} \mathrm{~cm}^{-2}$. The authors ascribed this excellent rate capability performance to two factors: First, the multiple connections between the nanorods and nanosheets created fast avenues for electron transport. Second, the voids among the nanorods and nanosheets throughout the hierarchical structure facilitated electrolyte ion percolation and ion diffusion.

\subsection{Vanadium Oxides}

Vanadium oxides $\left(\mathrm{VO}_{x}\right)$, mainly vanadium pentoxide $\left(\mathrm{V}_{2} \mathrm{O}_{5}\right)$, have the advantages of high specific capacitance 

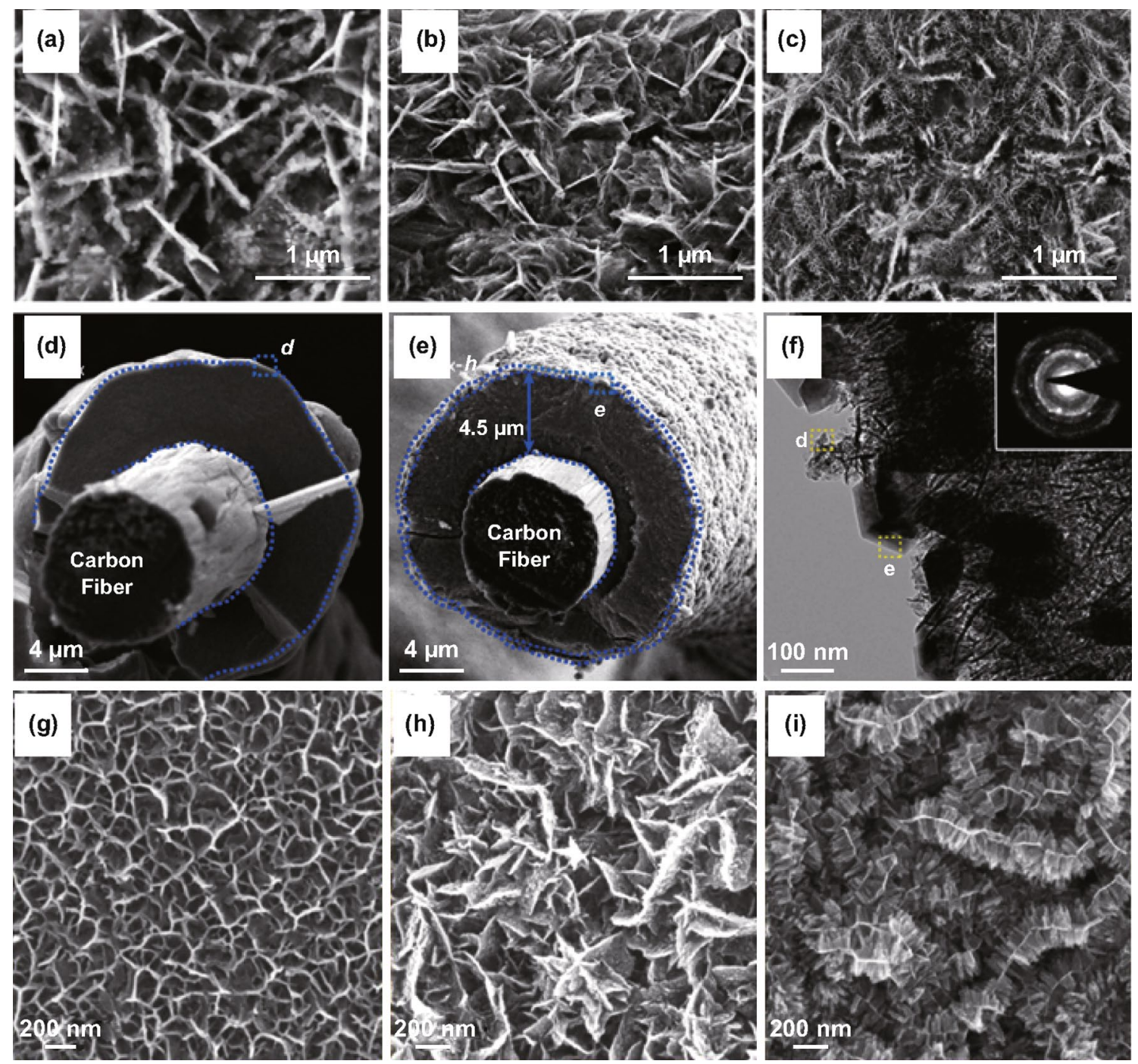

Fig. 20 a-c SEM image of a $\mathrm{Mn}_{3} \mathrm{O}_{4}$ nanowall arrays, b intermediates during electrochemical oxidation, and $\mathbf{c}$ hierarchical $\mathrm{Na}_{0.5} \mathrm{MnO}_{2}$ nanowall arrays. $\mathbf{d}$, e SEM images of $\mathbf{d}$ as-deposited and $\mathbf{e}$ hydrothermally treated $\mathrm{MnO}_{x}$ thick layer on carbon fiber. $\mathbf{f}$ TEM image of hydrothermally treated $\mathrm{MnO}_{x}$. $\mathbf{g}-\mathbf{i}$ SEM images of $\mathrm{MnO}_{2}$ deposited at $\mathbf{g} 25^{\circ} \mathrm{C}, \mathbf{h} 40{ }^{\circ} \mathrm{C}$, and i $60{ }^{\circ} \mathrm{C}$. Adapted from a-c Ref. [14]; d-f Ref. [197]; g-i Ref. [50] with permission

(multiple electron reaction, e.g., from +3 to +5 ), low cost, ease of fabrication, as well as wide potential windows [37, 198-202]. Electrochemical technologies are particularly suitable for synthesizing $\mathrm{VO}_{x}$ of diverse morphologies, crystal structures, and valence states [203-209]. In aqueous electrolytes, vanadium oxide is typically synthesized from the oxidation of vanadium-containing ions with the aid of water molecules. For example, oxovanadium(IV) cations, $\mathrm{VO}^{2+}$, are electrooxidized to high-valence vanadium oxides (e.g., $\mathrm{V}_{2} \mathrm{O}_{5}$ ) through the following equation [208]:

$2 \mathrm{VO}^{2+}+3 \mathrm{H}_{2} \mathrm{O} \rightarrow \mathrm{V}_{2} \mathrm{O}_{5}+6 \mathrm{H}^{+}+2 e^{-}$
For example, Xie et al. demonstrated that the $\mathrm{pH}$ value and composition of acetate salts $\left(\mathrm{CH}_{3} \mathrm{COONa}, \mathrm{CH}_{3} \mathrm{COOLi}\right.$, $\mathrm{CH}_{3} \mathrm{COOK}$ ) were critical in tuning the deposition rate, crystal structure, and morphology of $\mathrm{VO}_{x}$ [209]. Drosos et al. studied the effects of the deposition current density on the morphology and electrochemical performance of $\mathrm{V}_{2} \mathrm{O}_{5}$ coatings on indium-doped tin oxide glass substrates in $1 \mathrm{M}$ $\mathrm{LiClO}_{4}$ polypropylene carbonate electrolytes. The $\mathrm{V}_{2} \mathrm{O}_{5}$ film deposited at $1 \mathrm{~mA} \mathrm{~cm}^{-2}$ exhibited the highest capacitance owing to its roughest surface [210].

Electrodeposited $\mathrm{VO}_{x}$ with mixed $\mathrm{V}$ valences are platforms for studying the interplays between $\mathrm{V}$ valence and cycling stability. Recent studies indicated that the 
performance degradation was linked to dissolution, structural pulverization, and irreversible phase transition of $\mathrm{VO}_{x}$ [34, 37, 199]. Investigating the cycling behavior of electrodeposited $\mathrm{VO}_{x}$ electrodes in various aqueous environments, Engstrom and Doyle concluded that the formation of water-soluble $\mathrm{V}$-containing species, including $\mathrm{H}_{2} \mathrm{VO}_{4}{ }^{-}$, $\mathrm{HVO}_{4}{ }^{2-}, \mathrm{HV}_{2} \mathrm{O}_{5}{ }^{-}, \mathrm{VO}^{2+}, \mathrm{HVO}^{2+}$, and $\mathrm{VO}^{+}$(Fig. 21a), was the primary cause of capacitive decay of $\mathrm{VO}_{x}$ during extensive cycling tests [199]. Though chemical strategies such as surface coating [211,212] and electrolyte $\mathrm{pH}$ value tuning [199] minimized dissolution of $\mathrm{VO}_{x}$, the altered electrode kinetics usually compromised capacitance. To circumvent these limitations, Song et al. utilized a potentiostatic electrochemical method to tune the $\mathrm{V}$ valence in $\mathrm{VO}_{x}$ and achieved record-high cycling stability without capacitive decay over 100,000 cycles (Fig. 21b-d) [37]. $\mathrm{VO}_{x}$ nanorods were first electrodeposited on electrochemically exfoliated carbon cloth fibers using cyclic voltammetry between -1.5 and $1.4 \mathrm{~V}$ vs. SCE (Fig. 21c). The authors then reduced the asdeposited $\mathrm{VO}_{x}$ at a constant potential of $-1.5 \mathrm{~V}$ vs. SCE for $1 \mathrm{~min}$. This reduction raised the $\mathrm{V}^{4+} / \mathrm{V}^{5+}$ ratio from 0.4 to an optimal value of around 0.5 . The optimized $\mathrm{V}^{4+} / \mathrm{V}^{5+}$ ratio in $\mathrm{VO}_{x}$ effectively suppressed the chemical dissolution of $\mathrm{VO}_{x}$. Meanwhile, the firm anchoring of the reduced $\mathrm{VO}_{x}$ nanorods on oxygenated, exfoliated carbon cloth fibers via $\mathrm{C}-\mathrm{O}-\mathrm{V}$ bonds retained the structural integrity of $\mathrm{VO}_{x}$. Both factors contributed to the excellent cycling stability (ECC/ $\mathrm{RVO}_{x}$ in Fig. 21d).

The easy valence tuning of $\mathrm{VO}_{x}$ by electrochemical techniques allowed the synthesis of heterojunctions between $\mathrm{VO}_{x}$ of two valences. These configurations help facilitate electron transfer within $\mathrm{VO}_{x}$ electrodes having large thicknesses or high mass loadings [34]. For instance, Dong et al. performed a density functional theory (DFT) calculation and discovered that a built-in electric field formed at the $\mathrm{V}_{5} \mathrm{O}_{12} /$ $\mathrm{VO}_{2}$ heterojunction. The charge redistribution between the two oxides led to an electric field pointing from $\mathrm{VO}_{2}$ to $\mathrm{V}_{5} \mathrm{O}_{12}$ (Fig. 22a) [34]. This built-in electrical filed facilitated electron transfer and modulated ion absorption during charge storage processes, which improved electrochemical performance. Inspired by this calculation result, the authors adopted cyclic voltammetry ( -1.5 to $1.5 \mathrm{~V}$ vs. SCE) to electrodeposit $\mathrm{V}_{5} \mathrm{O}_{12} / \mathrm{VO}_{2}$ nanorods on an exfoliated graphite substrate. $\mathrm{V}_{5} \mathrm{O}_{12}$ first formed during the positive scan, and
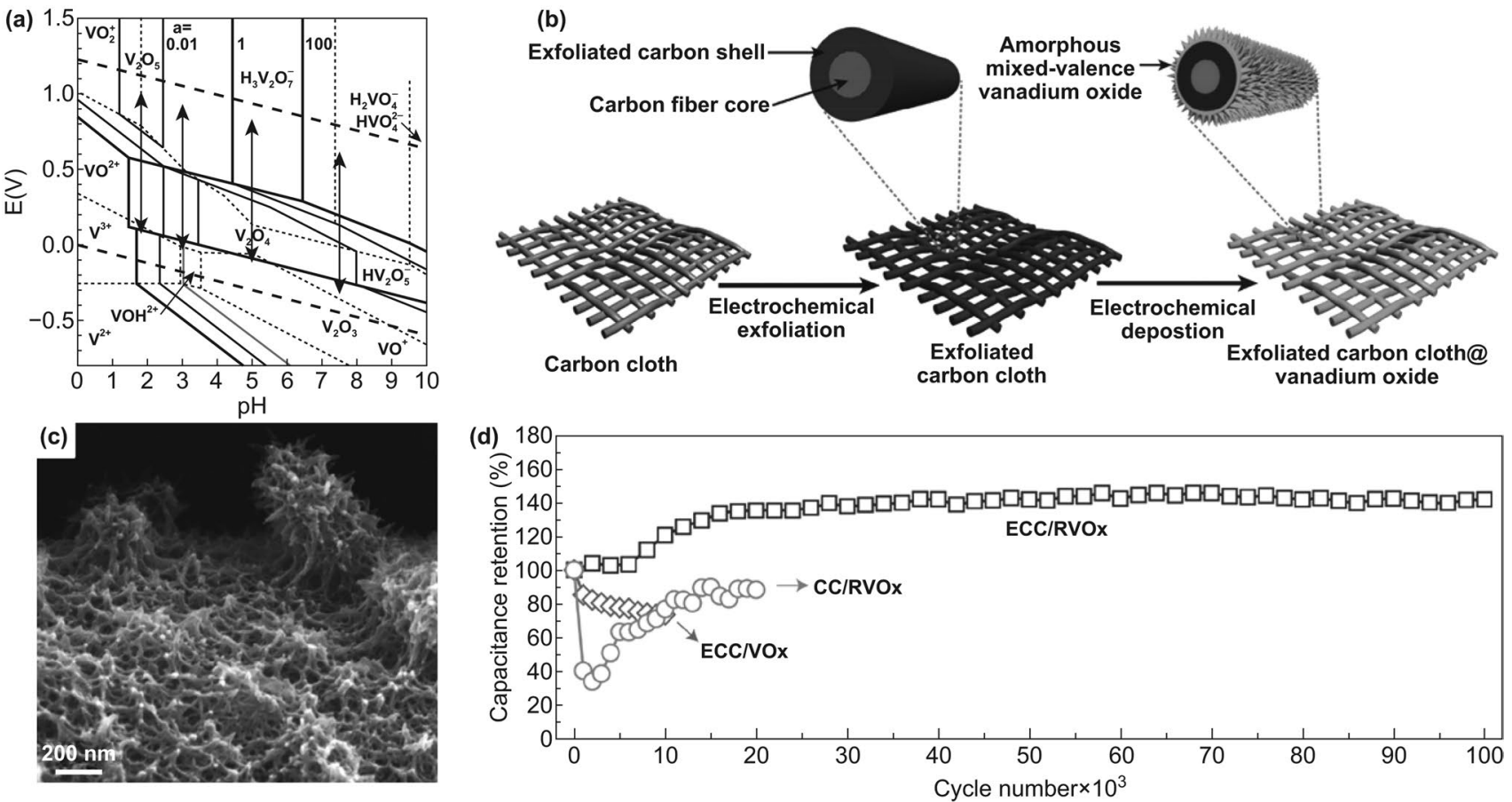

Fig. 21 a $E-$ pH diagram of vanadium oxide-water system with various V-based species at activities (the letter "a" in the figure) of $0.01,1$ and

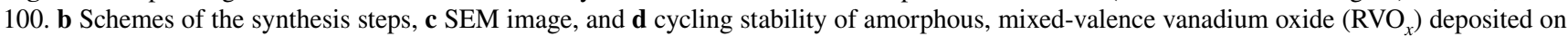
exfoliated carbon cloth fibers. Adapted from a Ref. [199] and b-d Ref. [37] with permission 
it was partially reduced to $\mathrm{VO}_{2}$ in the subsequent negative scan (Fig. 22b). $\mathrm{V}_{5} \mathrm{O}_{12} / \mathrm{VO}_{2}$ with a high mass loading of about $10.8 \mathrm{mg} \mathrm{cm}^{-2}$ delivered a high areal capacitance of $5.03 \mathrm{~F} \mathrm{~cm}^{-2}\left(465 \mathrm{~F} \mathrm{~g}^{-1}\right)$ at $1 \mathrm{~mA} \mathrm{~cm}{ }^{-2}$, outperforming pure $\mathrm{V}_{5} \mathrm{O}_{12}$ and $\mathrm{VO}_{2}$ (Fig. 22c). Significantly, $\mathrm{V}_{5} \mathrm{O}_{12} / \mathrm{VO}_{2}$ also exhibited enhanced cycling stability compared to $\mathrm{V}_{5} \mathrm{O}_{12}$ and $\mathrm{VO}_{2}$ alone (Fig. 22d). Two reasons could account for this stability enhancement. First, EIS indicated that $\mathrm{V}_{5} \mathrm{O}_{12} /$ $\mathrm{VO}_{2}$ exhibited reduced charge transfer resistance due to the heterojunction (Fig. 22e). Second, ex situ XRD confirmed that $\mathrm{V}_{5} \mathrm{O}_{12} / \mathrm{VO}_{2}$ underwent no phase transitions after charging and discharging, while the phases of $\mathrm{V}_{5} \mathrm{O}_{12}$ and $\mathrm{VO}_{2}$ changed dramatically (Fig. 22f-h). The reduced resistance and suppressed phase change of $\mathrm{V}_{5} \mathrm{O}_{12} / \mathrm{VO}_{2}$ both enhanced cycling stability.

\subsection{Molybdenum Oxides}

Molybdenum oxides $\left(\mathrm{MoO}_{x}\right)$ are another group of electrodeposited pseudocapacitive materials [213-215]. Unlike $\mathrm{MnO}_{x}$ discussed in the previous sections, $\mathrm{MoO}_{x}$ is acidresistant and thus can work in acidic electrolytes [216]. (a)

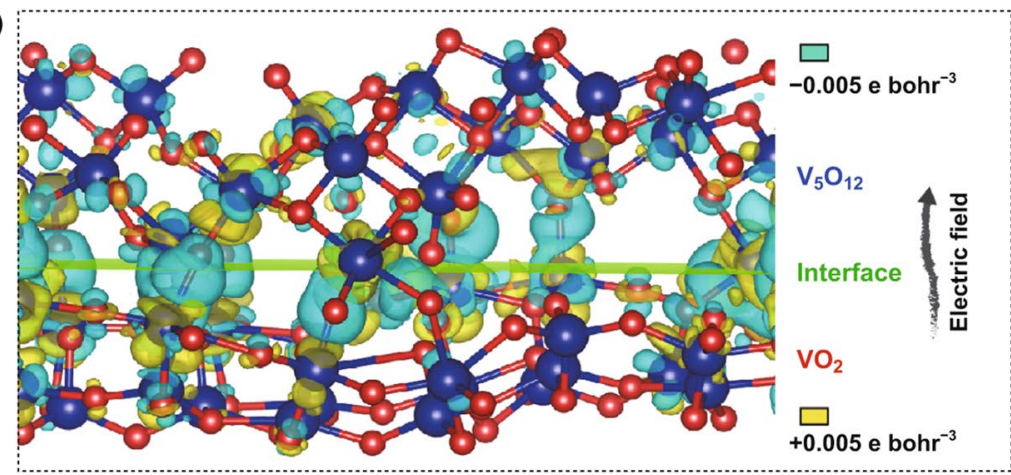

(b)
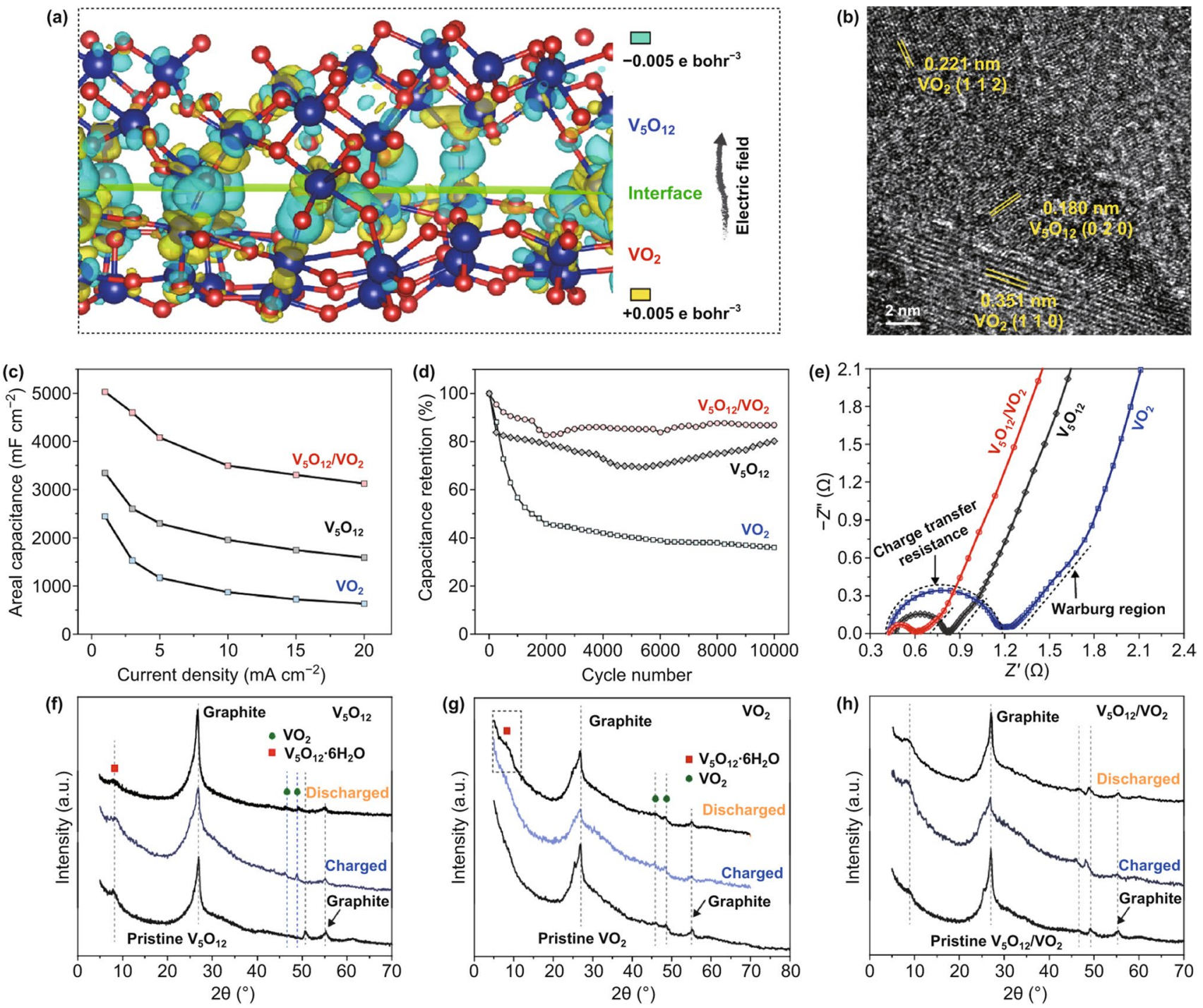

Fig. 22 a Charge density distribution along the interface of $\mathrm{V}_{5} \mathrm{O}_{12} / \mathrm{VO}_{2}$. b TEM image of $\mathrm{V}_{5} \mathrm{O}_{12} / \mathrm{VO}_{2}$ junction. c Areal capacitance of $\mathrm{V}_{5} \mathrm{O}_{12} /$ $\mathrm{VO}_{2}, \mathrm{~V}_{5} \mathrm{O}_{12}$, and $\mathrm{VO}_{2}$ as a function of current density. d Cycling stability of $\mathrm{V}_{5} \mathrm{O}_{12} / \mathrm{VO}_{2}, \mathrm{~V}_{5} \mathrm{O}_{12}$, and $\mathrm{VO}_{2}$ electrodes in $3 \mathrm{M}$ LiCl aqueous electrolyte. e Nyquist plots of $\mathrm{V}_{5} \mathrm{O}_{12} / \mathrm{VO}_{2}, \mathrm{~V}_{5} \mathrm{O}_{12}$, and $\mathrm{VO}_{2}$. $\mathbf{f}-\mathbf{h}$ Ex situ XRD patterns of $\mathbf{f} \mathrm{V}_{5} \mathrm{O}_{12}, \mathbf{e} \mathrm{VO}_{2}$ and $\mathbf{h} \mathrm{V}_{5} \mathrm{O}_{12} / \mathrm{VO}_{2}$ without charging (pristine), charged $(-1 \mathrm{~V})$, and discharged $(0 \mathrm{~V})$. Reproduced from Ref. [34] with permission 
Besides surface redox reactions, some $\mathrm{MoO}_{x}$, e.g., $\alpha-\mathrm{MoO}_{3}$, possess layered structures that allow ion insertion and deinsertion that contribute intercalative pseudocapacitance [217]. Specifically, $\alpha-\mathrm{MoO}_{3}$ can accommodate up to $1.5 \mathrm{Li}^{+}$ per Mo, having a high theoretical capacity of $1117 \mathrm{mAh} \mathrm{g}^{-1}$ [218].

$\mathrm{MoO}_{x}$ is usually deposited by cathodic electrodeposition in aqueous electrolytes containing molybdates (e.g., sodium molybdate and ammonium molybdate) [38], iso-/peroxo-polymolybdates [213], and ammonium paramolybdates [219]. Electrodeposited $\mathrm{MoO}_{x}$ are typically quasi-amorphous, nonstoichiometric oxide films [38, 220-222]. Its composition, structure, and electrochemical performance of the deposited $\mathrm{MoO}_{x}$ materials highly depend on electrolyte composition, $\mathrm{pH}$ value, and magnitudes of the applied current density and voltage [223-225].

Nanostructured substrates with large ion-accessible surface areas are preferred electrodeposition scaffolds for $\mathrm{MoO}_{x}$. For example, a 18-nm-thick layer of $\mathrm{MoO}_{x}$ $\left(3 \mathrm{mg} \mathrm{cm}^{-2}\right.$ ) was deposited on tungsten oxide nanowires, forming a $\mathrm{WO}_{3-x} / \mathrm{MoO}_{3-x}$ core/shell structure (Fig. 23a-d) [226]. This core/shell electrode delivered an areal capacitance of $500 \mathrm{mF} \mathrm{cm}^{-2}$. Li et al. electrodeposited a 40-nmthick $\mathrm{MoO}_{3}$ layer $\left(2.43 \mathrm{mg} \mathrm{cm}^{-2}\right)$ on $\mathrm{ZnO}$ nanorod arrays (Fig. 23e, f). The $\mathrm{ZnO}$-supported $\mathrm{MoO}_{3}$ displayed a specific capacitance of $241 \mathrm{~F} \mathrm{~g}^{-1}$ at $5 \mathrm{mV} \mathrm{s}^{-1}$ and $198 \mathrm{~F} \mathrm{~g}^{-1}$ at $100 \mathrm{mV} \mathrm{s}^{-1}$ [227]. Liu et al. demonstrated that functionalized, partially exfoliated graphite foil substrates could support $\mathrm{MoO}_{x}$ films with high mass loadings $\left(18.4 \mathrm{mg} \mathrm{cm}^{-2}\right.$ ) (Fig. 23g) [228]. The exfoliated graphene sheets and the laminar structure of the graphite base addressed the negative impact of the poor electrical conductivity of the atop $\mathrm{MoO}_{x}$. This highly conductive carbon-based structure permitted efficient ion diffusion and fast electron transport. Besides, the O-functional groups on the exfoliated graphite foil formed covalent $\mathrm{C}-\mathrm{O}-\mathrm{Mo}$ bonds with $\mathrm{MoO}_{3}$, which served as bridges that permitted fast charge transport from $\mathrm{MoO}_{x}$ to the substrate. All the above factors led to excellent rate capability: The optimized electrode with a high $\mathrm{MoO}_{x}$ mass loading of $15.4 \mathrm{mg} \mathrm{cm}^{-2}$ delivered an areal capacitance of $4.34 \mathrm{~F} \mathrm{~cm}^{-2}$ at $1 \mathrm{~mA} \mathrm{~cm}^{-2}$ and retained $67.8 \%$ of the initial capacitance at $20 \mathrm{~mA} \mathrm{~cm}^{-2}$.

Films deposited onto fibers can develop unique morphologies, such as helical cracks demonstrated by Lu et al. They utilized a combined electrochemistry-annealing strategy and deposited hierarchical porous $\mathrm{MoO}_{2}$ films composed of mesoporous nanoparticles on carbon cloth fibers (Fig. 23h, i) [229]. First, mixed-valence $\mathrm{MoO}_{x}$ was electrochemically deposited on carbon cloth by reducing $\mathrm{Mo}_{7} \mathrm{O}_{24}{ }^{6-}$ :

$$
\begin{aligned}
& 6 \mathrm{NH}_{4}^{+}+\mathrm{Mo}_{7} \mathrm{O}_{24}^{6+}+(18-7 x) \mathrm{H}_{2} \mathrm{O}+(42-14 x) e^{-} \\
& \quad \rightarrow 7 \mathrm{MoO}_{x}+6 \mathrm{NH}_{3}+(42-14 x) \mathrm{OH}^{-}
\end{aligned}
$$

Subsequently, the as-formed $\mathrm{MoO}_{x}$ was annealed in $\mathrm{NH}_{3}$ at $700{ }^{\circ} \mathrm{C}$ to obtain $\mathrm{MoO}_{2}$ films. Scanning electron microscopy revealed that the $\mathrm{MoO}_{2}$ films exhibited helical cracks of 100-200 nm wide. Owing to the helical openings that reduced the dead volume of $\mathrm{MoO}_{2}$, the electrode delivered a high areal capacitance of $175 \mathrm{mF} \mathrm{cm}^{-2}$ at $1.43 \mathrm{~mA} \mathrm{~cm}^{-2}$ in $\mathrm{Na}_{2} \mathrm{SO}_{4}$ aqueous electrolytes. The formation mechanism of the helical cracks remained unclear, but we hypothesized that it might be associated with dehydration of the electrodeposited films during the thermal treatment in $\mathrm{NH}_{3}$. The cracks were initiated by volume shrinkage during annealing and propagated around carbon fibers following a helical path.

Like other pseudocapacitive materials, electrodeposited $\mathrm{MoO}_{x}$ exhibits high capacitance, but unsatisfactory cycling instability. To extend the life span of electrodeposited $\mathrm{MoO}_{x}$, Cai et al. reported a potential window tuning strategy for $\mathrm{MoO}_{x}$ [38]. They discovered that the potential window within -1 to $-0.4 \mathrm{~V}$ vs. SCE permitted the redox reaction associated with $\mathrm{Mo}^{4+}$ and $\mathrm{Mo}^{5+}$ and prevented the formation of $\mathrm{Mo}^{6+}$. This feature resulted in no capacitance decay in 30,000 cycles. In contrast, the same electrode scanned between -1.0 and $0 \mathrm{~V}$ vs. SCE irreversibly generated $\mathrm{Mo}^{6+}$ and its capacitance decayed by more than $25 \%$ within 500 charge-discharge cycles. Electrochemical impedance spectroscopy revealed that the accumulation of $\mathrm{Mo}^{6+}$ increased the combined series resistance of $\mathrm{MoO}_{x}$, which made the electrode electrically insulating. Besides, optimizing the composition of electrodeposited $\mathrm{MoO}_{x}$ materials via electrochemical technologies could provide new opportunities for enhancing their durability, as already proved to be successful in stabilizing $\mathrm{VO}_{x}[34]$.

\subsection{Tungsten Oxides}

Another transition metal oxide is tungsten oxides $\left(\mathrm{WO}_{x}\right)$ [230-233]. $\mathrm{WO}_{x}$ is usually deposited by cathodic deposition (e.g., applying a CV scan of - $0.5-0$ V vs. SCE [234]) in aqueous electrolytes containing peroxy-tungstate species (e.g., $\mathrm{W}_{2} \mathrm{O}_{11}^{2-}$ ) [235-237]: 

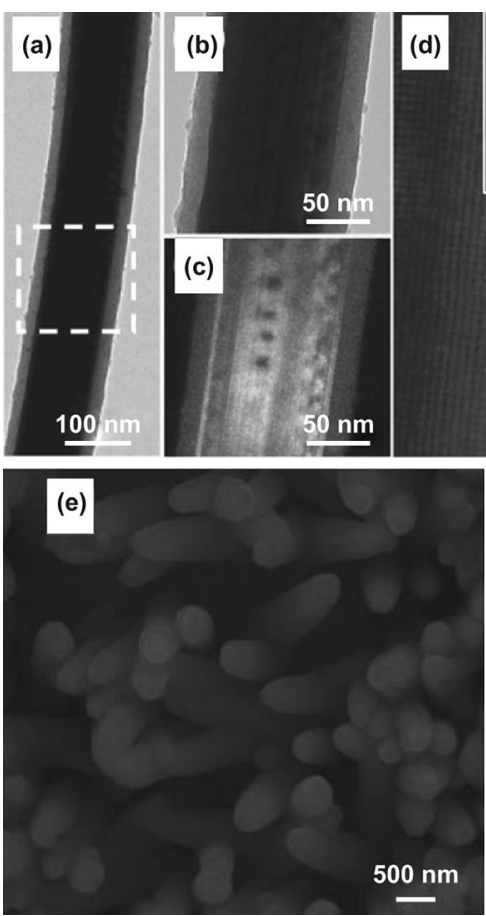
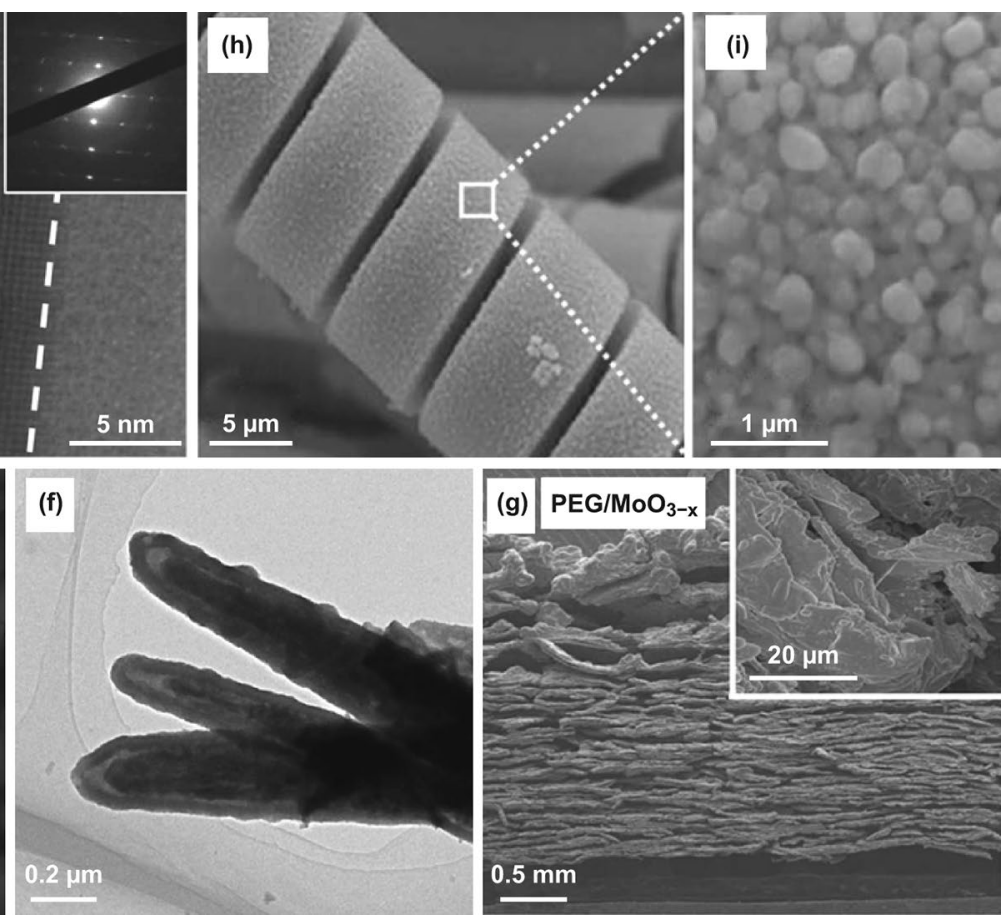

Fig. 23 a-c TEM images of a $\mathrm{MoO}_{3-x}$-coated $\mathrm{WO}_{3-x}$ nanowire: a, b bright and c dark fields. d High-resolution TEM image of a

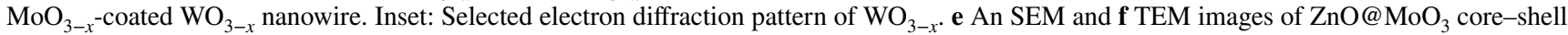
structure. $\mathbf{g}$ A SEM image of $\mathrm{MoO}_{3-x}$ film deposited on an exfoliated graphite substrate. $\mathbf{h}$, i SEM images of the helical porous $\mathrm{MoO}_{2}$ with different magnifications. Adapted from a-d Ref. [226], e, f Ref. [227], g Ref. [228], h Ref. [229] with permission

$\mathrm{W}_{2} \mathrm{O}_{11}^{2-}+(2+x) \mathrm{H}^{+}+x e^{-} \rightarrow 2 \mathrm{WO}_{3}+\frac{2+x}{2} \mathrm{H}_{2} \mathrm{O}+\frac{8-x}{4} \mathrm{O}_{2}$

$$
\begin{gathered}
\mathrm{W}_{2} \mathrm{O}_{11}^{2-}+2.36 \mathrm{H}^{+}+0.94 \mathrm{H}_{2} \mathrm{O}+0.36 e^{-} \\
\rightarrow 2 \mathrm{H}_{0.12} \mathrm{WO}_{3} \cdot \mathrm{H}_{2} \mathrm{O}+1.97 \mathrm{O}_{2}
\end{gathered}
$$

Most as-deposited $\mathrm{WO}_{x}$ materials are amorphous with stacked, hydrated nanoparticles, $\mathrm{WO}_{x} \cdot n \mathrm{H}_{2} \mathrm{O}[234,238,239]$. Thermal annealing of $\mathrm{WO}_{x} \cdot n \mathrm{H}_{2} \mathrm{O}$ at temperatures above $400{ }^{\circ} \mathrm{C}$ in air dehydrates the nanoparticles to crystalline $\mathrm{WO}_{x}$ $[239,240]$. However, the annealing treatment usually triggers particle coalescence that decreases surface area. To circumvent this problem, Sun et al. developed an electrochemical post-crystallization process to convert electrodeposited amorphous, mixed-valence $\mathrm{WO}_{x}$ into crystalline tungsten bronze $\mathrm{H}_{x} \mathrm{WO}_{3}$ (Fig. 24a-c) [234]. The electrochemical crystallization process turned the non-porous film into highly porous nanosheets, enhancing specific surface area (Fig. 24d).

Changing electrolyte composition to extend the lower potential limit of $\mathrm{WO}_{x}$ electrodes is necessary to increase the capacitance and energy density of $\mathrm{WO}_{x}$-based supercapacitors. As a hydrogen evolution reaction (HER) catalyst, $\mathrm{WO}_{x}$ has a low potential of around $-0.5 \mathrm{~V}$ vs. SCE [233]. Reducing pH values of electrolytes could push this limit to $-1 \mathrm{~V}$ vs. SCE, but at the cost of cycling stability (Fig. 24e) [234, 241]. Sun et al. achieved both a low cutoff potential to $-0.9 \mathrm{~V}$ vs. SCE and good cycling stability with $98 \%$ capacitive retained after 30,000 charge-discharge cycles by testing $\mathrm{H}_{x} \mathrm{WO}_{3}$ in a mixed electrolyte containing $1 \mathrm{M} \mathrm{Na}_{2} \mathrm{SO}_{4}$ and $0.01 \mathrm{M} \mathrm{H}_{2} \mathrm{SO}_{4}$ (Fig. 24f) [234]. XRD indicated that a new crystal phase $\left(\mathrm{Na}_{6} \mathrm{WO}_{6}\right)$ formed after cycling in the $\mathrm{Na}_{2} \mathrm{SO}_{4}$ electrolyte (Fig. $24 \mathrm{~g}$ ), creating internal stress and detaching the active material from the current collector (carbon cloth fibers). While cycled in the mixed electrolyte, the structure of $\mathrm{H}_{x} \mathrm{WO}_{3}$ was well maintained. It was because, in proton-rich electrolytes, $\mathrm{H}^{+}$insertion and de-insertion became the dominant charge storage mechanism, which was less destructive for the structure of $\mathrm{H}_{x} \mathrm{WO}_{3}$. Moreover, the mixed electrolyte enhanced the capacitance of $\mathrm{H}_{x} \mathrm{WO}_{3}$, as illustrated by the expanded area enclosed by the CV curve (Fig. 24h). Specifically, when tested in the mixed electrolyte, the electrode exhibited a high areal capacitance 
of $860 \mathrm{mF} \mathrm{cm}^{-2}$, corresponding to $143 \mathrm{~F} \mathrm{~g}^{-1}$, at $5 \mathrm{mV} \mathrm{s}^{-1}$ (Fig. 24i). The rational design of electrolyte composition enabled electrodeposited $\mathrm{WO}_{x}$ electrodes with mutually high capacitance and excellent cycling stability.

\subsection{Iron Oxides and Hydroxides}

Iron oxides and hydroxides are one of the most attractive, lowcost negative electrode active materials for supercapacitors
[242-244]. Electrodeposition is a simple strategy to prepare nanostructured iron oxide and hydroxide [245]. Typically, $\mathrm{Fe}^{2+}$ (e.g., $\left.\mathrm{Fe}\left(\mathrm{NH}_{4}\right)_{2}\left(\mathrm{SO}_{4}\right)_{2} \cdot 6 \mathrm{H}_{2} \mathrm{O}\right)$ is the iron source $[35,36$, 246, 247]. During electrodeposition, $\mathrm{Fe}^{2+}$ is first oxidized to $\mathrm{Fe}^{3+}$ on positive electrodes, which then combines with $\mathrm{OH}^{-}$that was present in weakly alkaline electrolytes $(\mathrm{pH} \sim 8)$ or dissociated from water reduction to form $\mathrm{Fe}(\mathrm{OH})_{3}$ deposits. The as-deposited $\mathrm{Fe}(\mathrm{OH})_{3}$ further dehydrates to $\mathrm{FeOOH}$ in air. The associated chemical reactions are [248]:
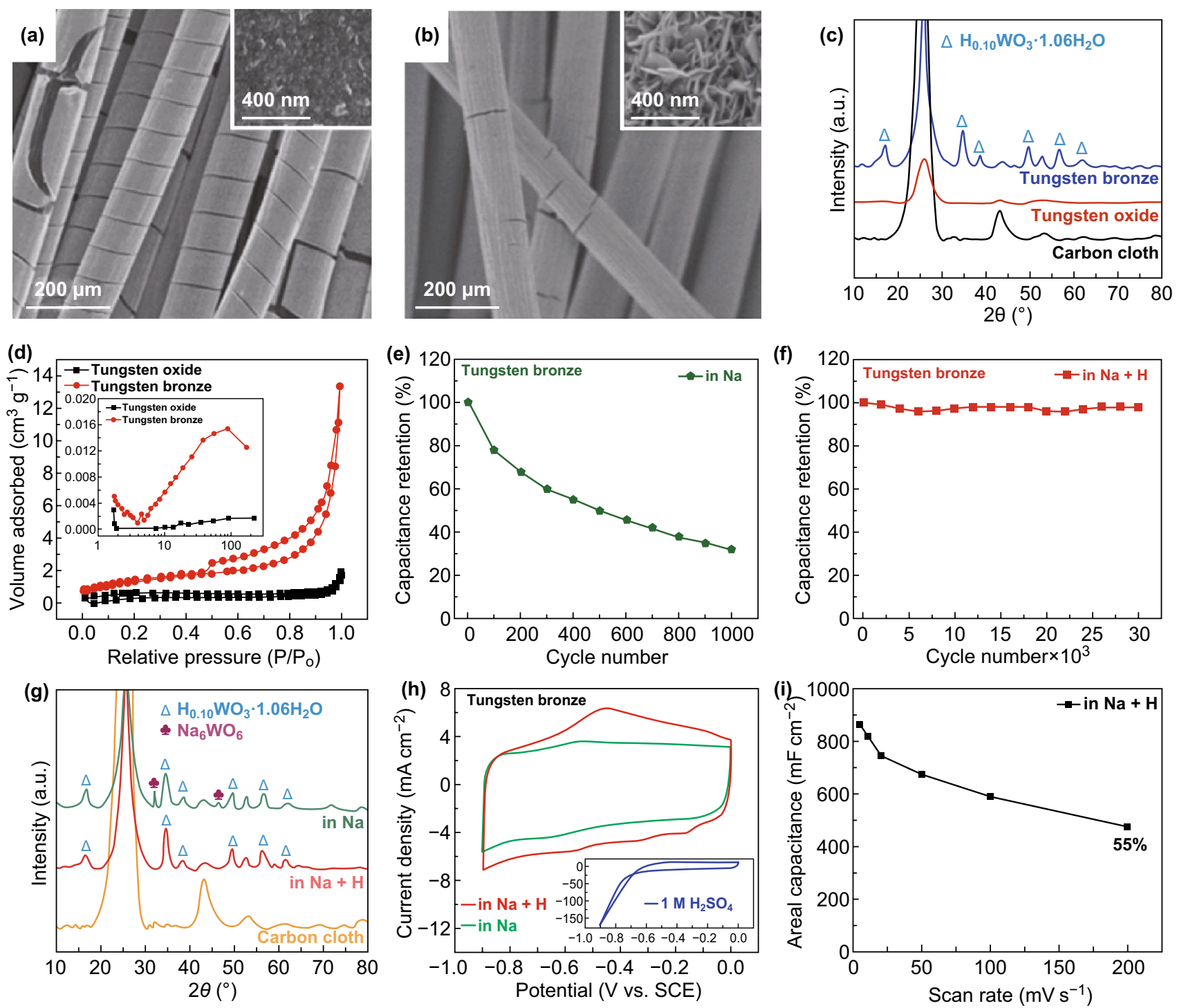

Fig. 24 a, b SEM images of a electrodeposited tungsten oxide and $\mathbf{b}$ tungsten bronze films on carbon cloth. $\mathbf{c}$ XRD patterns of tungsten oxide, tungsten bronze, and carbon cloth. $\mathbf{d ~ N _ { 2 }}$ adsorption-desorption isotherms of tungsten oxide and tungsten bronze. Inset: pore size distributions. e, f Cycling stability of tungsten bronze in e $1 \mathrm{M} \mathrm{Na}_{2} \mathrm{SO}_{4}$ and $\mathbf{f} \mathrm{Na}_{2} \mathrm{SO}_{4} / \mathrm{H}_{2} \mathrm{SO}_{4}(1 \mathrm{M} / 0.01 \mathrm{M})$ mixed aqueous electrolytes. $\mathbf{g}$ XRD patterns of tungsten bronze after cycled in $\mathrm{Na}_{2} \mathrm{SO}_{4}$ and $\mathrm{Na}_{2} \mathrm{SO}_{4} / \mathrm{H}_{2} \mathrm{SO}_{4}$. h CV curves of tungsten bronze in $\mathrm{Na}_{2} \mathrm{SO}_{4}$ ( $(\mathrm{green}), \mathrm{Na}_{2} \mathrm{SO}_{4} / \mathrm{H}_{2} \mathrm{SO}_{4}(\mathrm{red})$, and $\mathrm{H}_{2} \mathrm{SO}_{4}$ (blue) aqueous electrolytes. i Rate capability of tungsten bronze in $\mathrm{Na}_{2} \mathrm{SO}_{4} / \mathrm{H}_{2} \mathrm{SO}_{4}$. Adapted from Ref. [234] with permission 
$\mathrm{Fe}^{2+} \rightarrow \mathrm{Fe}^{3+}+e^{-}$

$\mathrm{Fe}^{3+}+3 \mathrm{OH}^{-} \rightarrow \mathrm{Fe}(\mathrm{OH})_{3}$

$\mathrm{Fe}(\mathrm{OH})_{3} \rightarrow \mathrm{FeOOH}+\mathrm{H}_{2} \mathrm{O}$

To date, iron oxides of different dimensionalities, including 0D nanoparticles (Fig. 25a) [249], 1D nanorods (Fig. 25b) [250], 2D nanosheets (Fig. 25c) [251], and 3D hierarchical structures (Fig. 25d) [35], have been synthesized electrochemically. For example, Mai et al. reported a cyclic voltammetry method that transformed highly crystalline $\mathrm{Fe}_{2} \mathrm{O}_{3}$ nanoparticles into low-crystalline FeOOH nanoparticles (Fig. 25a) [249]. The resultant $\mathrm{FeOOH}$ electrode, with a high mass loading of $9.1 \mathrm{mg} \mathrm{cm}^{-2}$, exhibited an outstanding specific capacitance of $716 \mathrm{~F} \mathrm{~g}^{-1}$ at $1 \mathrm{~A} \mathrm{~g}^{-1}$ in $2 \mathrm{M} \mathrm{KOH}$ electrolyte. The specific capacitance was attributed to the facilitated ion diffusion kinetics in the $\mathrm{FeOOH}$ electrode, but further studies were needed to unveil the mechanism fully.

As electrodeposited iron species are typically $\mathrm{Fe}(\mathrm{OH})_{3}$ and $\mathrm{FeOOH}$, thermal conversion to $\mathrm{Fe}_{2} \mathrm{O}_{3}$ with enhanced electrochemical activity is usually performed for processing supercapacitor electrodes [252]. For example, FeOOH nanoneedles were first deposited on Ni-plated $\mathrm{ZnO}$ nanorods using a constant potential of $1.5 \mathrm{~V}$ vs. $\mathrm{Ag} / \mathrm{AgCl}$ [253]. During the electrodeposition, the acidic environment created by $\mathrm{Fe}^{3+}$ hydrolysis corroded the $\mathrm{ZnO}$ nanorods, forming $\mathrm{Ni@}$ $\mathrm{FeOOH}$. Subsequent annealing $\mathrm{Ni@FeOOH}$ in $\mathrm{Ar}$ at $450{ }^{\circ} \mathrm{C}$ dehydrated $\mathrm{FeOOH}$ to $\mathrm{Ni} @ \mathrm{Fe}_{2} \mathrm{O}_{3}$ nanoneedles. The Ni nanotubes swiftly conducted electrons between $\mathrm{Fe}_{2} \mathrm{O}_{3}$ and the substrate, while the ultrathin thickness of $\mathrm{Fe}_{2} \mathrm{O}_{3}$ nanosheets endowed fast charge transfer kinetics. Benefiting from these merits, $\mathrm{Ni} @ \mathrm{Fe}_{2} \mathrm{O}_{3}$ achieved a high specific capacitance of $418 \mathrm{~F} \mathrm{~g}^{-1}$ at $10 \mathrm{mV} \mathrm{s}^{-1}$ in the potential window from -0.8 to $0 \mathrm{~V}$ vs. $\mathrm{Ag} / \mathrm{AgCl}$, excellent rate capability $\left(215 \mathrm{~F} \mathrm{~g}^{-1}\right.$ at $64 \mathrm{~A} \mathrm{~g}^{-1}$ ), and cycling stability (93\% capacitance retention after 5000 charge-discharge cycles).

In addition to thermal annealing, chemical conversion in hot alkaline solutions represents another means to convert electrodeposited $\mathrm{FeOOH}$ into iron oxides. Chemical conversion avoids high-temperature annealing that may trigger structural deformation and particle agglomeration. One excellent example was demonstrated by Sun et al. [35]. They utilized a post-chemical transition method to obtain composite mesoporous iron oxides $\left(\mathrm{Fe}_{3} \mathrm{O}_{4}\right.$ and $\left.\mathrm{Fe}_{2} \mathrm{O}_{3}\right)$ from electrodeposited $\mathrm{FeOOH}$ nanosheets on a 3D exfoliated graphite substrate (EG). First, $\mathrm{FeOOH}$ nanosheets were deposited on EG using a potentiostatic method $(-0.5 \mathrm{~V}$ vs. SCE for $80 \mathrm{~min}$ in an aqueous electrolyte containing $0.05 \mathrm{M}$ $\mathrm{Fe}\left(\mathrm{NH}_{4}\right)_{2}\left(\mathrm{SO}_{4}\right)_{2}$ and $\left.0.05 \mathrm{M}\left(\mathrm{NH}_{4}\right)_{2} \mathrm{SO}_{4}\right)$. Afterward, the asdeposited nanosheets were immersed in a $1 \mathrm{M} \mathrm{NaOH}$ aqueous solution for $1 \mathrm{~h}$ at $70{ }^{\circ} \mathrm{C}$ to convert iron oxy-hydroxides to iron oxide (containing $\mathrm{Fe}_{2} \mathrm{O}_{3}$ and $\mathrm{Fe}_{3} \mathrm{O}_{4}$ ) nanosheets interconnected into a honeycomb-like structure (Fig. 25d). The conversion mechanism is unclear, but we hypothesize that it is associated with dehydration of iron oxy-hydroxides during the treatment. High-resolution SEM image presented that each oxide nanosheet was composed of nanoparticles (Fig. 25d inset). The EG@ $@ \mathrm{Fe}_{3} \mathrm{O}_{4} / \mathrm{Fe}_{2} \mathrm{O}_{3}$ electrode delivered an ultrahigh areal capacitance of $1.57 \mathrm{~F} \mathrm{~cm}^{-2}$ at $5 \mathrm{~mA} \mathrm{~cm}{ }^{-2}$, corresponding to $165 \mathrm{~F} \mathrm{~g}^{-1}$ based on the total mass of the electrode. The excellent capacitive performance of the EG@ $\mathrm{Fe}_{3} \mathrm{O}_{4} / \mathrm{Fe}_{2} \mathrm{O}_{3}$ electrode was ascribed to several factors. First, the hierarchically porous structure with mesopores and macropores in the electrode shortened ion diffusion distance. Second, the heterojunction between $\mathrm{Fe}_{3} \mathrm{O}_{4} / \mathrm{Fe}_{2} \mathrm{O}_{3}$ introduced a built-in electric field that facilitated charge transfer between different oxide particles. Third, the interconnected graphene sheets on EG constructed highly conductive electron transport networks that minimized capacitance loss at fast discharging rates.

\subsection{Nickel/Cobalt Oxides and Hydroxides}

A critical issue that we would like to highlight first in this section is the concepts of intrinsic and extrinsic pseudocapacitive materials. Intrinsic pseudocapacitive materials refer to materials that always show pseudocapacitive characteristics (CV curves with broad or no redox peaks and plateaufree charge-discharge profiles) irrespective of size. Extrinsic pseudocapacitive materials exhibit pseudocapacitive signatures only at nanoscales. This transition of the electrochemical behaviors of extrinsic pseudocapacitive materials was due to the reduced ion diffusion distance that accelerated charge storage kinetics and, in some cases, suppressed phase transformations [13].

Nickel and cobalt oxides and hydroxides are extrinsic pseudocapacitive materials [254]. Charge storage in their bulk forms involves phase transitions, resulting in apparent redox peaks in CV curves (Fig. 26a) and plateaus in galvanostatic charge-discharge profiles (Fig. 26b) [255]. Therefore, these battery-like materials have been used as electrodes in 

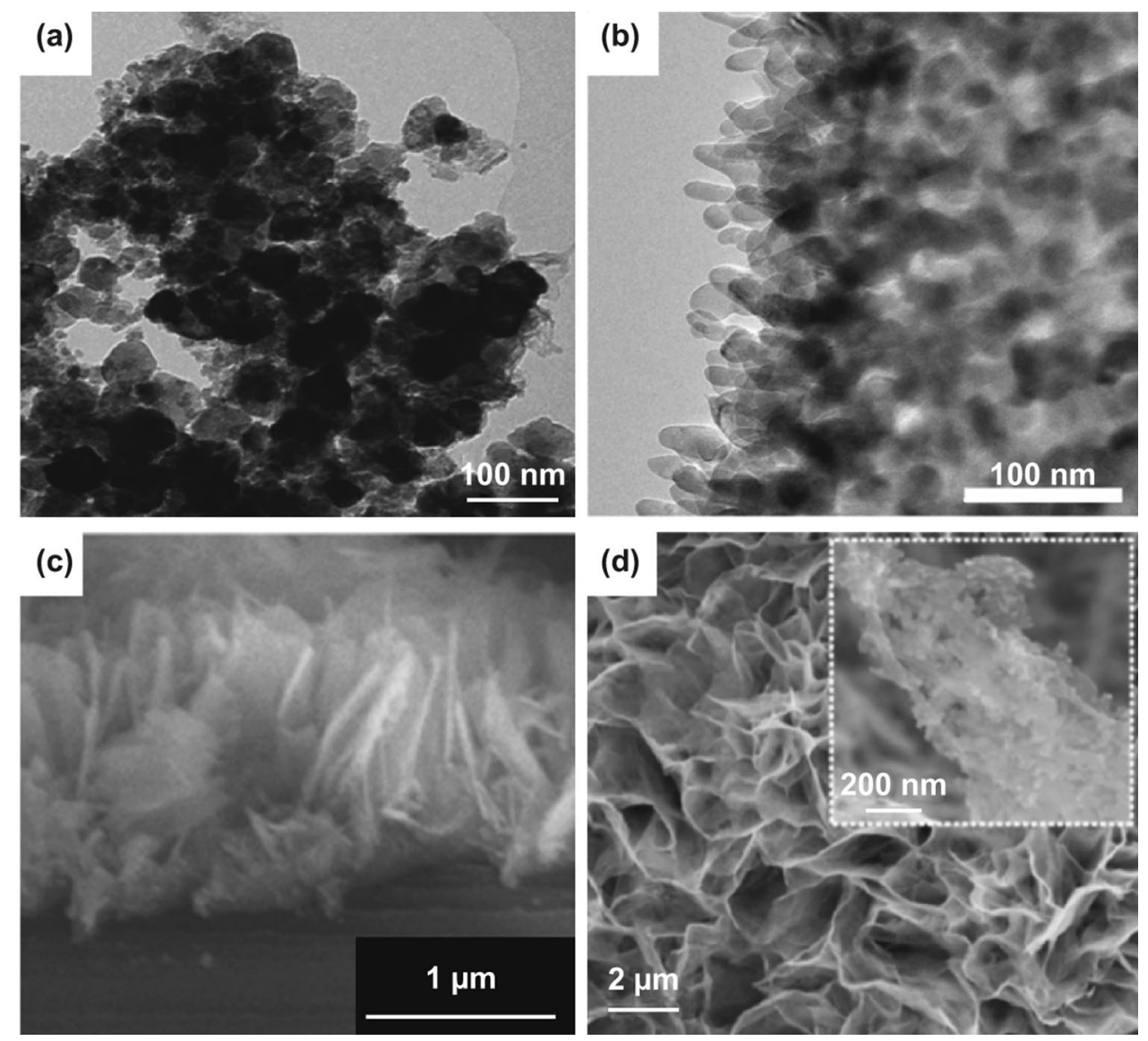

Fig. 25 a, b TEM images of a electrodeposited FeOOH nanoparticles and b $\mathrm{Fe}_{2} \mathrm{O}_{3}$ nanorods. c, d SEM images of electrodeposited FeOOH nanosheets and $\mathbf{d}$ chemically converted $\mathrm{Fe}_{3} \mathrm{O}_{4} / \mathrm{Fe}_{2} \mathrm{O}_{3}$ nanosheets. Inset: Magnified view of a nanosheet. Adapted from a Ref. [249], b Ref. [250], c Ref. [251], d Ref. [35] with permission

aqueous batteries [256-258] or battery-type electrodes in hybrid supercapacitors [96, 259-261], but cannot be studied in the context of pseudocapacitors. However, once their size shrinks to nanoscales, their pseudocapacitive features will emerge [262-266], as indicated by the broad redox peaks in CV curves (Fig. 26c) and sloping charge-discharge profiles (Fig. 26d) [267].

Nickel and cobalt (hydro)oxides are electrochemically synthesized via cathodic deposition in aqueous solutions. $\mathrm{Ni}^{2+}$ or $\mathrm{Co}^{2+}$ combines with $\mathrm{OH}^{-}$produced from water or anions in electrolytes. Taking $\mathrm{Co}(\mathrm{OH})_{2}$ as an example, one reported electrodeposition mechanism in $\mathrm{Co}\left(\mathrm{NO}_{3}\right)_{2}$ aqueous solutions is [268]:

$$
\begin{aligned}
& \mathrm{NO}_{3}^{-}+\mathrm{H}_{2} \mathrm{O}+2 e^{-} \rightarrow \mathrm{NO}_{2}^{-}+2 \mathrm{OH}^{-} \\
& \mathrm{Co}^{2+}+2 \mathrm{OH}^{-} \rightarrow \mathrm{Co}(\mathrm{OH})_{2}
\end{aligned}
$$

Guo et al. have recently demonstrated a converse voltage strategy to activate electrodeposited $\mathrm{Co}(\mathrm{OH})_{2}$ nanosheets on carbon fibers (Fig. 27a) [268]. First, $\mathrm{Co}(\mathrm{OH})_{2}$ nanosheets were electrodeposited with a constant potential of $-1.5 \mathrm{~V}$ vs. SCE (Fig. 27b). The voltage then reversed (1.5 V vs. SCE) (Fig. 27c), triggering a phase transition from $\mathrm{Co}(\mathrm{OH})_{2}$ to low-crystalline $\mathrm{CoOOH}$ (denoted as EA-CoOOH) containing abundant structural defects (oxygen vacancies, lattice disorders, and interconnected mesopores) (Fig. 27d). Quantitative analyses on the electrode kinetics revealed that the capacitance of EA-CoOOH contributing from kinetically fast, surface-controlled processes occupied $93 \%$ at $5 \mathrm{mV} \mathrm{s}^{-1}$, and further increased to $99 \%$ at $100 \mathrm{mV} \mathrm{s}^{-1}$. The nanosheets and defects altered the intrinsic battery-type behavior of $\mathrm{CoOOH}$ to pseudocapacitive characteristics. Outstandingly, EA-CoOOH electrode exhibited substantially enhanced capacitance than $\mathrm{Co}(\mathrm{OH})_{2}$ and deeply oxidized $\mathrm{O}-\mathrm{CoOOH}$ 
electrode (Fig. 27e), delivering a high specific capacitance of $832 \mathrm{~F} \mathrm{~g}^{-1}$ at $1 \mathrm{~A} \mathrm{~g}^{-1}$ and retained $78 \%$ of the capacitance (649 $\mathrm{F} \mathrm{g}^{-1}$ ) at $200 \mathrm{~A} \mathrm{~g}^{-1}$ (Fig. 27f).

Introducing a secondary cation, such as $\mathrm{Fe}^{3+}$ and $\mathrm{Al}^{3+}$, in $\mathrm{Ni} / \mathrm{Co}$ hydroxides to form double hydroxides have been proved to enhance capacitive performance due to charge hopping or valence interchange between different cations [96, 266, 269, 270]. Double hydroxides usually possess layered structures with large interlayer spacings (e.g., $~ 1 \mathrm{~nm}$ ), which resulted in their high specific capacitance (e.g., $>2000 \mathrm{~F} \mathrm{~g}^{-1}$ ) [96, 106, 271]. Unfortunately, their limited potential windows in alkaline electrolytes $(\sim 0.5 \mathrm{~V})$ and poor rate performance still hinder their large-scale applications in aqueous batteries and supercapacitors. Neutral aqueous electrolytes can suppress appreciable oxygen evolution in alkaline solutions and thus extend the potential window of layered double hydroxides (LDHs) to $\sim 1 \mathrm{~V}$.

Since anions residing between the interlayer space and the electrostatic repulsion from positively charge LDH laminate, cation intercalation into LDHs in neutral electrolytes remains thermodynamically unfavorable, resulting in unsatisfactory electrochemical performance. Recently, Li et al. have demonstrated an electrochemical strategy to ease the cation intercalation into LDHs in neutral electrolytes [272]. Co-Fe LDH nanoplates were first electrodeposited on $\mathrm{Ni}$ foam using a cathodic electrodeposition method (Fig. 28a). Subsequently, electrochemical activation (EA) of the $\mathrm{Co}-\mathrm{Fe}$ LDH nanosheets was conducted by $\mathrm{CV}$ between 0 and $0.6 \mathrm{~V}$ vs. SCE in $\mathrm{KOH}$ or $\mathrm{NaOH}$ electrolyte (denoted as EA-Co-Fe LDH). The obtained electrode exhibited pronounced electrochemical activity in various aqueous electrolytes, including $\mathrm{NaNO}_{3}, \mathrm{KNO}_{3}, \mathrm{Ca}\left(\mathrm{NO}_{3}\right)_{2}, \mathrm{Mg}\left(\mathrm{NO}_{3}\right)_{2}, \mathrm{Zn}\left(\mathrm{NO}_{3}\right)_{2}$ between 0 and $1 \mathrm{~V}$ vs. SCE (Fig. 28b, c). The specific capacitance of EA-Co-Fe LDH in $\mathrm{NaNO}_{3}$ reached $417 \mathrm{~F} \mathrm{~g}^{-1}$, which was 27 times higher than that of as-deposited $\mathrm{Co}-\mathrm{Fe} \mathrm{LDH}$ nanoplates. XRD, XPS, FTIR, and X-ray absorption nearedge structure (XANES) all indicated that during the electrochemical activation, $\mathrm{Co}(\mathrm{OH})_{2}$ in $\mathrm{CoFe}-\mathrm{LDH}$ was oxidized to $\mathrm{CoOOH}$, resulting in hydrogen vacancies and removal of carbonate anions residing within the interlayer space of
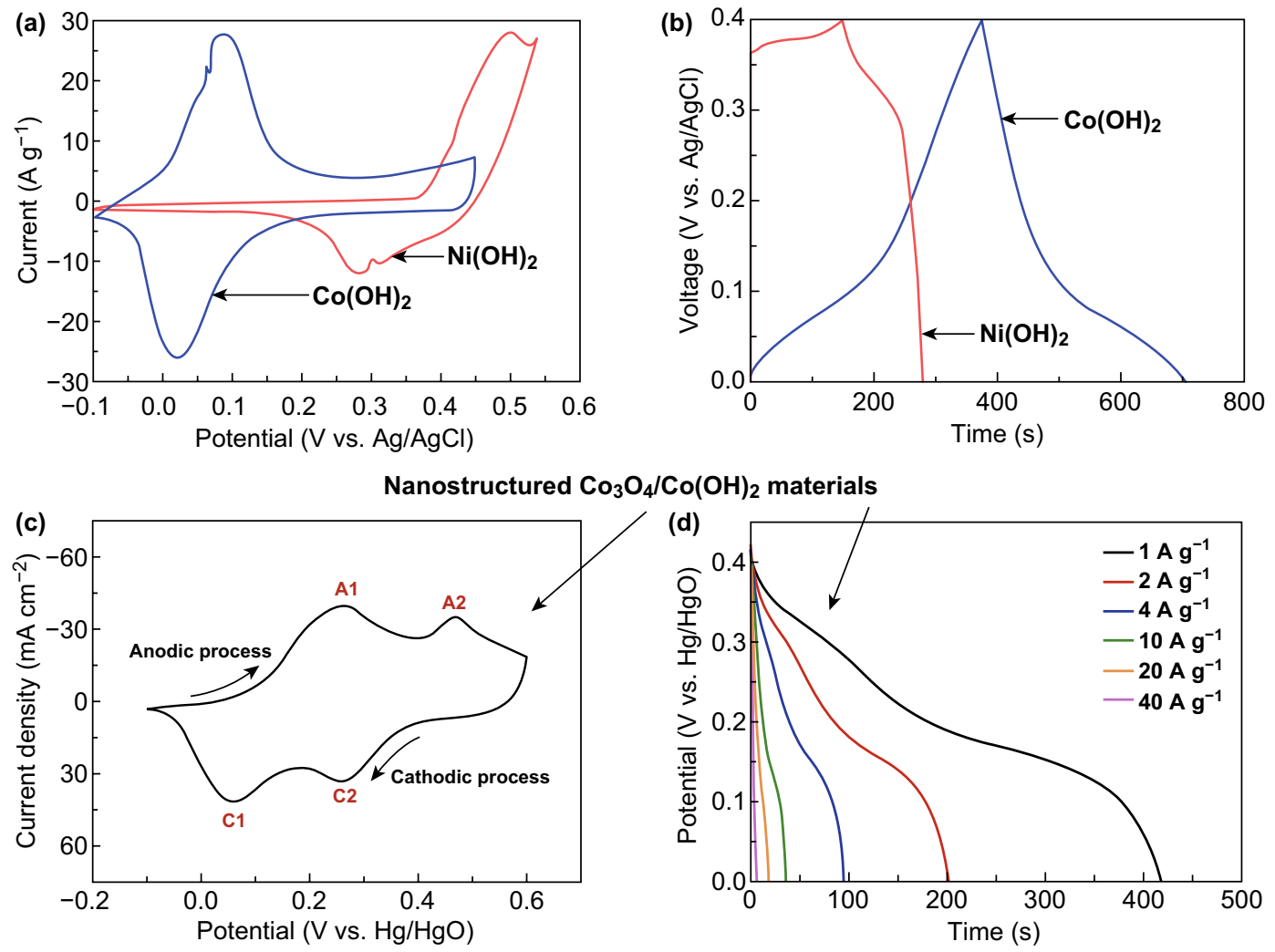

Fig. 26 a CV curves and b galvanostatic charge-discharge profiles of $\mathrm{Co}(\mathrm{OH})_{2}$ (blue) and $\mathrm{Ni}(\mathrm{OH})_{2}$ (red). c CV curves and d galvanostatic charge-discharge profiles of $\mathrm{Co}_{3} \mathrm{O}_{4} / \mathrm{Co}(\mathrm{OH})_{2}$ core/shell nanowire arrays. Adapted from a, b Ref. [255], $\mathbf{c}, \mathbf{d}$ Ref. [267] with permission 


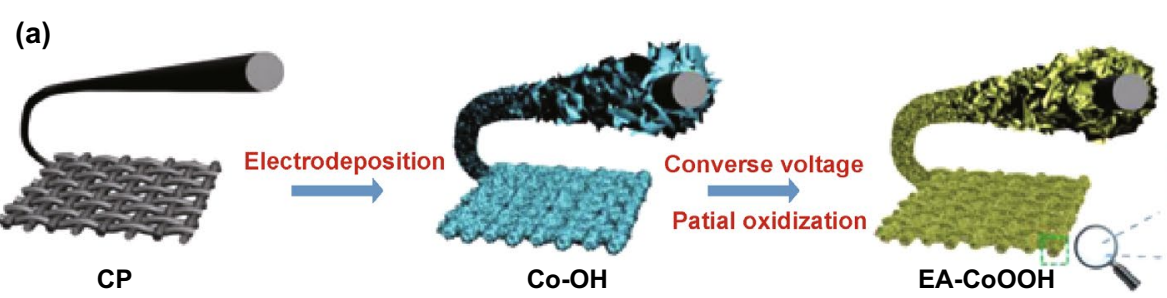

(b) Constant voltage for electrodeposition
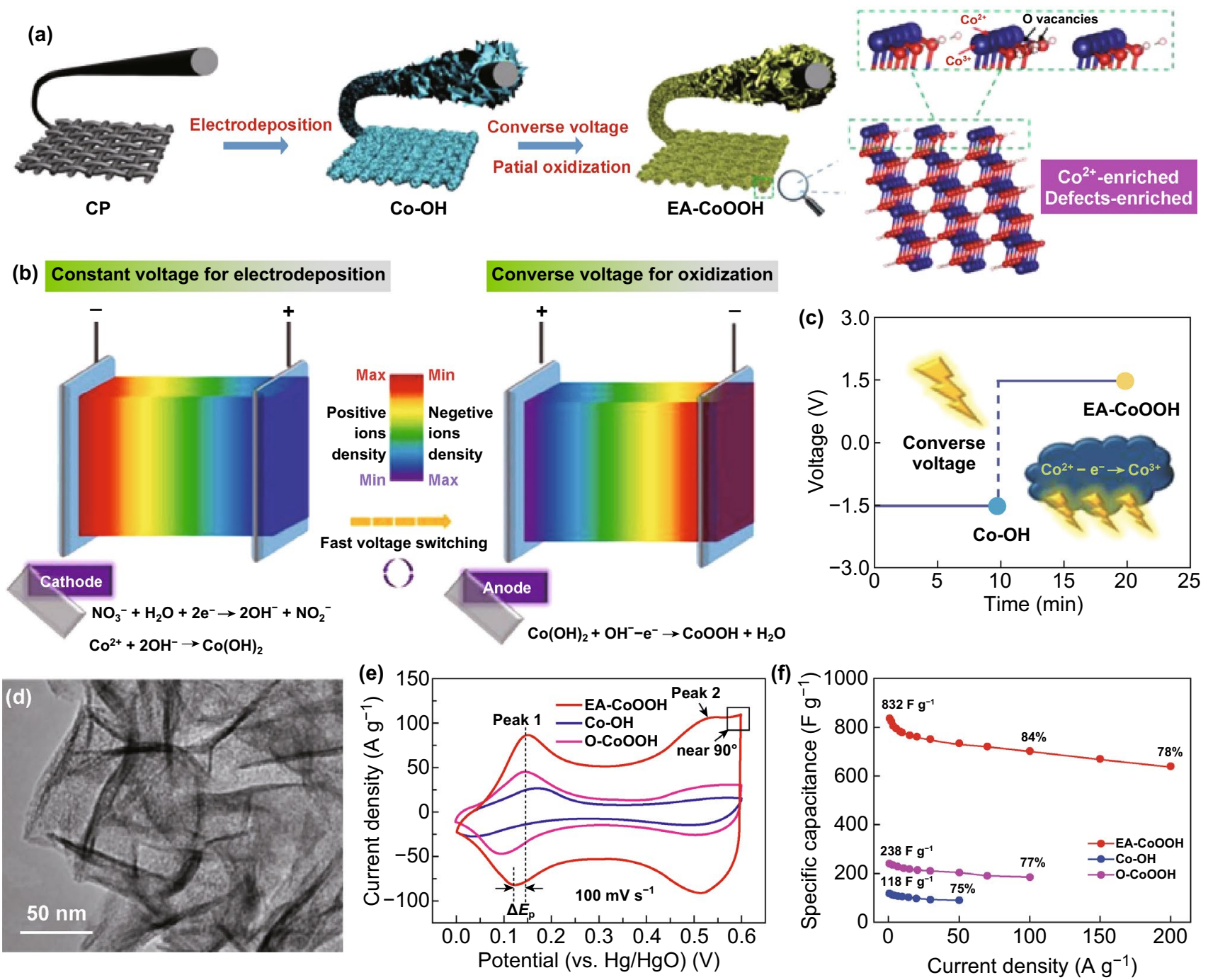

Fig. 27 a Schemes of the synthesis steps of EA-CoOOH by a converse voltage method and the molecular structure of $\mathrm{Co}^{2+}-$ and defect-rich EA-CoOOH. b Schemes showing the ion concentration gradients during constant voltage for electrodeposition (left) and converse voltage for oxidization (right). $\mathbf{c}$ Voltage profiles of electrodeposition and converse voltage stages. $\mathbf{d}$ TEM image of EA-CoOOH. e CV curves and $\mathbf{g}$ rate capability of EA-CoOOH in comparison with other electrodes. Adapted from Ref. [268] with permission

CoFe-LDH (Fig. 28d). Density functional theory calculations elucidated the adsorption sites of metal ions in $\mathrm{LDH}$ and EA-LDH materials (Fig. 28e). The results suggested that the adsorption of metal ions $\left(\mathrm{Li}^{+}, \mathrm{Na}^{+}, \mathrm{K}^{+}, \mathrm{Ca}^{2+}, \mathrm{Mg}^{2+}\right.$, and $\mathrm{Zn}^{2+}$ ) on terminal $\mathrm{H}$ was unfavorable, whereas adsorptions of the same set of ions on $\mathrm{O}$ termination were thermodynamically stable, as reflected from the negative adsorption energy (Fig. 28e, blue bars). The enhanced adsorption tendency with $\mathrm{O}$ terminals was ascribed to the $\mathrm{H}$ vacancies formed during the activation step. Taking together, the formation of $\mathrm{H}$ vacancies and extraction of interlayer anions after the electrochemical activation together imparted the ion intercalation capability of CoFe-LDH in neutral electrolytes.

\section{Composites}

Composites that combine the merits of two or more materials are versatile electrode candidates for supercapacitor electrodes. These composites are typically electrodeposited through a one-step co-electrodeposition. The reported electrodeposited composites are classified according to their 
constituent species, including composites having the same group of materials, such as oxide/oxide (manganese oxide/ molybdenum oxide [273, 274], nickel manganese oxide [275], molybdenum oxide/tungsten oxide [276]), and composites with different types of materials, including oxide/ conducting polymer (polypyrrole/manganese oxide [277, 278], manganese oxide/polyaniline [279, 280], manganese oxide/poly(3,4-ethylenedioxythiophene):poly(styrenesulfon ate) [281, 282], polyaniline/vanadium oxide [27], polypyrrole/vanadium oxide [283, 284], polypyrrole/molybdenum oxide [285], polyaniline/tungsten oxide [286]) and oxide/ hydroxide (NiAl-layered double hydroxide/manganese oxide [287] and manganese oxide/nickel hydroxide [288]). Their capacitance and corresponding synthesis methods
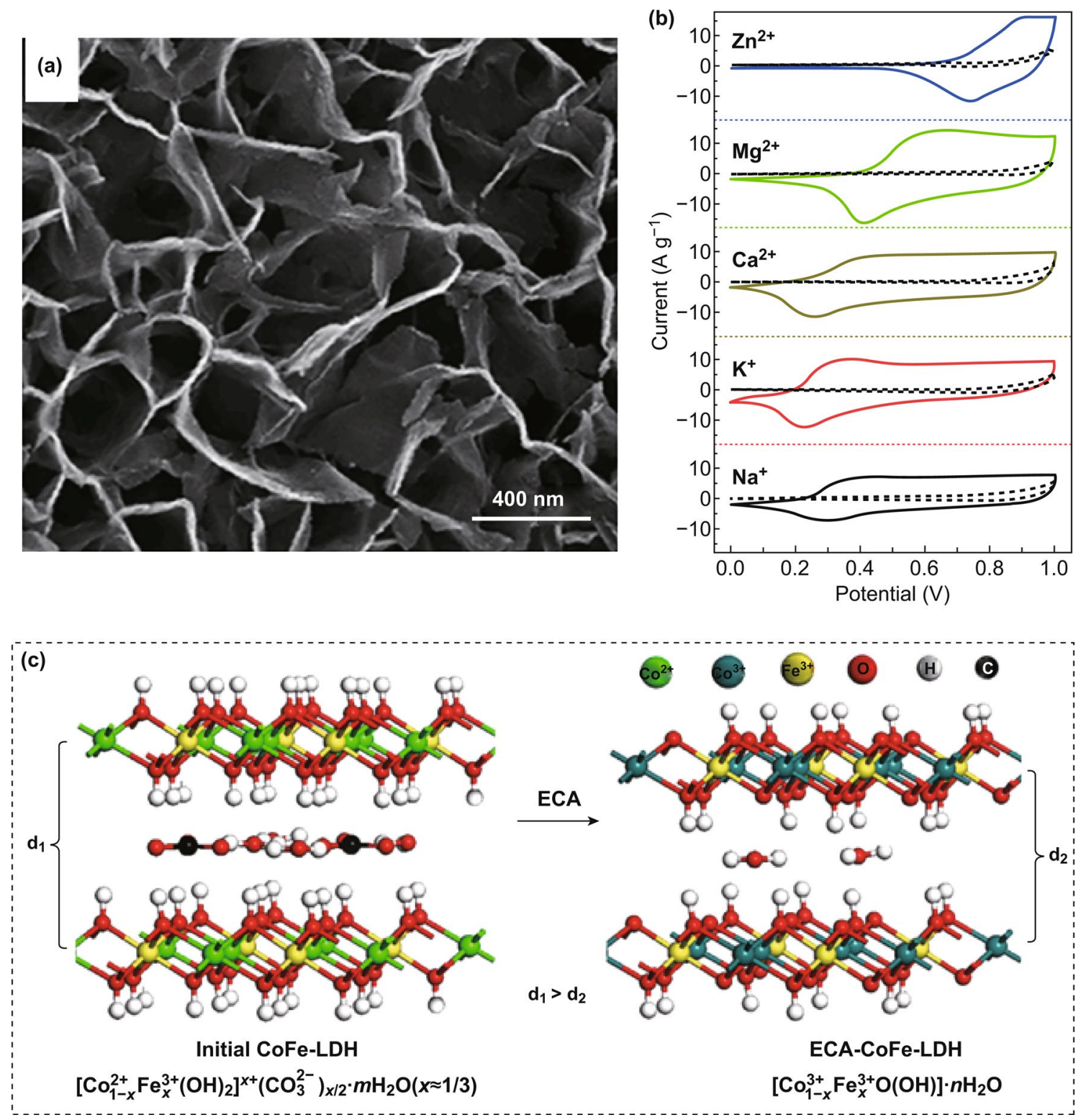

Fig. 28 a SEM image of CoFe layered double hydroxide (LDH) nanoplates. b CV curves and $\mathbf{c}$ galvanostatic charge-discharge profiles of CoFeLDH in different aqueous solutions. d Evolution of the crystal structure and composition of CoFe-LDH before and after electrochemical activation. e Adsorption energies of various metal ions over H-terminated (magenta) and O-terminated (blue) LDH laminates. Reproduced from Ref. [272] with permission 
are summarized in Table 2. Electrodeposited composites usually exhibit advantages of synergies and strong interactions among the incorporated materials that exhibit superior capacitive performance to the corresponding single-component counterparts.

Not all the active materials are co-electrodepositable in one step. One prerequisite is that the materials to be compounded must be synthesizable under similar electrochemical conditions, including $\mathrm{pH}$ value, polarization potential, current density, and temperature. For example, Zou et al. electrodeposited a tungsten oxide and polyaniline composite via one-step cyclic voltammetry in a mixed acidic electrolyte containing tungstic acid and aniline monomers [289]. The success of the co-deposition was owing to the acidic environment needed for both tungsten oxide and polyaniline. In contrast to the densely stacked tungsten oxide particles, the composite possessed widened pores and interconnected particles. This difference in the morphology was ascribed to the incorporated polyaniline, which acted as a structural scaffold that prevented the aggregation of tungsten oxide particles. The composite electrode exhibited enhanced pseudocapacitive performance over a wide potential window from -0.5 to 0.7 vs. SCE, which combined the potential windows of polyaniline $(-0.1-0.7 \mathrm{~V}$ vs. SCE) and tungsten oxide (-0.5-0.3 V vs. SCE). The synergistic effects between polyaniline and tungsten oxide improved the capacitive performance of the composite. Tungsten oxide offered high pseudocapacitance. Polyaniline created interparticle pores that increased surface area and conducted electrons to maintain superior rate capability to those of bare tungsten oxide or polyaniline.

Another example is a series of molybdenum-tungsten mixed oxide composites co-electrodeposited into titanium dioxide nanotube arrays using a one-step galvanostatic plating [276]. The plating electrolyte was an aqueous mixture of different concentrations of sodium molybdate dihydrate, sodium tungstate dihydrate, ethylenediamine tetra-acetic acid disodium, and ammonium acetate. The as-electrodeposited amorphous Mo-W mixed oxide film was thermally annealed at $450{ }^{\circ} \mathrm{C}$ in air to improve its crystallinity. The similarities in the valence state, ionic radius, and electronegativity of $\mathrm{W}^{6+}$ and $\mathrm{Mo}^{6+}$ were the keys to the successful co-deposition. XRD and Raman spectroscopy indicated that the fabricated Mo-W mixed oxides were monoclinic, and the crystal structure transited from $m-\mathrm{WO}_{3}$-like to $\beta-\mathrm{MoO}_{3}$ like when increasing the Mo/W ratio (Fig. 29a). Though pure $\mathrm{MoO}_{3}$ exhibited higher capacitance than the composite electrodes at $20 \mathrm{mV} \mathrm{s}^{-1}$ (Fig. 29b), its rate capability

Table 2 Different types of composites synthesized via electrochemical methods

\begin{tabular}{|c|c|c|c|c|}
\hline Component \#1 & Component \#2 & Synthesis method & Capacitance & References \\
\hline \multicolumn{5}{|l|}{ Conducting polymer-metal oxide } \\
\hline Polypyrrole & $\mathrm{MnO}_{x}$ & Galvanostatic deposition & $463 \mathrm{Fg}^{-1} @ 2 \mathrm{Ag}^{-1}$ & {$[277]$} \\
\hline Polyaniline & $\mathrm{MnO}_{x}$ & $\begin{array}{l}\text { Cyclic voltammetry } \\
\text { Pulse potential }\end{array}$ & $\begin{array}{l}415 \mathrm{~F} \mathrm{~g}^{-1} @ 1.67 \mathrm{~mA} \mathrm{~cm}^{-2} \\
90.25 \mathrm{Fg}^{-1} @ 1 \mathrm{~mA} \mathrm{~g}^{-1}\end{array}$ & $\begin{array}{l}{[279]} \\
{[280]}\end{array}$ \\
\hline $\begin{array}{l}\text { Poly(3,4-ethylenedioxythiophene):pol } \\
\text { y(styrenesulfonate) }\end{array}$ & $\mathrm{MnO}_{x}$ & $\begin{array}{l}\text { Constant potential } \\
\text { Constant potential }\end{array}$ & $\begin{array}{l}1.67 \mathrm{~F} \mathrm{~cm}^{-2} @ 0.5 \mathrm{~mA} \mathrm{~cm} \mathrm{~cm}^{-2} \\
386 \mathrm{mF} \mathrm{cm}-2 @ 1 \mathrm{~mA} \mathrm{~cm}{ }^{-2}\end{array}$ & $\begin{array}{l}{[281]} \\
{[282]}\end{array}$ \\
\hline Polyaniline & $\mathrm{VO}_{x}$ & Cyclic voltammetry & $0.66 \mathrm{~F} \mathrm{~cm}^{-2} @ 0.5 \mathrm{~mA} \mathrm{~cm}{ }^{-2}$ & {$[27]$} \\
\hline Polypyrrole & $\mathrm{VO}_{x}$ & $\begin{array}{l}\text { Constant potential } \\
\text { Constant potential }\end{array}$ & $\begin{array}{l}750 \mathrm{~F} \mathrm{~g}^{-1} @ 5 \mathrm{~A} \mathrm{~g}^{-1} \\
412 \mathrm{~F} \mathrm{~g}^{-1} @ 4.5 \mathrm{~mA} \mathrm{~cm}^{-2}\end{array}$ & $\begin{array}{l}{[283]} \\
{[284]}\end{array}$ \\
\hline Polypyrrole & $\mathrm{MoO}_{x}$ & Cyclic voltammetry & $398 \mathrm{Fg}^{-1} @ 1 \mathrm{Ag}^{-1}$ & [285] \\
\hline \multicolumn{4}{|l|}{ Metal oxide-metal oxide } & [286] \\
\hline $\mathrm{MnO}_{x}$ & $\mathrm{MoO}_{x}$ & $\begin{array}{l}\text { Cyclic voltammetry } \\
\text { Galvanostatic deposition }\end{array}$ & $\begin{array}{l}21 \mathrm{mF} \mathrm{cm}^{-2} @ 50 \mathrm{mV} \mathrm{s}^{-1} \\
408 \mathrm{Fg}^{-1} @ 2 \mathrm{mV} \mathrm{s}^{-1}\end{array}$ & $\begin{array}{l}{[273]} \\
{[274]}\end{array}$ \\
\hline $\mathrm{NiMnO}_{x}$ & & Cyclic voltammetry & $961.5 \mathrm{Fg}^{-1} @ 10 \mathrm{mV} \mathrm{s}^{-1}$ & [275] \\
\hline $\begin{array}{l}\mathrm{MoO}_{x} \\
\text { Hydroxide-metal oxide }\end{array}$ & $\mathrm{WO}_{x}$ & Galvanostatic deposition & $517.4 \mathrm{Fg}^{-1} @ 1 \mathrm{Ag}^{-1}$ & [276] \\
\hline NiAl-layered double hydroxide & $\mathrm{MnO}_{x}$ & Constant potential & $1554 \mathrm{Fg}^{-1} @ 1 \mathrm{Ag}^{-1}$ & [287] \\
\hline Nickel hydroxide & $\mathrm{MnO}_{x}$ & Constant potential & $344 \mathrm{Fg}^{-1} @ 0.5 \mathrm{~A} \mathrm{~g}^{-1}$ & [288] \\
\hline
\end{tabular}


(Fig. 29c) and cycling stability (Fig. 29d) were inferior to those of the composites. Among all the synthesized Mo-W mixed oxides, $0.5 \mathrm{MoW}$ with a Mo/W ratio of 1 achieved the best electrochemical performance: high specific capacitance of $517.4 \mathrm{~F} \mathrm{~g} \mathrm{~g}^{-1}$ at $1 \mathrm{~A} \mathrm{~g}^{-1}$ and good capacitance retention of $89.3 \%$ at $10 \mathrm{~A} \mathrm{~g}^{-1}$. The enhanced rate capability of the composites over that of $\mathrm{MoO}_{3}$ was attributed to two factors. First, the long-range ordered structure of pure oxides was disrupted in the mixed oxides, which decreased crystal size, increased surface area, and facilitated ion diffusion. Second, the disordered monoclinic crystal structure of the mixed oxides yielded a larger lattice space than those of $\mathrm{WO}_{3}$ and $\mathrm{MoO}_{3}$ alone, resulting in decreased ion diffusion resistance.

Recently, Zhang et al. have demonstrated a facile cyclic voltammetry method capable of depositing coupled strongly, layer-by-layer PPy/MoO $\mathrm{M}_{x}$ composite films on 3D exfoliated graphite substrates (Fig. 30a) [285]. $\mathrm{MoO}_{x}$ layer was first deposited on graphite foil during the cathodic scan, while the PPy layer was subsequently grown on $\mathrm{MoO}_{x}$ in the following anodic scan. Therefore, a layer-by-layer PPy/MoO $\mathrm{M}_{x}$ structure was obtained after multiple depositions (Fig. 30b-d). In addition, Fourier transform infrared spectroscopy and X-ray photoelectron spectroscopy detected the reduction in Mo valence and the enhancement of protonation level of PPy, both of which resulted from the strong coupling between PPy and $\mathrm{MoO}_{x}$ (Fig. 30h) that are beneficial for enhancing the electrochemical performance. The composite electrode exhibited a specific capacitance of $398 \mathrm{~F} \mathrm{~g}^{-1}$ at $1 \mathrm{~A} \mathrm{~g}^{-1}$, higher than those of PPy $\left(160 \mathrm{~F} \mathrm{~g}^{-1}\right)$ and $\mathrm{MoO}_{x}\left(320 \mathrm{~F} \mathrm{~g}^{-1}\right)$ at identical current density (Fig. 30i-k).

Besides one-step co-electrodeposition, composites have been prepared using multistep electrodeposition methods [290-294]. For example, Wang and Cai et al. synthesized a $\mathrm{VO}_{x} @ \mathrm{MoO}_{3}$ composite through a two-step electrochemical deposition. $\mathrm{VO}_{x}$ nanorods were first grown on carbon cloth by cyclic voltammetry (Fig. 31a) [295]. Subsequently, a thin layer of $\mathrm{MoO}_{3}$ was coated on the $\mathrm{VO}_{x}$ nanorods by a constant current deposition for $9 \mathrm{~s}$ (Fig. 31b, c). The composite electrode $\mathrm{VO}_{x} @ \mathrm{MoO}_{3}$ displayed an areal capacitance of $1980 \mathrm{mF} \mathrm{cm}^{-2}$ at $2 \mathrm{~mA} \mathrm{~cm}^{-2}$, against $1309 \mathrm{mF} \mathrm{cm}^{-2}$ of $\mathrm{VO}_{x}$ and $233 \mathrm{mF} \mathrm{cm}^{-2}$ of $\mathrm{MoO}_{3}$ under identical testing conditions. Fourier transform infrared spectroscopy revealed that the $\mathrm{V}-\mathrm{O}-\mathrm{V}$ peaks of $\mathrm{VO}_{x} @ \mathrm{MoO}_{3}$ blueshifted in comparison with that of $\mathrm{VO}_{x}$ (Fig. 31d). The V $2 p_{3 / 2}$ XPS spectrum

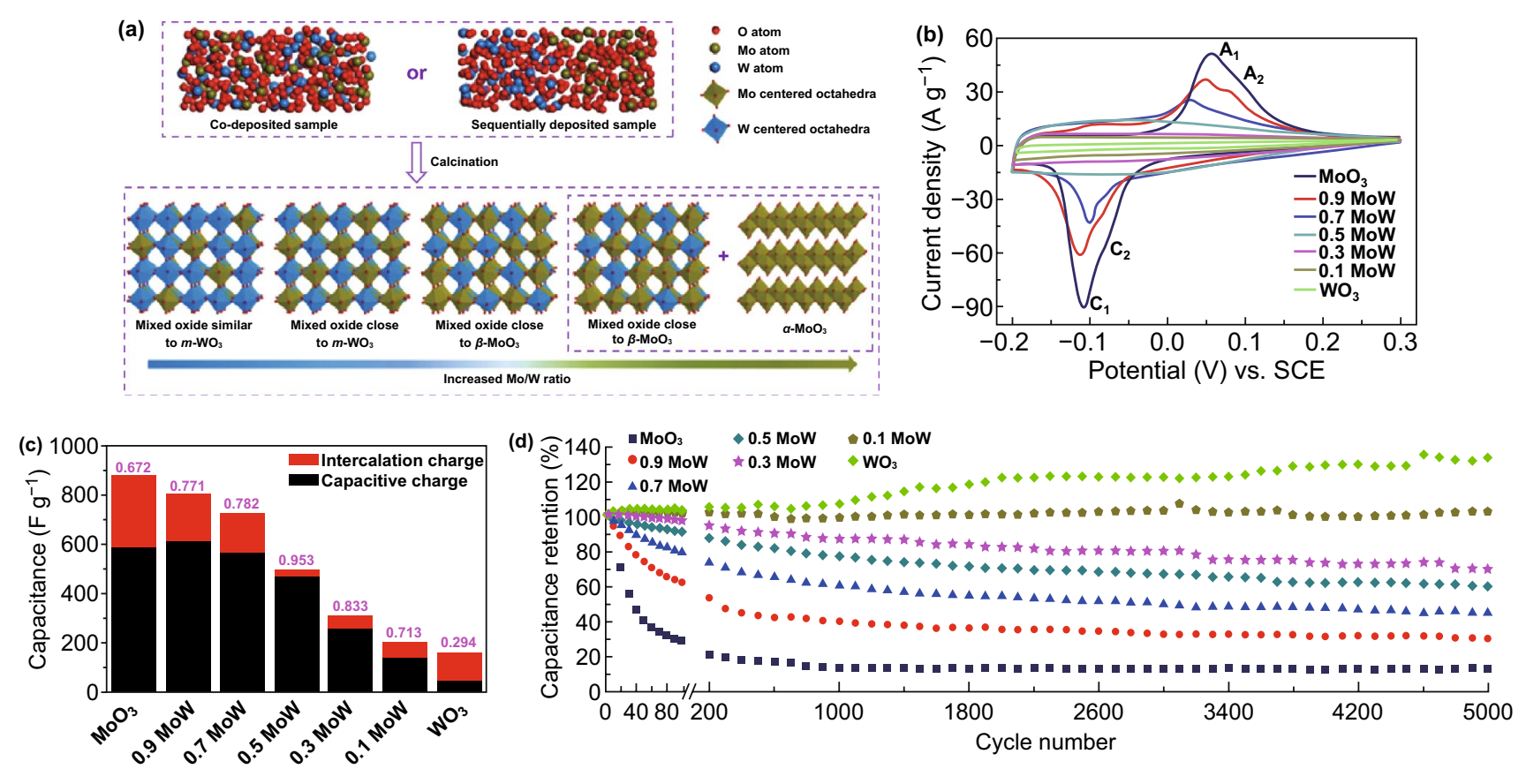

Fig. 29 a Schemes of the formation mechanism and crystal structure of Mo-W mixed oxides. b CV curves, c capacitance contributions (capacitive vs. diffusion-controlled processes), $\mathbf{d}$ cycling stability, and e ion transport patterns of different Mo-W mixed oxides. Reproduced from Ref. [276] with permission 


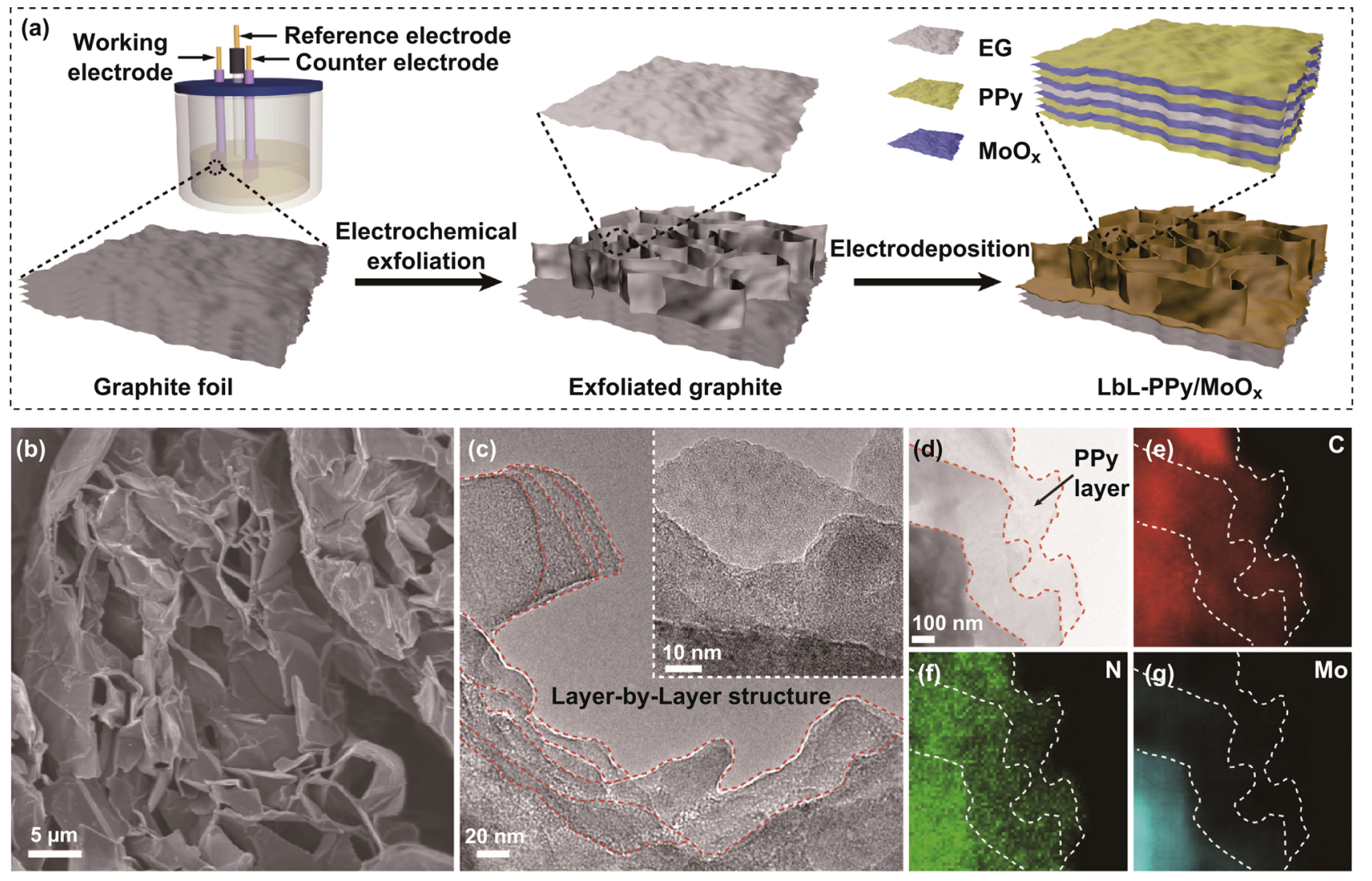

(h)
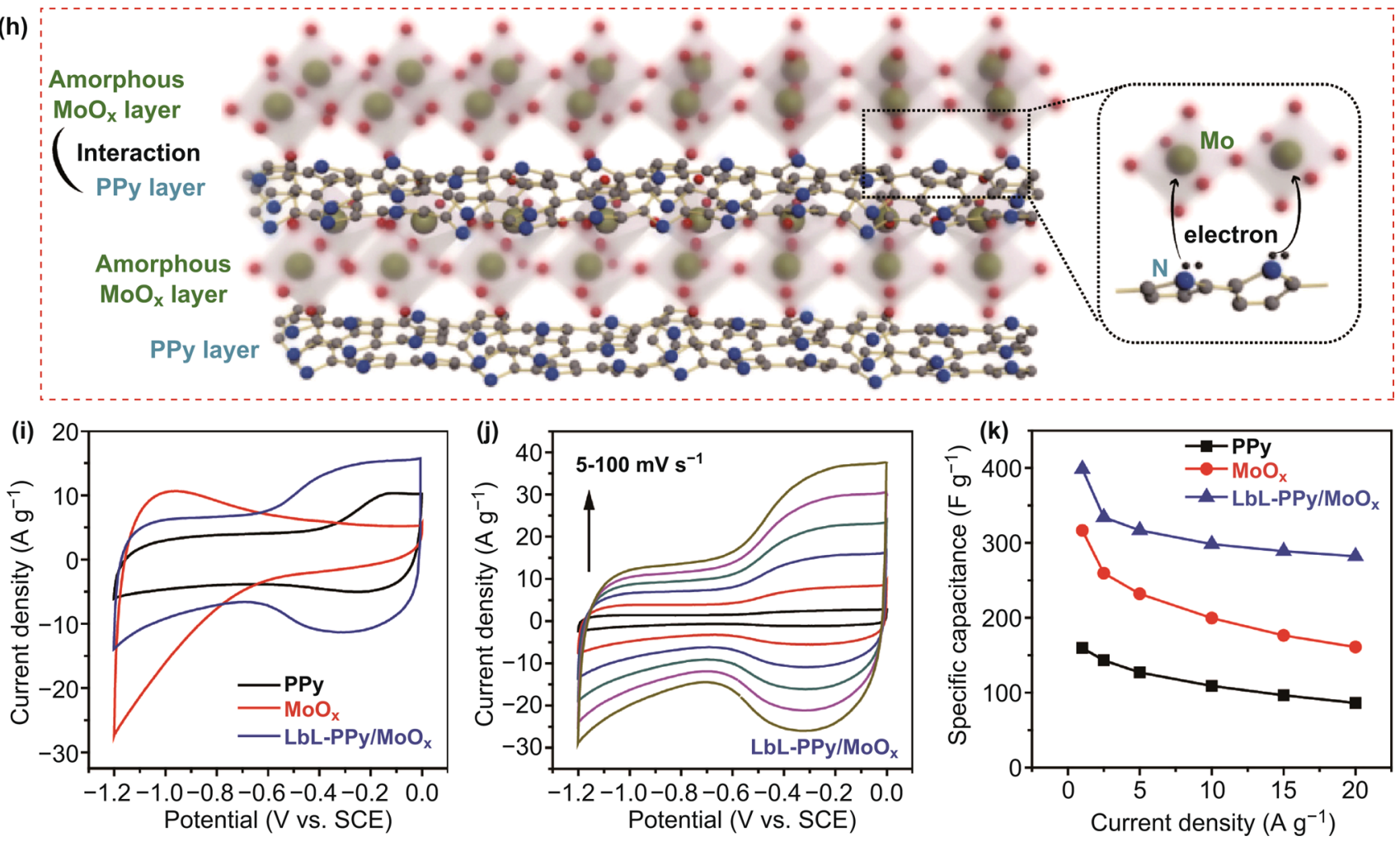

Fig. 30 a Schemes of the synthesis steps, b SEM image, $\mathbf{c}$ TEM image, and d-g elemental mappings of layer-by-layer PPy/MoO $\mathrm{M}_{x} \mathbf{h}$ Interactions between PPy and $\mathrm{MoO}_{x}$ layers. $\mathbf{i} \mathrm{CV}$ curves of $\mathrm{PPy}, \mathrm{MoO}_{x}$, and $\mathrm{PPy} / \mathrm{MoO}_{x} . \mathbf{j}$ CV curves of $\mathrm{PPy} / \mathrm{MoO}_{x}$ at different scan rates. $\mathbf{k}$ Rate capability of $\mathrm{PPy}, \mathrm{MoO}_{x}$, and $\mathrm{PPy} / \mathrm{MoO}$. Reproduced from Ref. [285] with permission 

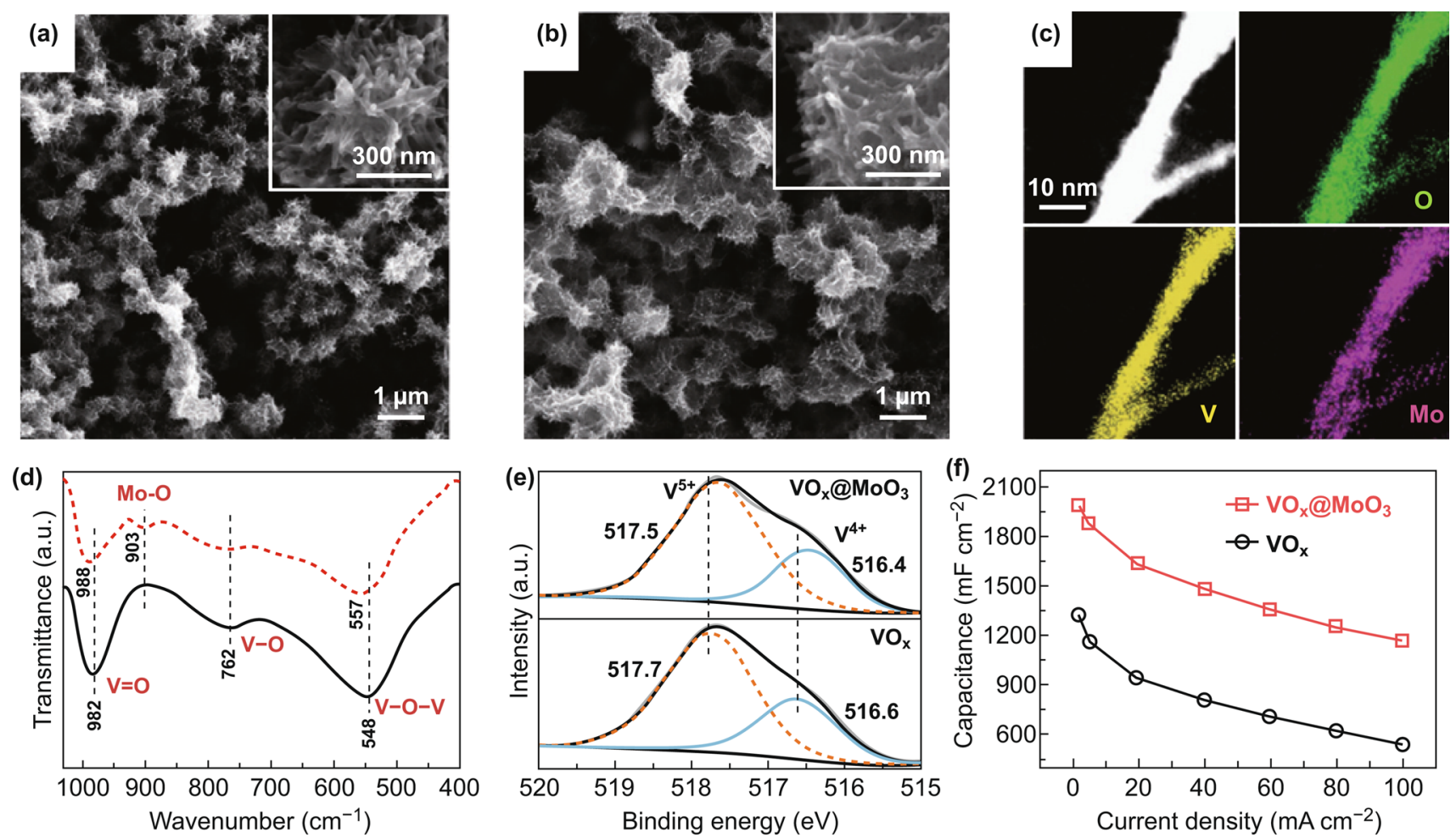

Fig. 31 a, b SEM images of a $\mathrm{VO}_{x}$ and $\mathbf{b} \mathrm{VO}_{x} @ \mathrm{MoO}_{3}$. c Elemental mappings of $\mathrm{VO}_{x} @ \mathrm{MoO}_{3}$. d FTIR spectra of $\mathrm{VO}_{x}$ and $\mathrm{VO}_{x} @ \mathrm{MoO}_{3}$. e V $2 p_{3 / 2}$ XPS spectra of $\mathrm{VO}_{x}$ and $\mathrm{VO}_{x} @ \mathrm{MoO}_{3}$. f Areal capacitances of $\mathrm{VO}_{x}$ and $\mathrm{VO}_{x} @ \mathrm{MoO}_{3}$ as a function of current density. Reproduced from Ref. [295] with permission

showed that the binding energies of both $\mathrm{V}^{5+}$ and $\mathrm{V}^{4+}$ of $\mathrm{VO}_{x} @ \mathrm{MoO}_{3}$ downshifted by $0.2 \mathrm{eV}$. Both results indicated that the electronic structure and chemical environment of $\mathrm{VO}_{x}$ in $\mathrm{VO}_{x} @ \mathrm{MoO}_{3}$ were modified by the strong interaction between $\mathrm{VO}_{x}$ and $\mathrm{MoO}_{3}$, accounting for the improved capacitive performance. Specifically, $\mathrm{VO}_{x} @ \mathrm{MoO}_{3}$ reached a high areal capacitance of $1980 \mathrm{mF} \mathrm{cm}^{-2}$ at $2 \mathrm{~mA} \mathrm{~cm}^{-2}$, exceeding $1309 \mathrm{mF} \mathrm{cm}^{-2}$ of $\mathrm{VO}_{x}$ (Fig. 31f). Strong interaction among the incorporated materials is indispensable in realizing the synergy of the composite electrodes. Poor interactions will not only interrupt electron transport but also induce structural instability of composite [296].

\section{Other Materials}

Electrodeposition has occasionally been used to synthesize nano-/microstructured sulfides [297-300], polyanionic compounds [28], and selenides [301]. These materials typically exhibit higher capacitance than their corresponding oxides due to the different chemical environments created by substituting oxygen near the redox sites, which enhanced electrical conductivity or led to crystal structures favorable for fast ion diffusion, e.g., channels, slits, and pores [28, 297, 302, 303]. Electrochemical syntheses of these materials usually proceed in electrolytes containing precursors of sulfide, phosphate, or selenide.

Using a one-step electrochemical co-deposition method, Chen et al. electrodeposited ternary nickel-cobalt sulfide nanosheets on carbon cloth [302]. The electrodeposition was conducted in a three-electrode electrolytic cell containing $5 \mathrm{mM} \mathrm{CoCl}_{2}$ with different concentrations of $\mathrm{NiCl}_{2}(1,2.5$, $5,7.5$, and $10 \mathrm{mM}$ ) and $0.75 \mathrm{M}$ thiourea. The deposition technique was cyclic voltammetry within a potential range between -1.2 and $0.2 \mathrm{~V}$ vs. $\mathrm{Ag} / \mathrm{AgCl}$ at $5 \mathrm{mV} \mathrm{s}^{-1}$ for 15 cycles. SEM displayed that the electrodeposited materials formed a dense array of highly porous nanosheets. Highangel annular dark-field scanning transmission electron microscopy (HAADF-STEM) and energy-dispersive X-ray spectroscopy (EDS) confirmed the uniform distributions of $\mathrm{Co}, \mathrm{Ni}$, and $\mathrm{S}$ in the deposited nanosheets. The as-deposited sulfide exhibited extrinsic pseudocapacitive characteristics 
of symmetric and plateau-free charge-discharge profiles. The sulfide with an optimal Ni-to-Co ratio (Ni-Co-S-4) showed the highest specific capacitance of $1418 \mathrm{~F} \mathrm{~g}^{-1}$ at $5 \mathrm{~A} \mathrm{~g}^{-1}$ among all $\mathrm{Ni}-\mathrm{Co}-\mathrm{S}$ compounds. It retained $90.6 \%$ of its initial capacitance when the current density increased to $100 \mathrm{~A} \mathrm{~g}^{-1}$. Falola et al. synthesized $\mathrm{MoS}_{2}$ film on a glass carbon electrode using an electrochemical deposition coupled with thermal annealing [300]. The electrochemical deposition was conducted via a CV scan from -1.2 to $1 \mathrm{~V}$ vs. $\mathrm{Ag} / \mathrm{AgCl}$ in an aqueous electrolyte containing $10 \mathrm{mM}$ $\left(\mathrm{NH}_{4}\right)_{2} \mathrm{MoS}_{4}$ and $0.2 \mathrm{M} \mathrm{KCl}$ at $\mathrm{pH}=6.8$, following the reaction [304]:

$\mathrm{MoS}_{4}^{2-}+4 \mathrm{H}^{+}+2 e^{-} \rightarrow \mathrm{MoS}_{2}+2 \mathrm{H}_{2} \mathrm{~S}$

The as-deposited $\mathrm{MoS}_{2}$ was thermally annealed under Ar at $600{ }^{\circ} \mathrm{C}$ to increase its crystallinity. The resultant $\mathrm{MoS}_{2}$ film exhibited a gravimetric capacitance of $\sim 500 \mathrm{~F} \mathrm{~g}^{-1}$ at $0.75 \mathrm{~A} \mathrm{~g}^{-1}$. Increasing the film thickness from 50 to $200 \mathrm{~nm}$ decreased the capacitance to $\sim 100 \mathrm{~F} \mathrm{~g}^{-1}$, which could be due to the sluggish ion diffusion kinetics throughout the thick films.

Molybdenophosphate (A-Mo-O-P, A = Na, K, etc.) materials are a family of polyanionic phosphate compounds with open frameworks, which have recently aroused great interest in rechargeable batteries [305-308]. Similar promising performance is also expected in capacitive applications, albeit seldomly reported. Recently, Song et al. have electrosynthesized a polyanionic molybdenophosphate film on a 3D exfoliated graphite substrate (EG) using a galvanostatic method [28]. The deposition electrolyte was $0.025 \mathrm{M}$ ammonium molybdate mixed with $0.2 \mathrm{M}$ phosphate buffer. The polyanion $\mathrm{PO}_{4}{ }^{3-}$ in the electrolyte were incorporated into the mixed-valence Mo oxide lattice (containing $\mathrm{Mo}^{5+}$ and $\mathrm{Mo}^{6+}$ ), replacing $\mathrm{O}$ atoms and forming $\mathrm{Mo}-\mathrm{O}-\mathrm{P}$ bonds (denoted as MoPO/EG). MoPO/EG was in situ electrochemically activated in $3 \mathrm{M} \mathrm{KCl}$ using cyclic voltammetry for 10,000 cycles at a scan rate of $200 \mathrm{mV} \mathrm{s}^{-1}$ (denoted as A-MoPO/EG). This process allowed repeated $\mathrm{K}^{+}$intercalation and de-intercalation. A-MoPO/EG exhibited a film morphology with an average thickness of $100 \mathrm{~nm}$ (Fig. 32a). EDS indicated the even contributions of Mo, O, P, and $\mathrm{K}$ elements in A-MoPO/EG (Fig. 32b-e). The stable P signal after the activation indicated the electrochemical stability of Mo-O-P bonds. Inductively coupled plasma mass spectroscopy (ICP-OES) suggested the chemical formulae of MoPO and A-MoPO were $\mathrm{K}_{0.7} \mathrm{Na}_{0.35} \mathrm{Mo}_{2} \mathrm{O}_{4.5} \mathrm{PO}_{4}$ and $\mathrm{K}_{1.55} \mathrm{Mo}_{2} \mathrm{O}_{4.2} \mathrm{PO}_{4}$, respectively. Due to the incorporation of $\mathrm{Mo}^{4+}$ after the activation, the average valence state of Mo in MoPO/EG was reduced from +5.38 to +4.84 (Fig. 32f, g) . Meanwhile, the content of $\mathrm{O}$ vacancy increased, as indicated by the enhanced intensity in the electron spin resonance (EPR) spectra (Fig. 32h). Additionally, all $\mathrm{Na}^{+}$in $\mathrm{MoPO} / \mathrm{EG}$ was fully exchanged by $\mathrm{K}^{+}$and additional $\mathrm{K}^{+}$incorporated, both expanding the lattice spacing of molybdophosphate. Benefiting from the widened layers, as well as the enhanced electrical conductivity brought by the $\mathrm{O}$ vacancy, $\mathrm{A}-\mathrm{MoPO} /$ EG showed better charge transfer kinetics than MoPO/EG (Fig. 32i). A-MoPO/EG exhibited quasi-rectangular CV curves, even at scan rates up to $200 \mathrm{mV} \mathrm{s}^{-1}$ (Fig. 32j). CV (Fig. 32k), XPS, and inductively coupled plasma mass spectroscopy (ICP-MS) indicated that cation (e.g., $\mathrm{Li}^{+}, \mathrm{Na}^{+}$, and $\mathrm{K}^{+}$) intercalation was the primary charge storage mechanism of A-MoPO/EG. This polyanionic negative electrode exhibited a high specific capacitance of $556 \mathrm{~F} \mathrm{~g}^{-1}$ at $4.5 \mathrm{~A} \mathrm{~g}^{-1}$, a low cutoff potential window limit of $-1.5 \mathrm{~V}$ vs. SCE, as well as high electrochemical durability without capacitance decay after 100,000 charge-discharge cycles (Fig. 321). The authors speculated that the stable potential window of A-MoPO/EG down to $-1.5 \mathrm{~V}$ vs. SCE could be due to the reversible $\mathrm{K}^{+}$-intercalation (around $-1.4 \mathrm{~V}$ vs. SCE) near the water splitting potential, which suppressed hydrogen gas evolution [309].

Besides electrodeposition, electrochemical exfoliation is applicable to synthesize high-quality two-dimensional (2D) nanomaterials, e.g., $\mathrm{MoS}_{2}$, boron nitride, and MXene, from their corresponding bulk materials [310]. One example is 2D titanium carbide, $\mathrm{Ti}_{3} \mathrm{C}_{2} \mathrm{~T}_{x}(\mathrm{~T}=\mathrm{O}$ and $\mathrm{OH})$, belonging to the MXene family [311]. Yang et al. applied a constant potential of $5 \mathrm{~V}$ for $5 \mathrm{~h}$ that delaminated bulk $\mathrm{TiAlC}_{2}$ into $\mathrm{Ti}_{3} \mathrm{C}_{2} \mathrm{~T}_{x}$. The experimental setup was a two-electrode system with the first exfoliation step in an aqueous electrolyte composed of $1.0 \mathrm{M}$ ammonium chloride $\left(\mathrm{NH}_{4} \mathrm{Cl}\right)$ and $0.2 \mathrm{M}$ tetramethylammonium hydroxide (TMA.OH). The subsequent delamination in $25 \mathrm{wt} \%$ TMA.OH yielded single- or double-layer $\mathrm{Ti}_{3} \mathrm{C}_{2} \mathrm{~T}_{x}$ flakes with sizes up to $18.6 \mu \mathrm{m}$. During the electrochemical etching, $\mathrm{Cl}^{-}$ions etched $\mathrm{Al}$ and broke the Ti-Al bonds. The intercalation of ammonium hydroxide subsequently opened the edges of the etched materials and triggered the etching. This fluoride-free electrochemical exfoliation process provided a safe and scalable way to synthesize MXenes. As a supercapacitor electrode, the $\mathrm{Ti}_{3} \mathrm{C}_{2} \mathrm{~T}_{x}$ 

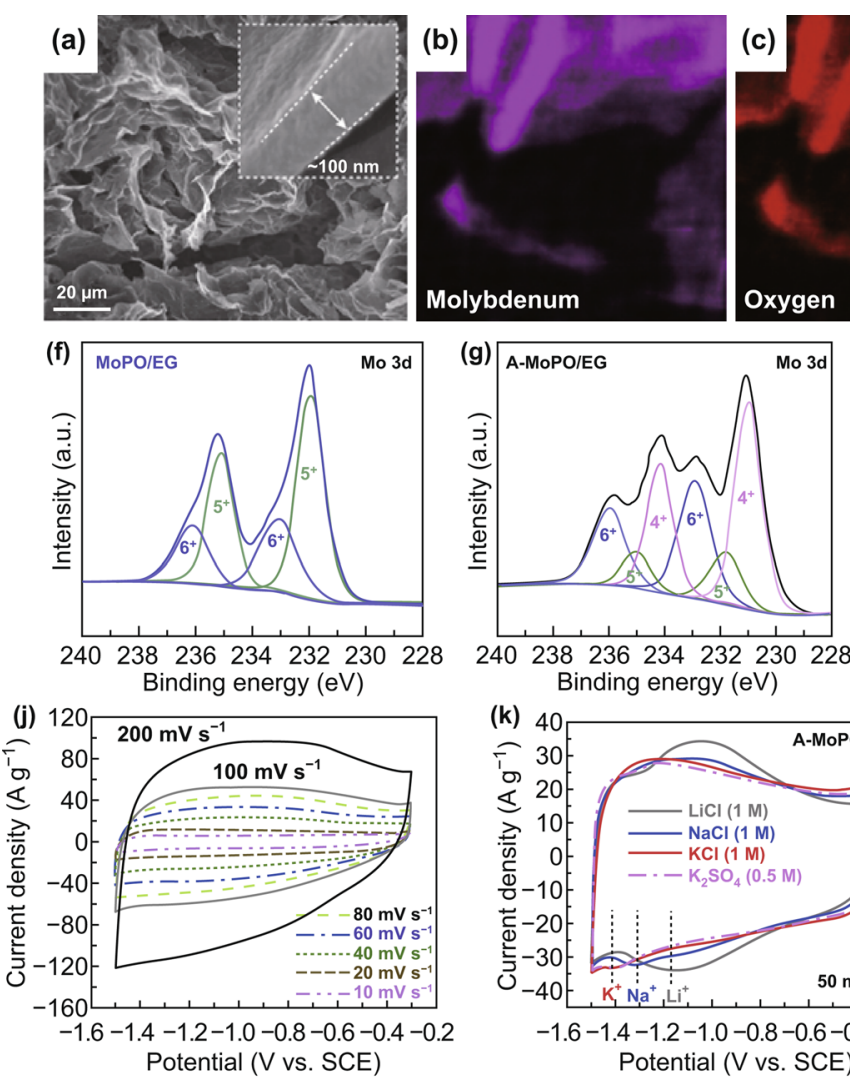
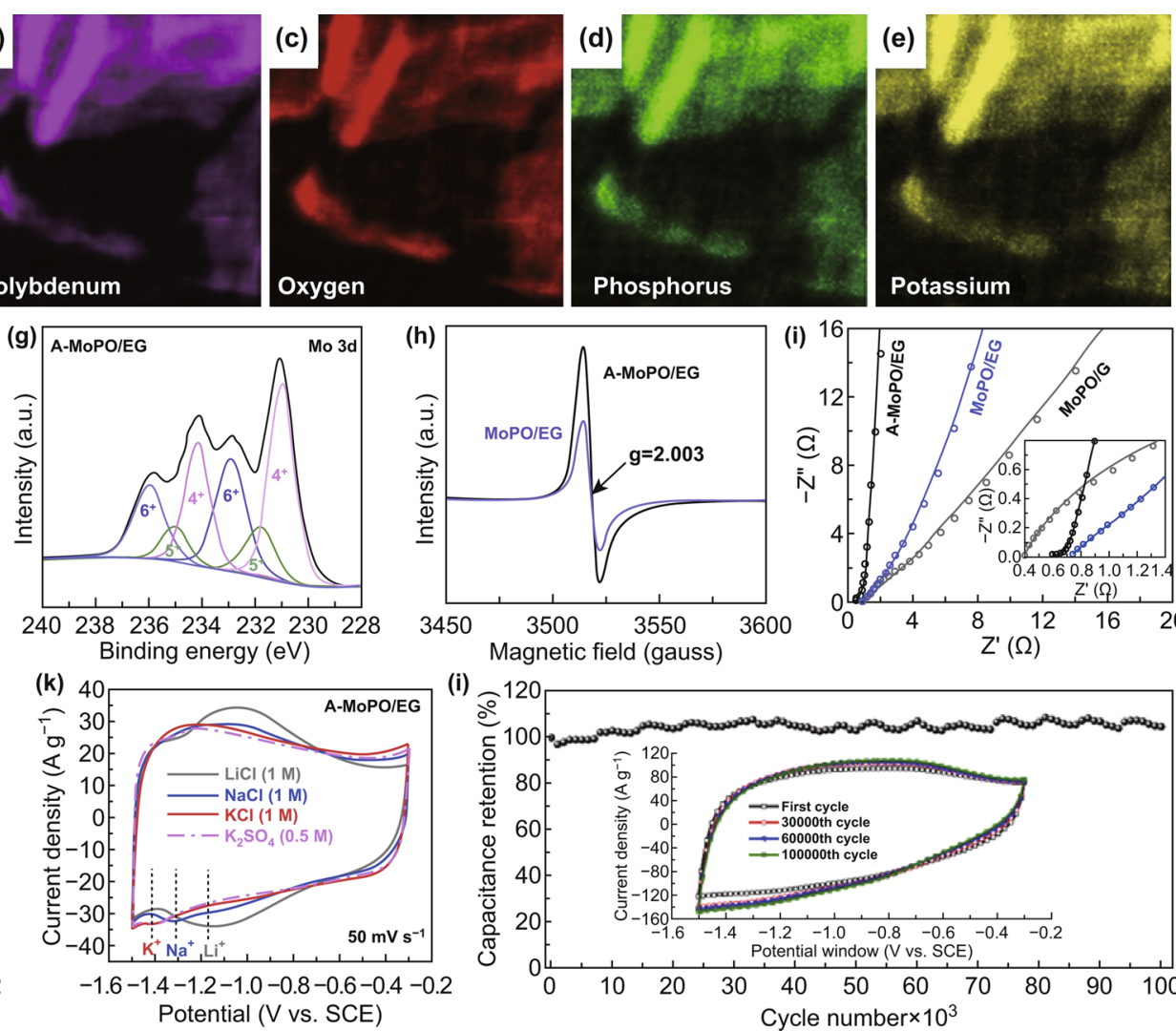
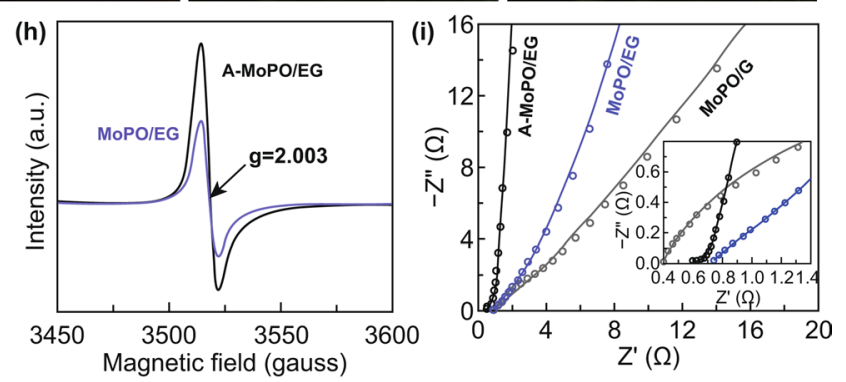

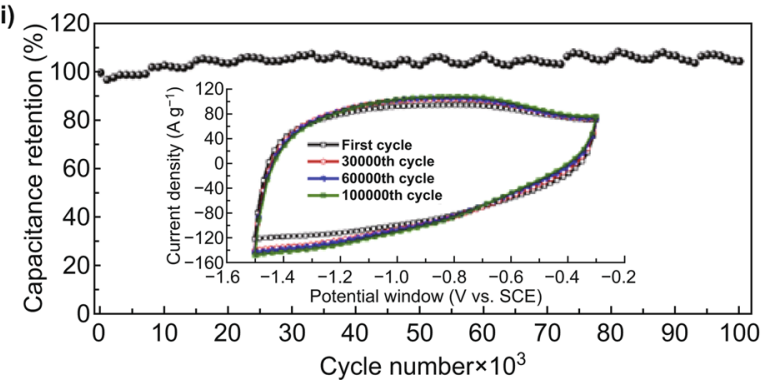

Fig. 32 a SEM image of activated polyanionic molybdenophosphate (A-MoPO/EG) on electrochemically exfoliated graphite foil. Inset: Magnified view showing the thickness of A-MoPO. b-e EDS elemental mappings of Mo, O, P, and K in A-MoPO/EG. f, $\mathbf{g}$ Mo $3 \mathrm{~d}$ XPS spectra of f MoOP/EG and $\mathbf{g ~ A - M o P O / E G . ~ h ~ E P R ~ s p e c t r a ~ o f ~ o x y g e n ~ d e f i c i e n c y ~ s i g n a l s ~ o f ~ M o O P / E G ~ a n d ~ A - M o O P / E G . ~ i ~ N y q u i s t ~ p l o t s ~ o f ~ A - M o P O / E G , ~}$ $\mathrm{MoPO} / \mathrm{EG}$, and MoPO/non-exfoliated graphite foil electrodes. $\mathbf{j} \mathrm{CV}$ curves of A-MoPO/EG at different scan rates in $3 \mathrm{M}$ aqueous $\mathrm{KCl}$ electrolyte. $\mathbf{k}$ CV curves of MoPO/EG recorded in various aqueous electrolytes. i Cycling stability of A-MoPO/EG in 100,000 charge-discharge cycles. Adapted from Ref. [28] with permission

film exhibited an areal capacitance of $220 \mathrm{mF} \mathrm{cm}^{-2}$ (volumetric capacitance $439 \mathrm{~F} \mathrm{~cm}^{-3}$ ) at $10 \mathrm{mV} \mathrm{s}^{-1}$, comparable or even superior to those made from traditional wet chemical etching methods.

\section{Summary and Outlook}

Electrochemical methods constitute a family of facile, economic, and versatile synthesis technology for a plethora of nano-/microstructured materials as active materials in supercapacitors. It has its unique advantages, challenges, and opportunities as a synthesis tool (Fig. 33). In this review article, we have demonstrated that electrodeposition strategies can synthesize active materials consisting of zero-dimensional, one-dimensional, two-dimensional, and three-dimensional nano-/micromaterials, including particles, rods, tubes, wires, plates, sheets, and hierarchical structures. 
To sum up, we have listed below the advantages of electrochemical technologies in preparing nano-/microstructured materials for supercapacitors or, broadly speaking, electrochemical energy storage devices.

(1) Their synthesis conditions are often mild (e.g., under room temperature) without elevated temperatures or ultrahigh pressures that might damage the structural integrity or alter the composition of the deposits and substrates. Additionally, electrochemical synthesis requires no advanced instruments and sophisticated operations, making it highly attainable and readily achievable.

(2) Electrodeposition directly and seamlessly incorporates active materials onto current collectors, a feature eliminating the need for polymer binders and conductive additives and easing electrode preparations.

(3) Electrodeposition offers facile tunability over the composition, crystal phase, and morphology of the deposited materials via changing depositing conditions, electrolyte compositions, current, voltage, and temperature.

(4) Electrodeposition is possible to direct the growth of active components onto user-designed patterns, as it only deposits materials in electrically conductive regions. This deposition selectivity makes electrodeposition particularly suitable to coat active materials on supercapacitors with delicate electrode architectures, such as micro-supercapacitors with interdigitated electrodes [196, 312, 313]. Additionally, the preferred deposition at ion-accessible locations ensures the high utilization efficiency of the active materials.

(5) Electrochemically synthesized materials are usually poorly crystalline or completely amorphous. The amorphous nature and abundant defects sometimes are beneficial for enhancing capacitance.

Despite the above strengths, electrochemical techniques are facing many challenges and difficulties, including:

(1) Post-treatments after electrodeposition, which are usually needed to improve the crystallinities of deposits, might alter the mechanical strength, functionality concentrations, crystal structures, or porous structure. For example, electrochemically exfoliated graphene sheets are usually stacks of 2-20 nm thick, instead of few- or single-layer graphene. Therefore, ultrasonication is needed to delaminate the exfoliated graphene into fewlayer graphene sheets. This process, however, will inevitably break the resultant graphene sheets into pieces that will increase sheet-to-sheet contact resistance.
(2) As discussed in Sect. 7, some active materials, e.g., metal sulfides, have not been extensively synthesized directly by electrodeposition. Converting metal oxides into the corresponding sulfides through sulfurization is one possible way. Still, this post-conversion usually involves high temperatures that might encounter problems with thermally unstable compounds or loss of structural water that are critical for charge transport [314].

(3) Controlling the uniformity of deposits remains a grand hurdle for electrodeposition, as edges of the deposition substrates are usually deposited first due to the strong local electrical field.

Projecting forward, we believe the following issues, if adequately addressed, could considerably enhance the electrochemical performance of electrodeposited materials and the practicality of electrodeposition.

(1) Rational design and realization of hierarchical structures with one-step electrodepositions is highly attractive to make high-performance supercapacitor electrodes with high mass loadings. Alternatively, combining electrodeposition strategies with other established materials synthesis methods (e.g., hydrothermal reactions to induce Ostwald ripening [197]) could also be explored to achieve hierarchical structures.

(2) Developing substrates with mutually high surface areas and excellent electrical conductivity is preferred to improve the ion diffusion kinetics in supercapacitors, but one must be meticulous about the deposition time and rate to avoid pore clogging. In this respect, selflimiting electrodeposition to control the deposit thickness is necessary [315].

(3) Diversifying the materials synthesized by electrodeposition. For example, metal sulfides have gained increasing attention as a new generation of electrochemical energy storage materials [316-318], but it is a pity that electrochemical methods can hardly synthesize them without post-treatments. Besides metal sulfides, electrodeposition can grow electrochemically active, 2D materials beyond graphene (e.g., layered metal oxides/hydroxides, boron nitride, and $g-\mathrm{C}_{3} \mathrm{~N}_{4}$ ) [319], porous polymers and organic compounds, or pseudocapacitive materials compatible with nonaqueous electrolytes. The room for the development of electrochemical synthesis technologies is undoubtedly immense.

(4) The purity of electrodeposited materials is often subpar to those made by vapor phase depositions. The multi- 
valence could benefit charge storage, but might pose challenges for studies on charge storage mechanisms because differentiating outcomes resulting from collective behaviors of all the active components is nontrivial.

(5) Deepening the understandings of the electrodepositions mechanism, including electrochemical nucleation and growth processes, will be highly rewarding to propel the development of electrochemical synthesis. For example, understanding the microscopic, complicated, and transient nucleation processes is imperative for controlling the morphology and uniformity of deposits. Mechanistic studies of electrodeposition, especially those developed recently, are limited. With the aid of in situ imaging technologies practiced in battery communities, the gain of insights into the early stages of electrodeposition will accumulate steadily.

Finally, we would like to stress that electrochemical synthesis technologies by no means can replace any existing materials synthesis methods. On the contrary, electrochemical strategies need to cooperate with other techniques to facilitate the explorations and development of high-performance electrodes in supercapacitors. Considering that electrodes play a central role in charge storage performances, we envision that the advancement and diversification of electrochemical synthesis technologies will directly push the development of electrochemical energy storage devices within and beyond electrochemical energy storage fields.

Acknowledgements Y.S. acknowledges the financial support from the National Natural Science Foundation of China (51804066) and the China Postdoctoral Science Foundation (2019T120214). X.X.L. acknowledges the financial support from the National Natural Science Foundation of China (21673035).

Open Access This article is licensed under a Creative Commons Attribution 4.0 International License, which permits use, sharing, adaptation, distribution and reproduction in any medium or format, as long as you give appropriate credit to the original author(s) and the source, provide a link to the Creative Commons licence, and indicate if changes were made. The images or other third party material in this article are included in the article's Creative Commons licence, unless indicated otherwise in a credit line to the material. If material is not included in the article's Creative Commons licence and your intended use is not permitted by statutory regulation or exceeds the permitted use, you will need to obtain permission directly from the copyright holder. To view a copy of this licence, visit http://creativeco mmons.org/licenses/by/4.0/.

\section{References}

1. C. Choi, D.S. Ashby, D.M. Butts, R.H. DeBlock, Q. Wei, J. Lau, B. Dunn, Achieving high energy density and high power density with pseudocapacitive materials. Nat. Rev. Mater. 5, 5-19 (2019). https://doi.org/10.1038/s41578-019-0142-Z

2. J. Pu, Z. Shen, C. Zhong, Q. Zhou, J. Liu, J. Zhu, H. Zhang, Electrodeposition technologies for Li-based batteries: new frontiers of energy storage. Adv. Mater. (2019). https://doi. org/10.1002/adma.201903808

3. P. Simon, Y. Gogotsi, B. Dunn, Materials science. Where do batteries end and supercapacitors begin? Science 343, 1210-1211 (2014). https://doi.org/10.1126/science.1249625

4. T. Liu, F. Zhang, Y. Song, Y. Li, Revitalizing carbon supercapacitor electrodes with hierarchical porous structures. J. Mater. Chem. A 5, 17705-17733 (2017). https://doi. org/10.1039/c7ta05646j

5. B.E. Conway, Electrochemical Supercapacitors: Scientific Fundamentals and Technological Applications (Springer, New York, 2013), pp. 11-31

6. Y. Jiang, J. Liu, Definitions of pseudocapacitive materials: a brief review. Energy Environ. Mater. 2, 30-37 (2019). https ://doi.org/10.1002/eem2.12028

7. J. Miller, Introduction to electrochemical capacitor technology. IEEE Electr. Insul. Mag. 26, 40-47 (2010). https://doi. org/10.1109/mei.2010.5511188

8. Y. Huang, Z. Tang, Z. Liu, J. Wei, H. Hu, C. Zhi, Toward enhancing wearability and fashion of wearable supercapacitor with modified polyurethane artificial leather electrolyte. Nano-Micro Lett. 10, 38 (2018). https://doi.org/10.1007/ s40820-018-0191-7

9. Z. Bo, C. Li, H. Yang, K. Ostrikov, J. Yan, K. Cen, Design of supercapacitor electrodes using molecular dynamics simulations. Nano-Micro Lett. 10, 33 (2018). https://doi. org/10.1007/s40820-018-0188-2

10. Y. Liu, B. Soucaze-Guillous, P.-L. Taberna, P. Simon, Understanding of carbon-based supercapacitors ageing mechanisms by electrochemical and analytical methods. J. Power Sources 366, 123-130 (2017). https://doi.org/10.1016/j.jpows our.2017.08.104

11. J.R. Miller, P. Simon, Materials science. Electrochemical capacitors for energy management. Science 321, 651-652 (2008). https://doi.org/10.1126/science.1158736

12. P. Simon, Y. Gogotsi, Materials for electrochemical capacitors. Nat. Mater. 7, 845-854 (2008). https://doi.org/10.1038/ nmat 2297

13. V. Augustyn, P. Simon, B. Dunn, Pseudocapacitive oxide materials for high-rate electrochemical energy storage. Energy Environ. Sci. 7, 1597-1614 (2014). https://doi. org/10.1039/c3ee44164d

14. N. Jabeen, A. Hussain, Q. Xia, S. Sun, J. Zhu, H. Xia, Highperformance $2.6 \mathrm{~V}$ aqueous asymmetric supercapacitors based on in situ formed $\mathrm{Na}_{0.5} \mathrm{MnO}_{2}$ nanosheet assembled nanowall arrays. Adv. Mater. 29, 1700804 (2017). https:// doi.org/10.1002/adma.201700804 
15. W. Wei, X. Cui, W. Chen, D.G. Ivey, Manganese oxidebased materials as electrochemical supercapacitor electrodes. Chem. Soc. Rev. 40, 1697-1721 (2011). https://doi. org/10.1039/c0cs00127a

16. Y. Wu, Y. Yang, X. Zhao, Y. Tan, Y. Liu, Z. Wang, F. Ran, A novel hierarchical porous 3D structured vanadium nitride/ carbon membranes for high-performance supercapacitor negative electrodes. Nano-Micro Lett. 10, 63 (2018). https:// doi.org/10.1007/s40820-018-0217-1

17. L.L. Zhang, X.S. Zhao, Carbon-based materials as supercapacitor electrodes. Chem. Soc. Rev. 38, 2520-2531 (2009). https://doi.org/10.1039/b813846j

18. D. Landolt, Electrodeposition science and technology in the last quarter of the twentieth century. J. Electrochem. Soc. 149, S9 (2002). https://doi.org/10.1149/1.1469028

19. I.M. Dharmadasa, J. Haigh, Strengths and advantages of electrodeposition as a semiconductor growth technique for applications in macroelectronic devices. J. Electrochem. Soc. 153, G47-G52 (2006). https://doi.org/10.1149/1.2128120

20. M.F. Montemor, S. Eugénio, N. Tuyen, R.P. Silva, T.M. Silva, M.J. Carmezim, Nanostructured Transition Metal Oxides Produced by Electrodeposition for Application as Redox Electrodes for Supercapacitors (Springer, Berlin, 2016), pp. 681-714. https://doi.org/10.1007/978-3-319-15266-0_14

21. J. Wang, K.K. Manga, Q. Bao, K.P. Loh, High-yield synthesis of few-layer graphene flakes through electrochemical expansion of graphite in propylene carbonate electrolyte. J. Am. Chem. Soc. 133, 8888-8891 (2011). https://doi.org/10.1021/ ja203725d

22. W. Chen, R.B. Rakhi, L. Hu, X. Xie, Y. Cui, H.N. Alshareef, High-performance nanostructured supercapacitors on a sponge. Nano Lett. 11, 5165-5172 (2011). https://doi. org/10.1021/nl2023433

23. X. Lang, A. Hirata, T. Fujita, M. Chen, Nanoporous metal/ oxide hybrid electrodes for electrochemical supercapacitors. Nat. Nanotechnol. 6, 232-236 (2011). https://doi. org/10.1038/nnano.2011.13

24. T. Liu, Y. Ling, Y. Yang, L. Finn, E. Collazo, T. Zhai, Y. Tong, Y. Li, Investigation of hematite nanorod-nanoflake morphological transformation and the application of ultrathin nanoflakes for electrochemical devices. Nano Energy 12, 169-177 (2015). https://doi.org/10.1016/j.nanoe n.2014.12.023

25. T. Liu, L. Finn, M. Yu, H. Wang, T. Zhai, X. Lu, Y. Tong, Y. $\mathrm{Li}$, Polyaniline and polypyrrole pseudocapacitor electrodes with excellent cycling stability. Nano Lett. 14, 2522-2527 (2014). https://doi.org/10.1021/nl500255v

26. Y. Song, T.-Y. Liu, X.-X. Xu, D.-Y. Feng, Y. Li, X.-X. Liu, Pushing the cycling stability limit of polypyrrole for supercapacitors. Adv. Funct. Mater. 25, 4626-4632 (2015). https ://doi.org/10.1002/adfm.201501709

27. M.-H. Bai, T.-Y. Liu, F. Luan, Y. Li, X.-X. Liu, Electrodeposition of vanadium oxide-polyaniline composite nanowire electrodes for high energy density supercapacitors. J. Mater. Chem. A 2, 10882-10888 (2014). https://doi.org/10.1039/ c3ta15391f
28. Y. Song, P. Deng, Z. Qin, D. Feng, D. Guo, X. Sun, X.-X. Liu, A polyanionic molybdenophosphate anode for a $2.7 \mathrm{~V}$ aqueous pseudocapacitor. Nano Energy 65, 104010 (2019). https://doi.org/10.1016/j.nanoen.2019.104010

29. F. Liu, Z. Chen, G. Fang, Z. Wang, Y. Cai, B. Tang, J. Zhou, $\mathrm{V}_{2} \mathrm{O}_{5}$ nanospheres with mixed vanadium valences as high electrochemically active aqueous zinc-ion battery cathode. Nano-Micro Lett. 11, 25 (2019). https://doi.org/10.1007/ s40820-019-0256-2

30. R.G. Kelly, J.R. Scully, D. Shoesmith, R.G. Buchheit, Electrochemical Techniques in Corrosion Science and Engineering. CRC Press, Boca Raton. (2002). https://doi. org/10.1201/9780203909133

31. A.J. Bard, L.R. Faulkner, J. Leddy, C.G. Zoski, Electrochemical Methods: Fundamentals and Applications (Wiley, New York, 1980)

32. N. Elgrishi, K.J. Rountree, B.D. McCarthy, E.S. Rountree, T.T. Eisenhart, J.L. Dempsey, A practical beginner's guide to cyclic voltammetry. J. Chem. Educ. 95, 197-206 (2017). https://doi.org/10.1021/acs.jchemed.7b00361

33. D.K. Gosser, Cyclic Voltammetry: Simulation and Analysis of Reaction Mechanisms (VCH, New York, 1993)

34. R. Dong, Y. Song, D. Yang, H.-Y. Shi, Z. Qin et al., Electrochemical in situ construction of vanadium oxide heterostructures with boosted pseudocapacitive charge storage. J. Mater. Chem. A 8, 1176-1183 (2020). https://doi.org/10.1039/c9ta12097a

35. Z. Sun, X. Cai, D.-Y. Feng, Z.-H. Huang, Y. Song, X.-X. Liu, Hybrid iron oxide on three-dimensional exfoliated graphite electrode with ultrahigh capacitance for energy storage applications. ChemElectroChem 5, 1501-1508 (2018). https://doi. org/10.1002/celc. 201800143

36. Z. Sun, X. Cai, Y. Song, X.-X. Liu, Electrochemical deposition of honeycomb magnetite on partially exfoliated graphite as anode for capacitive applications. J. Power Sources 359, 57-63 (2017). https://doi.org/10.1016/j.jpows our.2017.05.055

37. Y. Song, T.Y. Liu, B. Yao, T.Y. Kou, D.Y. Feng, X.X. Liu, Y. Li, Amorphous mixed-valence vanadium oxide/exfoliated carbon cloth structure shows a record high cycling stability. Small 13, 1700067 (2017). https://doi.org/10.1002/ smll.201700067

38. X. Cai, Y. Song, S.-Q. Wang, X. Sun, X.-X. Liu, Extending the cycle life of high mass loading $\mathrm{MoO}_{\mathrm{x}}$ electrode for supercapacitor applications. Electrochim. Acta 325, 134877 (2019). https://doi.org/10.1016/j.electacta.2019.134877

39. M. Paunovic, Electrochemical Deposition. Encyclopedia of Electrochemistry: Online (2007). https://doi. org/10.1002/9783527610426.bard050003

40. D. Lincot, Electrodeposition of semiconductors. Thin Solid Films 487, 40-48 (2005). https://doi.org/10.1016/j. tsf.2005.01.032

41. M. Paunovic, M. Schlesinger, Fundamentals of Electrochemical Deposition (Wiley, New York, 1998)

42. D.M. Kolb, M. Przasnyski, H. Gerischer, Underpotential deposition of metals and work function differences. J. 
Electroanal. Chem. 54, 25-38 (1974). https://doi.org/10.1016/ s0022-0728(74)80377-3

43. E. Herrero, L.J. Buller, H.D. Abruna, Underpotential deposition at single crystal surfaces of $\mathrm{Au}, \mathrm{Pt}, \mathrm{Ag}$ and other materials. Chem. Rev. 101, 1897-1930 (2001). https://doi. org/10.1021/cr9600363

44. Z. Shi, S. Wu, J. Lipkowski, Investigations of $\mathrm{Cl}^{-}$adsorption at the $\mathrm{Au}(111)$ electrode in the presence of underpotentially deposited copper atoms. J. Electroanal. Chem. 384, 171-177 (1995). https://doi.org/10.1016/0022-0728(94)03747-q

45. J.C. Ballesteros, E. Chaînet, P. Ozil, G. Trejo, Y. Meas, Electrochemical studies of $\mathrm{Zn}$ underpotential/overpotential deposition on a nickel electrode from non-cyanide alkaline solution containing glycine. Electrochim. Acta 56, 5443-5451 (2011). https://doi.org/10.1016/j.electacta.2011.02.106

46. M. Palomar-Pardavé, I. González, N. Batina, New insights into evaluation of kinetic parameters for potentiostatic metal deposition with underpotential and overpotential deposition processes. J. Phys. Chem. B 104, 3545-3555 (2000). https:// doi.org/10.1021/jp9931861

47. R.E. Rettew, J.W. Guthrie, F.M. Alamgir, Layer-by-layer Pt growth on polycrystalline Au: surface-limited redox replacement of overpotentially deposited Ni monolayers. J. Electrochem. Soc. 156, D513-D516 (2009). https://doi. org/10.1149/1.3224113

48. M.G. Pavlović, L.J. Pavlović, N.D. Nikolić, K.I. Popov, The effect of some parameters of electrolysis on apparent density of electrolytic copper powder in galvanostatic deposition. Mater. Sci. Forum 352, 65-72 (2000). https://doi. org/10.4028/www.scientific.net/MSF.352.65

49. R. Salazar, C. Lévy-Clément, V. Ivanova, Galvanostatic deposition of $\mathrm{ZnO}$ thin films. Electrochim. Acta 78, 547-556 (2012). https://doi.org/10.1016/j.electacta.2012.06.070

50. Z.H. Huang, Y. Song, D.Y. Feng, Z. Sun, X. Sun, X.X. Liu, High mass loading $\mathrm{MnO}_{2}$ with hierarchical nanostructures for supercapacitors. ACS Nano 12, 3557-3567 (2018). https ://doi.org/10.1021/acsnano.8b00621

51. E.J. Podlaha, Selective electrodeposition of nanoparticulates into metal matrices. Nano Lett. 1, 413-416 (2001). https:// doi.org/10.1021/n1015508u

52. G. Zhu, C. Pan, W. Guo, C.Y. Chen, Y. Zhou, R. Yu, Z.L. Wang, Triboelectric-generator-driven pulse electrodeposition for micropatterning. Nano Lett. 12, 4960-4965 (2012). https ://doi.org/10.1021/nl302560k

53. Y. Su, I. Zhitomirsky, Pulse electrosynthesis of $\mathrm{MnO}_{2}$ electrodes for supercapacitors. Adv. Eng. Mater. 16, 760-766 (2014). https://doi.org/10.1002/adem.201400077

54. M. Ghaemi, Effects of direct and pulse current on electrodeposition of manganese dioxide. J. Power Sources 111, 248-254 (2002). https://doi.org/10.1016/s0378-7753(02)00309-9

55. H. Cheh, Electrodeposition of gold by pulsed current. J. Electrochem. Soc. 118, 551 (1971). https://doi. org/10.1149/1.2408110

56. H.M.M.N. Hennayaka, H.S. Lee, Structural and optical properties of Zns thin film grown by pulsed electrodeposition.
Thin Solid Films 548, 86-90 (2013). https://doi.org/10.1016/j. tsf.2013.09.011

57. A. Davies, P. Audette, B. Farrow, F. Hassan, Z. Chen, J.-Y. Choi, A. Yu, Graphene-based flexible supercapacitors: pulseelectropolymerization of polypyrrole on free-standing graphene films. J. Phys. Chem. C 115, 17612-17620 (2011). https://doi.org/10.1021/jp205568v

58. L. Besra, M. Liu, A review on fundamentals and applications of electrophoretic deposition (EPD). Prog. Mater Sci. 52, 1-61 (2007). https://doi.org/10.1016/j.pmatsci.2006.07.001

59. P. Sarkar, P.S. Nicholson, Electrophoretic deposition (EPD): mechanisms, kinetics, and application to ceramics. J. Am. Ceram. Soc. 79, 1987-2002 (1996). https://doi. org/10.1111/j.1151-2916.1996.tb08929.x

60. C. Du, N. Pan, Supercapacitors using carbon nanotubes films by electrophoretic deposition. J. Power Sources 160, 1487-1494 (2006). https://doi.org/10.1016/j.jpows our.2006.02.092

61. C. Du, N. Pan, High power density supercapacitor electrodes of carbon nanotube films by electrophoretic deposition. Nanotechnology 17, 5314-5318 (2006). https://doi. org/10.1088/0957-4484/17/21/005

62. D. Pech, M. Brunet, H. Durou, P. Huang, V. Mochalin, Y. Gogotsi, P.L. Taberna, P. Simon, Ultrahigh-power micrometre-sized supercapacitors based on onion-like carbon. Nat. Nanotechnol. 5, 651-654 (2010). https://doi.org/10.1038/ nnano.2010.162

63. Y. Su, I. Zhitomirsky, Electrophoretic nanotechnology of composite electrodes for electrochemical supercapacitors. J. Phys. Chem. B 117, 1563-1570 (2013). https://doi. org/10.1021/jp304358q

64. Y. Wang, I. Zhitomirsky, Electrophoretic deposition of manganese dioxide-multiwalled carbon nanotube composites for electrochemical supercapacitors. Langmuir 25, 9684-9689 (2009). https://doi.org/10.1021/la900937e

65. H. Zhang, X. Zhang, D. Zhang, X. Sun, H. Lin, C. Wang, Y. $\mathrm{Ma}$, One-step electrophoretic deposition of reduced graphene oxide and $\mathrm{Ni}(\mathrm{OH})_{2}$ composite films for controlled syntheses supercapacitor electrodes. J. Phys. Chem. B 117, 1616-1627 (2013). https://doi.org/10.1021/jp305198j

66. Z.Y. Xia, S. Pezzini, E. Treossi, G. Giambastiani, F. Corticelli et al., The exfoliation of graphene in liquids by electrochemical, chemical, and sonication-assisted techniques: a nanoscale study. Adv. Funct. Mater. 23, 4684-4693 (2013). https://doi. org/10.1002/adfm.201203686

67. A.M. Abdelkader, I.A. Kinloch, R.A. Dryfe, Continuous electrochemical exfoliation of micrometer-sized graphene using synergistic ion intercalations and organic solvents. ACS Appl. Mater. Interfaces. 6, 1632-1639 (2014). https:// doi.org/10.1021/am404497n

68. A.M. Abdelkader, A.J. Cooper, R.A. Dryfe, I.A. Kinloch, How to get between the sheets: a review of recent works on the electrochemical exfoliation of graphene materials from bulk graphite. Nanoscale 7, 6944-6956 (2015). https://doi. org/10.1039/c4nr06942k 
69. A. Ambrosi, M. Pumera, Exfoliation of layered materials using electrochemistry. Chem. Soc. Rev. 47, 7213-7224 (2018). https://doi.org/10.1039/c7cs00811b

70. R. Kumar, S. Sahoo, E. Joanni, R.K. Singh, W.K. Tan, K.K. Kar, A. Matsuda, Recent progress in the synthesis of graphene and derived materials for next generation electrodes of high performance lithium ion batteries. Prog. Energy Combust. 75, 100786 (2019). https://doi.org/10.1016/j. pecs.2019.100786

71. A. Ambrosi, M. Pumera, Electrochemically exfoliated graphene and graphene oxide for energy storage and electrochemistry applications. Chemistry 22, 153-159 (2016). https ://doi.org/10.1002/chem.201503110

72. P. Yu, S.E. Lowe, G.P. Simon, Y.L. Zhong, Electrochemical exfoliation of graphite and production of functional graphene. Curr. Opin. Colloid Interface Sci. 20, 329-338 (2015). https ://doi.org/10.1016/j.cocis.2015.10.007

73. S. Yang, M.R. Lohe, K. Mullen, X. Feng, New-generation graphene from electrochemical approaches: production and applications. Adv. Mater. 28, 6213-6221 (2016). https://doi. org/10.1002/adma.201505326

74. W. Wei, G. Wang, S. Yang, X. Feng, K. Mullen, Efficient coupling of nanoparticles to electrochemically exfoliated graphene. J. Am. Chem. Soc. 137, 5576-5581 (2015). https ://doi.org/10.1021/jacs.5b02284

75. L. Wu, W. Li, P. Li, S. Liao, S. Qiu et al., Powder, paper and foam of few-layer graphene prepared in high yield by electrochemical intercalation exfoliation of expanded graphite. Small 10, 1421-1429 (2014). https://doi.org/10.1002/ smll.201302730

76. A. Ejigu, K. Fujisawa, B.F. Spencer, B. Wang, M. Terrones, I.A. Kinloch, R.A.W. Dryfe, On the role of transition metal salts during electrochemical exfoliation of graphite: antioxidants or metal oxide decorators for energy storage applications. Adv. Funct. Mater. 28, 1804357 (2018). https://doi. org/10.1002/adfm.201804357

77. K.S. Rao, J. Sentilnathan, H.-W. Cho, J.-J. Wu, M. Yoshimura, Soft processing of graphene nanosheets by glycine-bisulfate ionic-complex-assisted electrochemical exfoliation of graphite for reduction catalysis. Adv. Funct. Mater. 25, 298-305 (2015). https://doi.org/10.1002/adfm.201402621

78. C.Y. Su, A.Y. Lu, Y. Xu, F.R. Chen, A.N. Khlobystov, L.J. Li, High-quality thin graphene films from fast electrochemical exfoliation. ACS Nano 5, 2332-2339 (2011). https://doi. org/10.1021/nn200025p

79. J. Lu, J.X. Yang, J. Wang, A. Lim, S. Wang, K.P. Loh, One-pot synthesis of fluorescent carbon nanoribbons, nanoparticles, and graphene by the exfoliation of graphite in ionic liquids. ACS Nano 3, 2367-2375 (2009). https://doi. org/10.1021/nn900546b

80. W. Cai, X. Feng, W. Hu, Y. Pan, Y. Hu, X. Gong, Functionalized graphene from electrochemical exfoliation for thermoplastic polyurethane: thermal stability, mechanical properties, and flame retardancy. Ind. Eng. Chem. Res. 55, 10681-10689 (2016). https://doi.org/10.1021/acs.iecr.6b02579
81. M. Mao, M. Wang, J. Hu, G. Lei, S. Chen, H. Liu, Simultaneous electrochemical synthesis of few-layer graphene flakes on both electrodes in protic ionic liquids. Chem. Commun. 49, 5301-5303 (2013). https://doi.org/10.1039/c3cc41909f

82. H. Huang, Y. Xia, X. Tao, J. Du, J. Fang, Y. Gan, W. Zhang, Highly efficient electrolytic exfoliation of graphite into graphene sheets based on Li ions intercalation-expansionmicroexplosion mechanism. J. Mater. Chem. 22, 1045210456 (2012). https://doi.org/10.1039/c2jm00092j

83. Y. Yang, F. Lu, Z. Zhou, W. Song, Q. Chen, X. Ji, Electrochemically cathodic exfoliation of graphene sheets in room temperature ionic liquids N-butyl, methylpyrrolidinium bis(trifluoromethylsulfonyl)imide and their electrochemical properties. Electrochim. Acta 113, 9-16 (2013). https://doi. org/10.1016/j.electacta.2013.09.031

84. K. Parvez, R. Li, S.R. Puniredd, Y. Hernandez, F. Hinkel, S. Wang, X. Feng, K. Mullen, Electrochemically exfoliated graphene as solution-processable, highly conductive electrodes for organic electronics. ACS Nano 7, 3598-3606 (2013). https://doi.org/10.1021/nn400576v

85. W. Wang, W. Liu, Y. Zeng, Y. Han, M. Yu, X. Lu, Y. Tong, A novel exfoliation strategy to significantly boost the energy storage capability of commercial carbon cloth. Adv. Mater. 27, 3572-3578 (2015). https://doi.org/10.1002/adma.20150 0707

86. Y. Song, S. Duan, D. Yang, R. Dong, D. Guo, X. Sun, X.-X. Liu, 3D exfoliated carbon paper toward highly loaded aqueous energy storage applications. Energy Technol. 7, 1900892 (2019). https://doi.org/10.1002/ente.201900892

87. F. Zeng, Z. Sun, X. Sang, D. Diamond, K.T. Lau, X. Liu, D.S. Su, In situ one-step electrochemical preparation of graphene oxide nanosheet-modified electrodes for biosensors. Chemsuschem 4, 1587-1591 (2011). https://doi.org/10.1002/ cssc.201100319

88. Y. Song, D.Y. Feng, T.Y. Liu, Y. Li, X.X. Liu, Controlled partial-exfoliation of graphite foil and integration with $\mathrm{MnO}_{2}$ nanosheets for electrochemical capacitors. Nanoscale 7, 3581-3587 (2015). https://doi.org/10.1039/c4nr06559j

89. K. Parvez, Z.S. Wu, R. Li, X. Liu, R. Graf, X. Feng, K. Mullen, Exfoliation of graphite into graphene in aqueous solutions of inorganic salts. J. Am. Chem. Soc. 136, 6083-6091 (2014). https://doi.org/10.1021/ja5017156

90. M. Alanyalıŏ̆lu, J.J. Segura, J. Oró-Solè, N. Casañ-Pastor, The synthesis of graphene sheets with controlled thickness and order using surfactant-assisted electrochemical processes. Carbon 50, 142-152 (2012). https://doi.org/10.1016/j.carbo n.2011.07.064

91. C.-H. Chen, S.-W. Yang, M.-C. Chuang, W.-Y. Woon, C.-Y. $\mathrm{Su}$, Towards the continuous production of high crystallinity graphene via electrochemical exfoliation with molecular in situ encapsulation. Nanoscale 7, 15362-15373 (2015). https://doi.org/10.1039/c5nr03669k

92. K. Chen, D. Xue, Preparation of colloidal graphene in quantity by electrochemical exfoliation. J. Colloid Interface Sci. 436, 41-46 (2014). https://doi.org/10.1016/j.jcis.2014.08.057 
93. A.J. Cooper, N.R. Wilson, I.A. Kinloch, R.A.W. Dryfe, Single stage electrochemical exfoliation method for the production of few-layer graphene via intercalation of tetraalkylammonium cations. Carbon 66, 340-350 (2014). https://doi. org/10.1016/j.carbon.2013.09.009

94. A. Ejigu, I.A. Kinloch, R.A. Dryfe, Single stage simultaneous electrochemical exfoliation and functionalization of graphene. ACS Appl. Mater. Interfaces 9, 710-721 (2017). https ://doi.org/10.1021/acsami.6b12868

95. S. Yang, S. Bruller, Z.S. Wu, Z. Liu, K. Parvez et al., Organic radical-assisted electrochemical exfoliation for the scalable production of high-quality graphene. J. Am. Chem. Soc. 137, 13927-13932 (2015). https://doi.org/10.1021/jacs.5b09000

96. X. Cai, Y. Song, Z. Sun, D. Guo, X.-X. Liu, Rate capability improvement of $\mathrm{Co}-\mathrm{Ni}$ double hydroxides integrated in cathodically partially exfoliated graphite. J. Power Sources 365, 126-133 (2017). https://doi.org/10.1016/j.jpows our.2017.08.039

97. D.-Y. Feng, Y. Song, Z.-H. Huang, X.-X. Xu, X.-X. Liu, Rate capability improvement of polypyrrole via integration with functionalized commercial carbon cloth for pseudocapacitor. J. Power Sources 324, 788-797 (2016). https://doi. org/10.1016/j.jpowsour.2016.05.112

98. L. Hu, X. Peng, Y. Li, L. Wang, K. Huo, L.Y.S. Lee, K.Y. Wong, P.K. Chu, Direct anodic exfoliation of graphite onto high-density aligned graphene for large capacity supercapacitors. Nano Energy 34, 515-523 (2017). https://doi. org/10.1016/j.nanoen.2017.03.007

99. T. Liu, C. Zhu, T. Kou, M.A. Worsley, F. Qian, C. Condes, E.B. Duoss, C.M. Spadaccini, Y. Li, Ion intercalation induced capacitance improvement for graphene-based supercapacitor electrodes. ChemNanoMat 2, 635-641 (2016). https://doi. org/10.1002/cnma.201600107

100. Y. Song, T. Liu, F. Qian, C. Zhu, B. Yao, E. Duoss, C. Spadaccini, M. Worsley, Y. Li, Three-dimensional carbon architectures for electrochemical capacitors. J. Colloid Interface Sci. 509, 529-545 (2018). https://doi.org/10.1016/j. jcis.2017.07.081

101. Y. Song, T.-Y. Liu, G.-L. Xu, D.-Y. Feng, B. Yao, T.-Y. Kou, X.-X. Liu, Y. Li, Tri-layered graphite foil for electrochemical capacitors. J. Mater. Chem. A 4, 7683-7688 (2016). https:// doi.org/10.1039/c6ta02075e

102. Y. Zou, S. Wang, Interconnecting carbon fibers with the in situ electrochemically exfoliated graphene as advanced binder-free electrode materials for flexible supercapacitor. Sci. Rep. 5, 11792 (2015). https://doi.org/10.1038/srep11792

103. S.-H. Lee, S.-D. Seo, Y.-H. Jin, H.-W. Shim, D.-W. Kim, A graphite foil electrode covered with electrochemically exfoliated graphene nanosheets. Electrochem. Commun. 12, 14191422 (2010). https://doi.org/10.1016/j.elecom.2010.07.036

104. R.M. Tamgadge, A. Shukla, A PH-dependent partial electrochemical exfoliation of highly oriented pyrolytic graphite for high areal capacitance electric double layer capacitor electrode. Electrochim. Acta 325, 134933 (2019). https://doi. org/10.1016/j.electacta.2019.134933
105. Y. Song, J.-L. Xu, X.-X. Liu, Electrochemical anchoring of dual doping polypyrrole on graphene sheets partially exfoliated from graphite foil for high-performance supercapacitor electrode. J. Power Sources 249, 48-58 (2014). https://doi. org/10.1016/j.jpowsour.2013.10.102

106. Y. Song, X. Cai, X. Xu, X.-X. Liu, Integration of nickelcobalt double hydroxide nanosheets and polypyrrole films with functionalized partially exfoliated graphite for asymmetric supercapacitors with improved rate capability. J. Mater. Chem. A 3, 14712-14720 (2015). https://doi.org/10.1039/ c5ta02810h

107. Z. Liu, Z.S. Wu, S. Yang, R. Dong, X. Feng, K. Mullen, Ultraflexible in-plane micro-supercapacitors by direct printing of solution-processable electrochemically exfoliated graphene. Adv. Mater. 28, 2217-2222 (2016). https://doi. org/10.1002/adma.201505304

108. J.M. Munuera, J.I. Paredes, M. Enterria, A. Pagan, S. VillarRodil, M.F.R. Pereira et al., Electrochemical exfoliation of graphite in aqueous sodium halide electrolytes toward low oxygen content graphene for energy and environmental applications. ACS Appl. Mater. Interfaces 9, 24085-24099 (2017). https://doi.org/10.1021/acsami.7b04802

109. N. Parveen, M.O. Ansari, S.A. Ansari, M.H. Cho, Simultaneous sulfur doping and exfoliation of graphene from graphite using an electrochemical method for supercapacitor electrode materials. J. Mater. Chem. A 4, 233-240 (2016). https://doi. org/10.1039/c5ta07963b

110. J. Liu, M. Notarianni, G. Will, V.T. Tiong, H. Wang, N. Motta, Electrochemically exfoliated graphene for electrode films: effect of graphene flake thickness on the sheet resistance and capacitive properties. Langmuir 29, 13307-13314 (2013). https://doi.org/10.1021/la403159n

111. S.M. Jung, D.L. Mafra, C.T. Lin, H.Y. Jung, J. Kong, Controlled porous structures of graphene aerogels and their effect on supercapacitor performance. Nanoscale 7, 4386-4393 (2015). https://doi.org/10.1039/c4nr07564a

112. X. Xiao, Y. Zeng, H. Feng, K. Xu, G. Zhong et al., Threedimensional nitrogen-doped graphene frameworks from electrochemical exfoliation of graphite as efficient supercapacitor electrodes. ChemNanoMat 5, 152-157 (2019). https://doi. org/10.1002/cnma.201800452

113. P. Khanra, T. Kuila, S.H. Bae, N.H. Kim, J.H. Lee, Electrochemically exfoliated graphene using 9-anthracene carboxylic acid for supercapacitor application. J. Mater. Chem. 22, 24403-24410 (2012). https://doi.org/10.1039/c2jm34838a

114. S. Liu, J. Ou, J. Wang, X. Liu, S. Yang, A simple two-step electrochemical synthesis of graphene sheets film on the ITO electrode as supercapacitors. J. Appl. Electrochem. 41, 881-884 (2011). https://doi.org/10.1007/s10800-011-0304-1

115. V. Thirumal, A. Pandurangan, R. Jayavel, K.S. Venkatesh, N.S. Palani, R. Ragavan, R. Ilangovan, Single pot electrochemical synthesis of functionalized and phosphorus doped graphene nanosheets for supercapacitor applications. J. Mater. Sci.: Mater. Electron. 26, 6319-6328 (2015). https:// doi.org/10.1007/s10854-015-3219-5 
116. C. Li, H. Bai, G. Shi, Conducting polymer nanomaterials: electrosynthesis and applications. Chem. Soc. Rev. 38, 23972409 (2009). https://doi.org/10.1039/b816681c

117. G.A. Snook, P. Kao, A.S. Best, Conducting-polymer-based supercapacitor devices and electrodes. J. Power Sources 196, 1-12 (2011). https://doi.org/10.1016/j.jpowsour.2010.06.084

118. R. Gangopadhyay, A. De, Conducting polymer nanocomposites: a brief overview. Chem. Mater. 12, 608-622 (2000). https://doi.org/10.1021/cm990537f

119. Z. Cai, L. Li, J. Ren, L. Qiu, H. Lin, H. Peng, Flexible, weavable and efficient microsupercapacitor wires based on polyaniline composite fibers incorporated with aligned carbon nanotubes. J. Mater. Chem. A 1, 258-261 (2013). https://doi. org/10.1039/c2ta00274d

120. K.M. Kim, Y.-G. Lee, D.O. Shin, J.M. Ko, Supercapacitive properties of layered electrodes composed of electrodeposited $\mathrm{RuO}_{2}$ and polyaniline. Electrochim. Acta 196, 309-315 (2016). https://doi.org/10.1016/j.electacta.2016.02.194

121. H. Li, J. Song, L. Wang, X. Feng, R. Liu, W. Zeng, Z. Huang, Y. Ma, L. Wang, Flexible all-solid-state supercapacitors based on polyaniline orderly nanotubes array. Nanoscale $\mathbf{9}$, 193-200 (2017). https://doi.org/10.1039/c6nr07921k

122. C. Tran, R. Singhal, D. Lawrence, V. Kalra, Polyanilinecoated freestanding porous carbon nanofibers as efficient hybrid electrodes for supercapacitors. J. Power Sources 293, 373-379 (2015). https://doi.org/10.1016/j.jpows our.2015.05.054

123. Y. Xie, D. Wang, J. Ji, Preparation and supercapacitor performance of freestanding polypyrrole/polyaniline coaxial nanoarrays. Energy Technol. 4, 714-721 (2016). https://doi. org/10.1002/ente.201500460

124. C. Fu, H. Zhou, R. Liu, Z. Huang, J. Chen, Y. Kuang, Supercapacitor based on electropolymerized polythiophene and multi-walled carbon nanotubes composites. Mater. Chem. Phys. 132, 596-600 (2012). https://doi.org/10.1016/j.match emphys.2011.11.074

125. A. Laforgue, P. Simon, C. Sarrazin, J.-F. Fauvarque, Polythiophene-based supercapacitors. J. Power Sources 80, 142-148 (1999). https://doi.org/10.1016/s0378-7753(98)00258-4

126. F.N. Ajjan, N. Casado, T. Rębiś, A. Elfwing, N. Solin, D. Mecerreyes, O. Inganäs, High performance PEDOT/lignin biopolymer composites for electrochemical supercapacitors. J. Mater. Chem. A 4, 1838-1847 (2016). https://doi. org/10.1039/c5ta10096h

127. A.M. Osterholm, D.E. Shen, A.L. Dyer, J.R. Reynolds, Optimization of PEDOT films in ionic liquid supercapacitors: demonstration as a power source for polymer electrochromic devices. ACS Appl. Mater. Interfaces 5, 13432-13440 (2013). https://doi.org/10.1021/am4043454

128. J. Xu, Z. Ku, Y. Zhang, D. Chao, H.J. Fan, Integrated photosupercapacitor based on PEDOT modified printable perovskite solar cell. Adv. Mater. Technol. 1, 1600074 (2016). https ://doi.org/10.1002/admt.201600074

129. S.-B. Yoon, K.-B. Kim, Effect of poly(3,4-ethylenedioxythiophene) (PEDOT) on the pseudocapacitive properties of manganese oxide $\left(\mathrm{MnO}_{2}\right)$ in the PEDOT/MnO$/$ multiwall carbon nanotube (MWNT) composite. Electrochim. Acta 106, 135142 (2013). https://doi.org/10.1016/j.electacta.2013.05.058

130. G. Cai, P. Darmawan, M. Cui, J. Wang, J. Chen, S. Magdassi, P.S. Lee, Highly stable transparent conductive silver grid/PEDOT:PSS electrodes for integrated bifunctional flexible electrochromic supercapacitors. Adv. Energy Mater. 6, 1501882 (2016). https://doi.org/10.1002/aenm.201501882

131. D. Yang, Y. Song, Y.-J. Ye, M. Zhang, X. Sun, X.-X. Liu, Boosting the pseudocapacitance of nitrogen-rich carbon nanorod arrays for electrochemical capacitors. J. Mater. Chem. A 7, 12086-12094 (2019). https://doi.org/10.1039/c9ta01973a

132. Y. Huang, J. Tao, W. Meng, M. Zhu, Y. Huang, Y. Fu, Y. Gao, C. Zhi, Super-high rate stretchable polypyrrole-based supercapacitors with excellent cycling stability. Nano Energy 11, 518-525 (2015). https://doi.org/10.1016/j.nanoe n.2014.10.031

133. J.G. Ibanez, M.E. Rincon, S. Gutierrez-Granados, M. Chahma, O.A. Jaramillo-Quintero, B.A. Frontana-Uribe, Conducting polymers in the fields of energy, environmental remediation, and chemical-chiral sensors. Chem. Rev. 118, 4731-4816 (2018). https://doi.org/10.1021/acs.chemr ev. $7 \mathrm{~b} 00482$

134. G. Sabouraud, S. Sadki, N. Brodie, The mechanisms of pyrrole electropolymerization. Chem. Soc. Rev. 29, 283-293 (2000). https://doi.org/10.1039/a807124a

135. J. Jang, Conducting Polymer Nanomaterials and Their Applications (Springer, Berlin, 2006), pp. 189-260

136. S.C. Erwin, L. Zu, M.I. Haftel, A.L. Efros, T.A. Kennedy, D.J. Norris, Doping semiconductor nanocrystals. Nature 436, 91-94 (2005). https://doi.org/10.1038/nature03832

137. T.F. Otero, J.G. Martinez, Structural and biomimetic chemical kinetics: kinetic magnitudes include structural information. Adv. Funct. Mater. 23, 404-416 (2013). https://doi. org/10.1002/adfm.201200719

138. T. Liu, Y. Li, Addressing the achilles' heel of pseudocapacitive materials: long-term stability. InfoMat (2020). https:// doi.org/10.1002/inf2.12105

139. Y. Shi, L. Peng, Y. Ding, Y. Zhao, G. Yu, Nanostructured conductive polymers for advanced energy storage. Chem. Soc. Rev. 44, 6684-6696 (2015). https://doi.org/10.1039/c5cs0 0362h

140. B. Anothumakkool, A.T.A. Torris, S.N. Bhange, M.V. Badiger, S. Kurungot, Electrodeposited polyethylenedioxythiophene with infiltrated gel electrolyte interface: a close contest of an all-solid-state supercapacitor with its liquid-state counterpart. Nanoscale 6, 5944-5952 (2014). https://doi. org/10.1039/c4nr00659c

141. Y. Xie, Y. Liu, Y. Zhao, Y.H. Tsang, S.P. Lau, H. Huang, Y. Chai, Stretchable all-solid-state supercapacitor with wavy shaped polyaniline/graphene electrode. J. Mater. Chem. A 2, 9142-9149 (2014). https://doi.org/10.1039/c4ta00734d

142. S. Lehtimaki, M. Suominen, P. Damlin, S. Tuukkanen, C. Kvarnstrom, D. Lupo, Preparation of supercapacitors on flexible substrates with electrodeposited PEDOT/graphene composites. ACS Appl. Mater. Interfaces 7, 22137-22147 (2015). https://doi.org/10.1021/acsami.5b05937 
143. Y. Huang, M. Zhu, Z. Pei, Y. Huang, H. Geng, C. Zhi, Extremely stable polypyrrole achieved via molecular ordering for highly flexible supercapacitors. ACS Appl. Mater. Interfaces 8, 24352440 (2016). https://doi.org/10.1021/acsami.5b11815

144. N. Kurra, M.K. Hota, H.N. Alshareef, Conducting polymer micro-supercapacitors for flexible energy storage and Ac line-filtering. Nano Energy 13, 500-508 (2015). https://doi. org/10.1016/j.nanoen.2015.03.018

145. N. Hui, F. Chai, P. Lin, Z. Song, X. Sun, Y. Li, S. Niu, X. Luo, Electrodeposited conducting polyaniline nanowire arrays aligned on carbon nanotubes network for high performance supercapacitors and sensors. Electrochim. Acta 199, 234-241 (2016). https://doi.org/10.1016/j.electacta.2016.03.115

146. X.-Y. Peng, F. Luan, X.-X. Liu, D. Diamond, K.-T. Lau, pHcontrolled morphological structure of polyaniline during electrochemical deposition. Electrochim. Acta 54, 6172-6177 (2009). https://doi.org/10.1016/j.electacta.2009.05.075

147. B. Yao, L. Yuan, X. Xiao, J. Zhang, Y. Qi et al., Paper-based solid-state supercapacitors with pencil-drawing graphite/polyaniline networks hybrid electrodes. Nano Energy 2, 10711078 (2013). https://doi.org/10.1016/j.nanoen.2013.09.002

148. Y. Wang, Y. Shi, L. Pan, Y. Ding, Y. Zhao, Y. Li, Y. Shi, G. $\mathrm{Yu}$, Dopant-enabled supramolecular approach for controlled synthesis of nanostructured conductive polymer hydrogels. Nano Lett. 15, 7736-7741 (2015). https://doi.org/10.1021/ acs.nanolett.5b03891

149. Z.H. Huang, Y. Song, X.X. Xu, X.X. Liu, Ordered polypyrrole nanowire arrays grown on a carbon cloth substrate for a high-performance pseudocapacitor electrode. ACS Appl. Mater. Interfaces 7, 25506-25513 (2015). https://doi. org/10.1021/acsami.5b08830

150. S. Huang, Y. Han, S. Lyu, W. Lin, P. Chen, S. Fang, A facile one-step approach for the fabrication of polypyrrole nanowire/carbon fiber hybrid electrodes for flexible high performance solid-state supercapacitors. Nanotechnology 28, 435204 (2017). https://doi.org/10.1088/1361-6528/aa84cb

151. J. Huang, R.B. Kaner, Nanofiber formation in the chemical polymerization of aniline: a mechanistic study. Angew. Chem. Int. Ed. 43, 5817-5821 (2004). https://doi.org/10.1002/ anie. 200460616

152. N.R. Chiou, C. Lu, J. Guan, L.J. Lee, A.J. Epstein, Growth and alignment of polyaniline nanofibres with superhydrophobic, superhydrophilic and other properties. Nat. Nanotechnol. 2, 354-357 (2007). https://doi.org/10.1038/nnano.2007.147

153. K. Wang, J. Huang, Z. Wei, Conducting polyaniline nanowire arrays for high performance supercapacitors. J. Phys. Chem. C 114, 8062-8067 (2010). https://doi.org/10.1021/jp9113255

154. Y.-J. Ye, Z.-H. Huang, Y. Song, J.-W. Geng, X.-X. Xu, X.-X. Liu, Electrochemical growth of polyaniline nanowire arrays on graphene sheets in partially exfoliated graphite foil for high-performance supercapacitive materials. Electrochim. Acta 240, 72-79 (2017). https://doi.org/10.1016/j.elect acta.2017.04.025

155. H.-P. Cong, X.-C. Ren, P. Wang, S.-H. Yu, Flexible graphene-polyaniline composite paper for high-performance supercapacitor. Energy Environ. Sci. 6, 1185-1191 (2013). https://doi.org/10.1039/c2ee24203f

156. M. Yu, Y. Ma, J. Liu, S. Li, Polyaniline nanocone arrays synthesized on three-dimensional graphene network by electrodeposition for supercapacitor electrodes. Carbon 87, 98-105 (2015). https://doi.org/10.1016/j.carbon.2015.02.017

157. G.F. Chen, X.X. Li, L.Y. Zhang, N. Li, T.Y. Ma, Z.Q. Liu, A porous perchlorate-doped polypyrrole nanocoating on nickel nanotube arrays for stable wide-potential-window supercapacitors. Adv. Mater. 28, 7680-7687 (2016). https://doi. org/10.1002/adma.201601781

158. G. Lu, G. Shi, Electrochemical polymerization of pyrene in the electrolyte of boron trifluoride diethyl etherate containing trifluoroacetic acid and polyethylene glycol oligomer. J. Electroanal. Chem. 586, 154-160 (2006). https://doi. org/10.1016/j.jelechem.2005.10.020

159. D.P. Dubal, S.H. Lee, J.G. Kim, W.B. Kim, C.D. Lokhande, Porous polypyrrole clusters prepared by electropolymerization for a high performance supercapacitor. J. Mater. Chem. 22, 3044-3052 (2012). https://doi.org/10.1039/c2jm14470k

160. D.W. Wang, F. Li, J. Zhao, W. Ren, Z.G. Chen et al., Fabrication of graphene/polyaniline composite paper via in situ anodic electropolymerization for high-performance flexible electrode. ACS Nano 3, 1745-1752 (2009). https://doi. org/10.1021/nn900297m

161. J. Han, Y. Dou, J. Zhao, M. Wei, D.G. Evans, X. Duan, Flexible CoAl LDH@PEDOT core/shell nanoplatelet array for high-performance energy storage. Small 9, 98-106 (2013). https://doi.org/10.1002/smll.201201336

162. G. Lu, L. Qu, G. Shi, Electrochemical fabrication of neuron-type networks based on crystalline oligopyrene nanosheets. Electrochim. Acta 51, 340-346 (2005). https:// doi.org/10.1016/j.electacta.2005.04.043

163. X. He, W. Yang, X. Mao, L. Xu, Y. Zhou et al., All-solid state symmetric supercapacitors based on compressible and flexible free-standing 3D carbon nanotubes (CNTs)/poly(3,4-ethylenedioxythiophene) (PEDOT) sponge electrodes. J. Power Sources 376, 138-146 (2018). https://doi.org/10.1016/j.jpows our.2017.09.084

164. H. Park, J.W. Kim, S.Y. Hong, G. Lee, D.S. Kim, J.H. Oh et al., Microporous polypyrrole-coated graphene foam for high-performance multifunctional sensors and flexible supercapacitors. Adv. Funct. Mater. 28, 1707013 (2018). https:// doi.org/10.1002/adfm.201707013

165. C. Wang, Y. Ding, Y. Yuan, A. Cao, X. He, Q. Peng, Y. Li, Multifunctional, highly flexible, free-standing 3D polypyrrole foam. Small 12, 4070-4076 (2016). https://doi.org/10.1002/ smll.201601905

166. D.-Y. Feng, Z. Sun, Z.-H. Huang, X. Cai, Y. Song, X.-X. Liu, Highly loaded manganese oxide with high rate capability for capacitive applications. J. Power Sources 396, 238-245 (2018). https://doi.org/10.1016/j.jpowsour.2018.06.026

167. T. Zhai, S. Xie, M. Yu, P. Fang, C. Liang, X. Lu, Y. Tong, Oxygen vacancies enhancing capacitive properties of $\mathrm{MnO}_{2}$ nanorods for wearable asymmetric supercapacitors. Nano 
Energy 8, 255-263 (2014). https://doi.org/10.1016/j.nanoe n.2014.06.013

168. Z. Sun, S. Firdoz, E.Y. Yap, L. Li, X. Lu, Hierarchically structured $\mathrm{MnO}_{2}$ nanowires supported on hollow Ni dendrites for high-performance supercapacitors. Nanoscale 5, 4379-4387 (2013). https://doi.org/10.1039/c3nr00209h

169. W. Wei, X. Cui, W. Chen, D.G. Ivey, Phase-controlled synthesis of $\mathrm{MnO}_{2}$ nanocrystals by anodic electrodeposition: implications for high-rate capability electrochemical supercapacitors. J. Phys. Chem. C 112, 15075-15083 (2008). https ://doi.org/10.1021/jp804044s

170. W. Wei, X. Cui, X. Mao, W. Chen, D.G. Ivey, Morphology evolution in anodically electrodeposited manganese oxide nanostructures for electrochemical supercapacitor applications-effect of supersaturation ratio. Electrochim. Acta 56, 1619-1628 (2011). https://doi.org/10.1016/j.elect acta.2010.10.044

171. F. Grote, Y. Lei, A complete three-dimensionally nanostructured asymmetric supercapacitor with high operating voltage window based on PPy and $\mathrm{MnO}_{2}$. Nano Energy 10, 63-70 (2014). https://doi.org/10.1016/j.nanoen.2014.08.019

172. S.B. Singh, T.I. Singh, N.H. Kim, J.H. Lee, A core-shell $\mathrm{MnO}_{2} @$ Au nanofiber network as a high-performance flexible transparent supercapacitor electrode. J. Mater. Chem. A 7, 10672-10683 (2019). https://doi.org/10.1039/c9ta00778d

173. Q. Li, X.F. Lu, H. Xu, Y.X. Tong, G.R. Li, Carbon/ $/ \mathrm{MnO}_{2}$ double-walled nanotube arrays with fast ion and electron transmission for high-performance supercapacitors. ACS Appl. Mater. Interfaces 6, 2726-2733 (2014). https://doi. org/10.1021/am405271q

174. H. Xia, J. Feng, H. Wang, M.O. Lai, L. Lu, $\mathrm{MnO}_{2}$ nanotube and nanowire arrays by electrochemical deposition for supercapacitors. J. Power Sources 195, 4410-4413 (2010). https:// doi.org/10.1016/j.jpowsour.2010.01.075

175. J. Duay, S.A. Sherrill, Z. Gui, E. Gillette, S.B. Lee, Self-limiting electrodeposition of hierarchical $\mathrm{MnO}_{2}$ and $\mathrm{Mn}(\mathrm{OH})_{2} /$ $\mathrm{MnO}_{2}$ nanofibril/nanowires: mechanism and supercapacitor properties. ACS Nano 7, 1200-1214 (2013). https://doi. org/10.1021/nn3056077

176. X. Lu, M. Yu, G. Wang, T. Zhai, S. Xie, Y. Ling, Y. Tong, Y. Li, H-TiO ${ }_{2} @ \mathrm{MnO}_{2} / / \mathrm{H}-\mathrm{TiO}_{2} @ \mathrm{C}$ core-shell nanowires for high performance and flexible asymmetric supercapacitors. Adv. Mater. 25, 267-272 (2013). https://doi.org/10.1002/ adma.201203410

177. E. Eustache, C. Douard, R. Retoux, C. Lethien, T. Brousse, $\mathrm{MnO}_{2}$ thin films on 3D scaffold: microsupercapacitor electrodes competing with "bulk" carbon electrodes. Adv. Energy Mater. 5, 1500680 (2015). https://doi.org/10.1002/ aenm.201500680

178. L. Yuan, X.H. Lu, X. Xiao, T. Zhai, J. Dai et al., Flexible solid-state supercapacitors based on carbon nanoparticles/ $\mathrm{MnO}_{2}$ nanorods hybrid structure. ACS Nano 6, 656-661 (2012). https://doi.org/10.1021/nn2041279

179. S.H. Lee, H. Lee, M.S. Cho, J.-D. Nam, Y. Lee, Morphology and composition control of manganese oxide by the pulse reverse electrodeposition technique for high performance supercapacitors. J. Mater. Chem. A 1, 14606-14611 (2013). https://doi.org/10.1039/c3ta12828h

180. X. Lu, D. Zheng, T. Zhai, Z. Liu, Y. Huang, S. Xie, Y. Tong, Facile synthesis of large-area manganese oxide nanorod arrays as a high-performance electrochemical supercapacitor. Energy Environ. Sci. 4, 2915-2921 (2011). https://doi. org/10.1039/c1ee01338f

181. T. Beyazay, F. Eylul Sarac Oztuna, U. Unal, Self-standing reduced graphene oxide papers electrodeposited with manganese oxide nanostructures as electrodes for electrochemical capacitors. Electrochim. Acta 296, 916-924 (2019). https:// doi.org/10.1016/j.electacta.2018.11.033

182. Q. Chen, Y. Meng, C. Hu, Y. Zhao, H. Shao, N. Chen, L. Qu, $\mathrm{MnO}_{2}$-modified hierarchical graphene fiber electrochemical supercapacitor. J. Power Sources 247, 32-39 (2014). https:// doi.org/10.1016/j.jpowsour.2013.08.045

183. H. Gao, F. Xiao, C.B. Ching, H. Duan, High-performance asymmetric supercapacitor based on graphene hydrogel and nanostructured $\mathrm{MnO}_{2}$. ACS Appl. Mater. Interfaces 4, 28012810 (2012). https://doi.org/10.1021/am300455d

184. S.H. Kazemi, M.A. Kiani, M. Ghaemmaghami, H. Kazemi, Nano-architectured $\mathrm{MnO}_{2}$ electrodeposited on the $\mathrm{Cu}$-decorated nickel foam substrate as supercapacitor electrode with excellent areal capacitance. Electrochim. Acta 197, 107-116 (2016). https://doi.org/10.1016/j.electacta.2016.03.063

185. M. Kundu, L. Liu, Direct growth of mesoporous $\mathrm{MnO}_{2}$ nanosheet arrays on nickel foam current collectors for highperformance pseudocapacitors. J. Power Sources 243, 676681 (2013). https://doi.org/10.1016/j.jpowsour.2013.06.059

186. L. Li, X. Zhang, G. Wu, X. Peng, K. Huo, P.K. Chu, Supercapacitor electrodes based on hierarchical mesoporous $\mathrm{MnO}_{\mathrm{x}} /$ nitrided $\mathrm{TiO}_{2}$ nanorod arrays on carbon fiber paper. Adv. Mater. Interfaces 2, 1400446 (2015). https://doi.org/10.1002/ admi.201400446

187. S.-M. Li, Y.-S. Wang, S.-Y. Yang, C.-H. Liu, K.-H. Chang et al., Electrochemical deposition of nanostructured manganese oxide on hierarchically porous graphene-carbon nanotube structure for ultrahigh-performance electrochemical capacitors. J. Power Sources 225, 347-355 (2013). https:// doi.org/10.1016/j.jpowsour.2012.10.037

188. W. Li, K. Xu, B. Li, J. Sun, F. Jiang et al., $\mathrm{MnO}_{2}$ nanoflower arrays with high rate capability for flexible supercapacitors. ChemElectroChem 1, 1003-1008 (2014). https://doi. org/10.1002/celc.201400006

189. Y.-H. Lin, T.-Y. Wei, H.-C. Chien, S.-Y. Lu, Manganese oxide/carbon aerogel composite: an outstanding supercapacitor electrode material. Adv. Energy Mater. 1, 901-907 (2011). https://doi.org/10.1002/aenm.201100256

190. Z. Pan, Y. Qiu, J. Yang, F. Ye, Y. Xu, X. Zhang, M. Liu, Y. Zhang, Ultra-endurance flexible all-solid-state asymmetric supercapacitors based on three-dimensionally coated $\mathrm{MnO}_{\mathrm{x}}$ nanosheets on nanoporous current collectors. Nano Energy 26, 610-619 (2016). https://doi.org/10.1016/j.nanoe n.2016.05.053

191. Z. Qi, A. Younis, D. Chu, S. Li, A facile and template-free one-pot synthesis of $\mathrm{Mn}_{3} \mathrm{O}_{4}$ nanostructures as electrochemical 
supercapacitors. Nano-Micro Lett. 8, 165-173 (2016). https ://doi.org/10.1007/s40820-015-0074-0

192. A. Rafique, A. Massa, M. Fontana, S. Bianco, A. Chiodoni, C.F. Pirri, S. Hernandez, A. Lamberti, Highly uniform anodically deposited film of $\mathrm{MnO}_{2}$ nanoflakes on carbon fibers for flexible and wearable fiber-shaped supercapacitors. ACS Appl. Mater. Interfaces 9, 28386-28393 (2017). https://doi. org/10.1021/acsami.7b06311

193. W. Wei, X. Cui, W. Chen, D.G. Ivey, Electrochemical cyclability mechanism for $\mathrm{MnO}_{2}$ electrodes utilized as electrochemical supercapacitors. J. Power Sources 186, 543-550 (2009). https://doi.org/10.1016/j.jpowsour.2008.10.058

194. Z. Ye, T. Li, G. Ma, X. Peng, J. Zhao, Morphology controlled $\mathrm{MnO}_{2}$ electrodeposited on carbon fiber paper for high-performance supercapacitors. J. Power Sources 351, 51-57 (2017). https://doi.org/10.1016/j.jpowsour.2017.03.104

195. Y. Zheng, W. Pann, D. Zhengn, C. Sun, Fabrication of functionalized graphene-based $\mathrm{MnO}_{2}$ nanoflower through electrodeposition for high-performance supercapacitor electrodes. J. Electrochem. Soc. 163, D230-D238 (2016). https://doi. org/10.1149/2.0341606jes

196. B. Yao, S. Chandrasekaran, J. Zhang, W. Xiao, F. Qian, C. Zhu, E.B. Duoss, C.M. Spadaccini, M.A. Worsley, Y. Li, Efficient 3D printed pseudocapacitive electrodes with ultrahigh $\mathrm{MnO}_{2}$ loading. Joule 3, 459-470 (2019). https://doi. org/10.1016/j.joule.2018.09.020

197. Y. Song, T. Liu, B. Yao, M. Li, T. Kou et al., Ostwald ripening improves rate capability of high mass loading manganese oxide for supercapacitors. ACS Energy Lett. 2, 1752-1759 (2017). https://doi.org/10.1021/acsenergylett.7b00405

198. Z.-H. Huang, Y. Song, X.-X. Liu, Boosting operating voltage of vanadium oxide-based symmetric aqueous supercapacitor to 2V. Chem. Eng. J. 358, 1529-1538 (2019). https://doi. org/10.1016/j.cej.2018.10.136

199. A.M. Engstrom, F.M. Doyle, Exploring the cycle behavior of electrodeposited vanadium oxide electrochemical capacitor electrodes in various aqueous environments. J. Power Sources 228, 120-131 (2013). https://doi.org/10.1016/j.jpows our.2012.11.075

200. A. Ghosh, E.J. Ra, M. Jin, H.-K. Jeong, T.H. Kim, C. Biswas, Y.H. Lee, High pseudocapacitance from ultrathin $\mathrm{V}_{2} \mathrm{O}_{5}$ films electrodeposited on self-standing carbon-nanofiber paper. Adv. Funct. Mater. 21, 2541-2547 (2011). https://doi. org/10.1002/adfm.201002603

201. R.S. Ingole, B.J. Lokhande, Electrochemically synthesized mesoporous architecture of vanadium oxide on flexible stainless steel for high performance supercapacitor. J. Mater. Sci.: Mater. Electron. 28, 10951-10957 (2017). https://doi. org/10.1007/s10854-017-6875-9

202. C.-H. Lai, C.-K. Lin, S.-W. Lee, H.-Y. Li, J.-K. Chang, M.-J. Deng, Nanostructured Na-doped vanadium oxide synthesized using an anodic deposition technique for supercapacitor applications. J. Alloys Compd. 536, S428-S431 (2012). https ://doi.org/10.1016/j.jallcom.2011.12.038

203. E. Armstrong, M. O’Sullivan, J. O'Connell, J.D. Holmes, C. O'Dwyer, 3D vanadium oxide inverse opal growth by electrodeposition. J. Electrochem. Soc. 162, D605-D612 (2015). https://doi.org/10.1149/2.0541514jes

204. D.L. da Silva, R.G. Delatorre, G. Pattanaik, G. Zangari, W. Figueiredo, R.-P. Blum, H. Niehus, A.A. Pasa, Electrochemical synthesis of vanadium oxide nanofibers. J. Electrochem. Soc. 155, E14 (2008). https://doi.org/10.1149/1.2804856

205. Y.R. Lu, T.Z. Wu, C.L. Chen, D.H. Wei, J.L. Chen, W.C. Chou, C.L. Dong, Mechanism of electrochemical deposition and coloration of electrochromic $\mathrm{V}_{2} \mathrm{O}_{5}$ nano thin films: an in situ X-ray spectroscopy study. Nanoscale Res. Lett. 10, 387 (2015). https://doi.org/10.1186/s11671-015-1095-9

206. D. Rehnlund, M. Valvo, K. Edström, L. Nyholm, Electrodeposition of vanadium oxide/manganese oxide hybrid thin films on nanostructured aluminum substrates. J. Electrochem. Soc. 161, D515-D521 (2014). https://doi.org/10.1149/2.05114 $10 \mathrm{jes}$

207. K. Takahashi, S.J. Limmer, Y. Wang, G. Cao, Synthesis and electrochemical properties of single-crystal $\mathrm{V}_{2} \mathrm{O}_{5}$ nanorod arrays by template-based electrodeposition. J. Phys. Chem. B 108, 9795-9800 (2004). https://doi.org/10.1021/jp0491820

208. Y. Wang, K. Takahashi, H. Shang, G. Cao, Synthesis and electrochemical properties of vanadium pentoxide nanotube arrays. J. Phys. Chem. B 109, 3085-3088 (2005). https://doi. org/10.1021/jp044286w

209. J.-D. Xie, H.-Y. Li, T.-Y. Wu, J.-K. Chang, Y.A. Gandomi, Electrochemical energy storage of nanocrystalline vanadium oxide thin films prepared from various plating solutions for supercapacitors. Electrochim. Acta 273, 257-263 (2018). https://doi.org/10.1016/j.electacta.2018.04.007

210. H. Drosos, A. Sapountzis, E. Koudoumas, N. Katsarakis, D. Vernardou, Effect of deposition current density on electrodeposited vanadium oxide coatings. J. Mater. Chem. 159, E145-E147 (2012). https://doi.org/10.1149/2.017208jes

211. Q. Qu, Y. Zhu, X. Gao, Y. Wu, Core-shell structure of polypyrrole grown on $\mathrm{V}_{2} \mathrm{O}_{5}$ nanoribbon as high performance anode material for supercapacitors. Adv. Energy Mater. 2, 950-955 (2012). https://doi.org/10.1002/aenm.201200088

212. J.G. Wang, H. Liu, H. Liu, W. Hua, M. Shao, Interfacial constructing flexible $\mathrm{V}_{2} \mathrm{O}_{5} @$ polypyrrole core-shell nanowire membrane with superior supercapacitive performance. ACS Appl. Mater. Interfaces. 10, 18816-18823 (2018). https://doi. org/10.1021/acsami.8b05660

213. T.M. McEvoy, K.J. Stevenson, Elucidation of the electrodeposition mechanism of molybdenum oxide from iso- and peroxo-polymolybdate solutions. J. Mater. Res. 19, 429-438 (2011). https://doi.org/10.1557/jmr.2004.19.2.429

214. V.S. Saji, C.W. Lee, Molybdenum, molybdenum oxides, and their electrochemistry. Chemsuschem 5, 1146-1161 (2012). https://doi.org/10.1002/cssc.201100660

215. W. Zhang, H. Li, C.J. Firby, M. Al-Hussein, A.Y. Elezzabi, Oxygen-vacancy-tunable electrochemical properties of electrodeposited molybdenum oxide films. ACS Appl. Mater. Interfaces. 11, 20378-20385 (2019). https://doi.org/10.1021/ acsami.9b04386

216. H. Farsi, F. Gobal, H. Raissi, S. Moghiminia, The pH effects on the capacitive behavior of nanostructured molybdenum 
oxide. J. Solid State Electrochem. 14, 681-686 (2009). https ://doi.org/10.1007/s10008-009-0828-z

217. H. Farsi, F. Gobal, H. Raissi, S. Moghiminia, On the pseudocapacitive behavior of nanostructured molybdenum oxide. J. Solid State Electrochem. 14, 643-650 (2009). https://doi. org/10.1007/s10008-009-0830-5

218. T. Tsumura, Lithium insertion/extraction reaction on crystalline $\mathrm{MoO}_{3}$. Solid State Ion. 104, 183-189 (1997). https://doi. org/10.1016/s0167-2738(97)00418-9

219. C.R. Clayton, Y.C. Lu, Electrochemical and XPS evidence of the aqueous formation of $\mathrm{Mo}_{2} \mathrm{O}_{5}$. Surf. Interface Anal. 14, 66-70 (1989). https://doi.org/10.1002/sia.740140114

220. C. Liu, Z. Xie, W. Wang, Z. Li, Z. Zhang, The Ti@ MoO nanorod array as a threedimensional film electrode for microsupercapacitors. Electrochem. Commun. 44, 23-26 (2014). https://doi.org/10.1016/j.elecom.2014.04.007

221. C. Liu, Z. Xie, W. Wang, Z. Li, Z. Zhang, Fabrication of $\mathrm{MoO}_{\mathrm{x}}$ film as a conductive anode material for microsupercapacitors by electrodeposition and annealing. J. Electrochem. Soc. 161, A1051-A1057 (2014). https://doi. org/10.1149/2.081406jes

222. K.K. Upadhyay, T. Nguyen, T.M. Silva, M.J. Carmezim, M.F. Montemor, Electrodeposited $\mathrm{MoO}_{\mathrm{x}}$ films as negative electrode materials for redox supercapacitors. Electrochim. Acta 225, 19-28 (2017). https://doi.org/10.1016/j.elect acta.2016.12.106

223. D.D. Yao, J.Z. Ou, K. Latham, S. Zhuiykov, A.P. O’Mullane, K. Kalantar-zadeh, Electrodeposited $\alpha$ - and $\beta$-phase $\mathrm{MoO}_{3}$ films and investigation of their gasochromic properties. Cryst. Growth Des. 12, 1865-1870 (2012). https://doi.org/10.1021/ cg201500b

224. F. Wang, Z. Liu, X. Wang, X. Yuan, X. Wu, Y. Zhu, L. Fu, $\mathrm{Y}$. $\mathrm{Wu}, \mathrm{A}$ conductive polymer coated $\mathrm{MoO}_{3}$ anode enables an Al-ion capacitor with high performance. J. Mater. Chem. A 4, 5115-5123 (2016). https://doi.org/10.1039/c6ta01398h

225. S. Sun, X. Liao, Y. Sun, G. Yin, Y. Yao, Z. Huang, X. Pu, Facile synthesis of a $\alpha-\mathrm{MoO}_{3}$ nanoplate/TiO nanotube composite for high electrochemical performance. RSC Adv. 7, 22983-22989 (2017). https://doi.org/10.1039/c7ra01164d

226. X. Xiao, T. Ding, L. Yuan, Y. Shen, Q. Zhong et al., $\mathrm{WO}_{3-\mathrm{x}} /$ $\mathrm{MoO}_{3}$ Electrochemical and XPS evidence of the aqueous formation of $\mathrm{Mo}_{2} \mathrm{O}_{5 \mathrm{x}}$ core/shell nanowires on carbon fabric as an anode for all-solid-state asymmetric supercapacitors. Adv. Energy Mater. 2, 1328-1332 (2012). https://doi.org/10.1002/ aenm. 201200380

227. G.-R. Li, Z.-L. Wang, F.-L. Zheng, Y.-N. Ou, Y.-X. Tong, $\mathrm{ZnO} @ \mathrm{MoO}_{3}$ core/shell nanocables: facile electrochemical synthesis and enhanced supercapacitor performances. J. Mater. Chem. 21, 4217-4221 (2011). https://doi.org/10.1039/ c0jm03500a

228. J.-C. Liu, H. Li, M. Batmunkh, X. Xiao, Y. Sun et al., Structural engineering to maintain the superior capacitance of molybdenum oxides at ultrahigh mass loadings. J. Mater. Chem. A 7, 23941-23948 (2019). https://doi.org/10.1039/ c9ta04835a
229. X.F. Lu, Z.X. Huang, Y.X. Tong, G.R. Li, Asymmetric supercapacitors with high energy density based on helical hierarchical porous $\mathrm{Na}_{\mathrm{x}} \mathrm{MnO}_{2}$ and $\mathrm{MoO}_{2}$. Chem. Sci. 7, 510-517 (2016). https://doi.org/10.1039/c5sc03326h

230. H. Zheng, J.Z. Ou, M.S. Strano, R.B. Kaner, A. Mitchell, K. Kalantar-zadeh, Nanostructured tungsten oxide-properties, synthesis, and applications. Adv. Funct. Mater. 21, 21752196 (2011). https://doi.org/10.1002/adfm.201002477

231. B. Yang, H. Li, M. Blackford, V. Luca, Novel low density mesoporous $\mathrm{WO}_{3}$ films prepared by electrodeposition. Curr. Appl. Phys. 6, 436-439 (2006). https://doi.org/10.1016/j. cap.2005.11.035

232. S. Wang, X. Feng, J. Yao, L. Jiang, Controlling wettability and photochromism in a dual-responsive tungsten oxide film. Angew. Chem. Int. Ed. 45, 1264-1267 (2006). https://doi. org/10.1002/anie.200502061

233. P. Shen, N. Chi, K.-Y. Chan, Morphology of electrodeposited $\mathrm{WO}_{3}$ studied by atomic force microscopy. J. Mater. Chem. 10, 697-700 (2000). https://doi.org/10.1039/a908348k

234. Z. Sun, X.G. Sang, Y. Song, D. Guo, D.Y. Feng, X. Sun, X.X. Liu, A high performance tungsten bronze electrode in a mixed electrolyte and applications in supercapacitors. Chem. Commun. 55, 14323-14326 (2019). https://doi.org/10.1039/ c9cc06845g

235. G. Yang, X.-X. Liu, Electrochemical fabrication of interconnected tungsten bronze nanosheets for high performance supercapacitor. J. Power Sources 383, 17-23 (2018). https:// doi.org/10.1016/j.jpowsour.2018.02.035

236. T. Pauporté, A simplified method for $\mathrm{WO}_{3}$ electrodeposition. J. Electrochem. Soc. 149, C539-C545 (2002). https:// doi.org/10.1088/2053-1583/ab1e0a

237. S.H. Baeck, K.S. Choi, T.F. Jaramillo, G.D. Stucky, E.W. McFarland, Enhancement of photocatalytic and electrochromic properties of electrochemically fabricated mesoporous $\mathrm{WO}_{3}$ thin films. Adv. Mater. 15, 1269-1273 (2003). https:// doi.org/10.1002/adma.200304669

238. A.K. Srivastava, M. Deepa, S. Singh, R. Kishore, S.A. Agnihotry, Microstructural and electrochromic characteristics of electrodeposited and annealed $\mathrm{WO}_{3}$ films. Solid State Ionics 176, 1161-1168 (2005). https://doi.org/10.1016/j. ssi.2004.10.006

239. M. Deepa, A.K. Srivastava, T.K. Saxena, S.A. Agnihotry, Annealing induced microstructural evolution of electrodeposited electrochromic tungsten oxide films. Appl. Surf. Sci. 252, 1568-1580 (2005). https://doi.org/10.1016/j.apsus c. 2005.02 .123

240. M. Deepa, M. Kar, S.A. Agnihotry, Electrodeposited tungsten oxide films: annealing effects on structure and electrochromic performance. Thin Solid Films 468, 32-42 (2004). https:// doi.org/10.1016/j.tsf.2004.04.056

241. C. Yao, B. Wei, H. Li, G. Wang, Q. Han, H. Ma, Q. Gong, Carbon-encapsulated tungsten oxide nanowires as a stable and high-rate anode material for flexible asymmetric supercapacitors. J. Mater. Chem. A 5, 56-61 (2017). https://doi. org/10.1039/c6ta08274b 
242. Y. Zeng, M. Yu, Y. Meng, P. Fang, X. Lu, Y. Tong, Iron-based supercapacitor electrodes: advances and challenges. Adv. Energy Mater. 6, 1601053 (2016). https://doi.org/10.1002/ aenm. 201601053

243. Q. Xia, M. Xu, H. Xia, J. Xie, Nanostructured iron oxide/ hydroxide-based electrode materials for supercapacitors. ChemNanoMat 2, 588-600 (2016). https://doi.org/10.1002/ cnma. 201600110

244. J. Chen, J. Xu, S. Zhou, N. Zhao, C.-P. Wong, Amorphous nanostructured $\mathrm{FeOOH}$ and $\mathrm{Co}-\mathrm{Ni}$ double hydroxides for high-performance aqueous asymmetric supercapacitors. Nano Energy 21, 145-153 (2016). https://doi.org/10.1016/j.nanoe n.2015.12.029

245. X.-F. Lu, X.-Y. Chen, W. Zhou, Y.-X. Tong, G.-R. Li, $\alpha-\mathrm{Fe}_{2} \mathrm{O}_{3} @ \mathrm{PANI}$ core-shell nanowire arrays as negative electrodes for asymmetric supercapacitors. ACS Appl. Mater. Interfaces 7, 14843-14850 (2015). https://doi.org/10.1021/ acsami.5b03126

246. J. Liu, M. Zheng, X. Shi, H. Zeng, H. Xia, Amorphous FeOOH quantum dots assembled mesoporous film anchored on graphene nanosheets with superior electrochemical performance for supercapacitors. Adv. Funct. Mater. 26, 919-930 (2016). https://doi.org/10.1002/adfm.201504019

247. J. Sun, Y. Huang, C. Fu, Y. Huang, M. Zhu, X. Tao, C. Zhi, H. $\mathrm{Hu}$, A high performance fiber-shaped PEDOT@ $\mathrm{MnO}_{2} / / \mathrm{C} @$ $\mathrm{Fe}_{3} \mathrm{O}_{4}$ asymmetric supercapacitor for wearable electronics. J. Mater. Chem. A 4, 14877-14883 (2016). https://doi. org/10.1039/c6ta05898a

248. M.-S. Wu, R.-H. Lee, Electrochemical growth of iron oxide thin films with nanorods and nanosheets for capacitors. J. Electrochem. Soc. 156, A737-A743 (2009). https://doi. org/10.1149/1.3160547

249. K.A. Owusu, L. Qu, J. Li, Z. Wang, K. Zhao et al., Lowcrystalline iron oxide hydroxide nanoparticle anode for high-performance supercapacitors. Nat. Commun. 8, 14264 (2017). https://doi.org/10.1038/ncomms14264

250. W. Fu, E. Zhao, X. Ren, A. Magasinski, G. Yushin, Hierarchical fabric decorated with carbon nanowire/metal oxide nanocomposites for $1.6 \mathrm{~V}$ wearable aqueous supercapacitors. Adv. Energy Mater. 8, 1703454 (2018). https://doi.org/10.1002/ aenm.201703454

251. Y.C. Chen, Y.G. Lin, Y.K. Hsu, S.C. Yen, K.H. Chen, L.C. Chen, Novel iron oxyhydroxide lepidocrocite nanosheet as ultrahigh power density anode material for asymmetric supercapacitors. Small 10, 3803-3810 (2014). https://doi. org/10.1002/smll.201400597

252. X. Tang, R. Jia, T. Zhai, H. Xia, Hierarchical $\mathrm{Fe}_{3} \mathrm{O}_{4} @ \mathrm{Fe}_{2} \mathrm{O}_{3}$ core-shell nanorod arrays as high-performance anodes for asymmetric supercapacitors. ACS Appl. Mater. Interfaces 7, 27518-27525 (2015). https://doi.org/10.1021/acsami.5b097 66

253. Y. Li, J. Xu, T. Feng, Q. Yao, J. Xie, H. Xia, $\mathrm{Fe}_{2} \mathrm{O}_{3}$ nanoneedles on ultrafine nickel nanotube arrays as efficient anode for high-performance asymmetric supercapacitors. Adv. Funct. Mater. 27, 1606728 (2017). https://doi.org/10.1002/ adfm. 201606728
254. T. Deng, W. Zhang, O. Arcelus, J.G. Kim, J. Carrasco et al., Atomic-level energy storage mechanism of cobalt hydroxide electrode for pseudocapacitors. Nat. Commun. 8, 15194 (2017). https://doi.org/10.1038/ncomms15194

255. V. Gupta, S. Gupta, N. Miura, Potentiostatically deposited nanostructured $\mathrm{Co}_{\mathrm{x}} \mathrm{Ni}_{1-\mathrm{x}}$ layered double hydroxides as electrode materials for redox-supercapacitors. J. Power Sources 175, 680-685 (2008). https://doi.org/10.1016/j.jpows our.2007.09.004

256. Y. Zeng, Z. Lai, Y. Han, H. Zhang, S. Xie, X. Lu, Oxygenvacancy and surface modulation of ultrathin nickel cobaltite nanosheets as a high-energy cathode for advanced $\mathrm{Zn}$ ion batteries. Adv. Mater. 30, 1802396 (2018). https://doi. org/10.1002/adma.201802396

257. Y. Zeng, Y. Meng, Z. Lai, X. Zhang, M. Yu et al., An ultrastable and high-performance flexible fiber-shaped $\mathrm{Ni}-\mathrm{Zn}$ battery based on a $\mathrm{Ni}-\mathrm{NiO}$ heterostructured nanosheet cathode. Adv. Mater. 29, 1702698 (2017). https://doi.org/10.1002/ adma.201702698

258. M. Huang, M. Li, C. Niu, Q. Li, L. Mai, Recent advances in rational electrode designs for high-performance alkaline rechargeable batteries. Adv. Funct. Mater. 29, 1807847 (2019). https://doi.org/10.1002/adfm.201807847

259. Y. Liu, N. Fu, G. Zhang, M. Xu, W. Lu, L. Zhou, H. Huang, Design of hierarchical Ni-Co@Ni-Co layered double hydroxide core-shell structured nanotube array for highperformance flexible all-solid-state battery-type supercapacitors. Adv. Funct. Mater. 27, 1605307 (2017). https://doi. org/10.1002/adfm.201605307

260. G. Nagaraju, S. Chandra Sekhar, L. Krishna Bharat, J.S. $\mathrm{Yu}$, Wearable fabrics with self-branched bimetallic layered double hydroxide coaxial nanostructures for hybrid supercapacitors. ACS Nano 11, 10860-10874 (2017). https://doi. org/10.1021/acsnano.7b04368

261. T. Wang, B. Zhao, H. Jiang, H.-P. Yang, K. Zhang et al., Electro-deposition of $\mathrm{CoNi}_{2} \mathrm{~S}_{4}$ flower-like nanosheets on 3D hierarchically porous nickel skeletons with high electrochemical capacitive performance. J. Mater. Chem. A 3, 23035-23041 (2015). https://doi.org/10.1039/c5ta04705f

262. H. Xu, C. Zhang, W. Zhou, G.R. Li, $\mathrm{Co}(\mathrm{OH})_{2} / \mathrm{RGO} / \mathrm{NiO}$ sandwich-structured nanotube arrays with special surface and synergistic effects as high-performance positive electrodes for asymmetric supercapacitors. Nanoscale 7, 16932-16942 (2015). https://doi.org/10.1039/c5nr04449a

263. G. Xiong, P. He, D. Wang, Q. Zhang, T. Chen, T.S. Fisher, Hierarchical Ni-Co hydroxide petals on mechanically robust graphene petal foam for high-energy asymmetric supercapacitors. Adv. Funct. Mater. 26, 5460-5470 (2016). https:// doi.org/10.1002/adfm.201600879

264. J.A. Syed, J. Ma, B. Zhu, S. Tang, X. Meng, Hierarchical multicomponent electrode with interlaced $\mathrm{Ni}(\mathrm{OH})_{2}$ nanoflakes wrapped zinc cobalt sulfide nanotube arrays for sustainable high-performance supercapacitors. Adv. Energy Mater. 7, 1701228 (2017)

265. X. Lu, X. Huang, S. Xie, T. Zhai, C. Wang et al., Controllable synthesis of porous nickel-cobalt oxide nanosheets for 
supercapacitors. J. Mater. Chem. 22, 13357-13364 (2012). https://doi.org/10.1039/c2jm30927k

266. H. Li, Y. Gao, C. Wang, G. Yang, A simple electrochemical route to access amorphous mixed-metal hydroxides for supercapacitor electrode materials. Adv. Energy Mater. 5, 1401767 (2015). https://doi.org/10.1002/aenm.201401767

267. X. Xia, J. Tu, Y. Zhang, J. Chen, X. Wang, C. Gu, C. Guan, J. Luo, H.J. Fan, Porous hydroxide nanosheets on preformed nanowires by electrodeposition: branched nanoarrays for electrochemical energy storage. Chem. Mater. 24, 3793-3799 (2012). https://doi.org/10.1021/cm302416d

268. W. Guo, C. Yu, S. Li, X. Song, H. Huang et al., A universal converse voltage process for triggering transition metal hybrids in situ phase restruction toward ultrahigh-rate supercapacitors. Adv. Mater. 31, 1901241 (2019). https://doi. org/10.1002/adma.201901241

269. J.C. Chen, C.-T. Hsu, C.-C. Hu, Superior capacitive performances of binary nickel-cobalt hydroxide nanonetwork prepared by cathodic deposition. J. Power Sources 253, 205-213 (2014). https://doi.org/10.1016/j.jpowsour.2013.12.073

270. R. Li, S. Wang, Z. Huang, F. Lu, T. He, $\mathrm{NiCo}_{2} \mathrm{~S}_{4} @ \mathrm{Co}(\mathrm{OH})_{2}$ core-shell nanotube arrays in situ grown on $\mathrm{Ni}$ foam for high performances asymmetric supercapacitors. J. Power Sources 312, 156-164 (2016). https://doi.org/10.1016/j.jpows our.2016.02.047

271. H. Pourfarzad, M. Shabani-Nooshabadi, M.R. Ganjali, H. Kashani, Synthesis of Ni-Co-Fe layered double hydroxide and $\mathrm{Fe}_{2} \mathrm{O}_{3}$ /graphene nanocomposites as actively materials for high electrochemical performance supercapacitors. Electrochim. Acta 317, 83-92 (2019). https://doi.org/10.1016/j.elect acta.2019.05.122

272. Z. Li, H. Duan, M. Shao, J. Li, D. O'Hare, M. Wei, Z.L. Wang, Ordered-vacancy-induced cation intercalation into layered double hydroxides: a general approach for high-performance supercapacitors. Chem 4, 2168-2179 (2018). https ://doi.org/10.1016/j.chempr.2018.06.007

273. G. Lee, J.W. Kim, H. Park, J.Y. Lee, H. Lee et al., Dynamically stretchable, planar supercapacitors with buckled carbon nanotube/Mn-Mo mixed oxide electrodes and air-stable organic electrolyte. ACS Nano 13, 855-866 (2019). https:// doi.org/10.1021/acsnano.8b08645

274. K. Okamura, R. Inoue, T. Sebille, K. Tomono, M. Nakayama, An approach to optimize the composition of supercapacitor electrodes consisting of manganese-molybdenum mixed oxide and carbon nanotubes. J. Electrochem. Soc. 158, A711 (2011). https://doi.org/10.1149/1.3578039

275. Y.-H. Li, Q.-Y. Li, H.-Q. Wang, Y.-G. Huang, X.-H. Zhang et al., Synthesis and electrochemical properties of nickelmanganese oxide on MWCNTs/CFP substrate as a supercapacitor electrode. Appl. Energy 153, 78-86 (2015). https:// doi.org/10.1016/j.apenergy.2014.09.055

276. H. Zhou, X. Zou, K. Zhang, P. Sun, M.S. Islam, J. Gong, Y. Zhang, J. Yang, Molybdenum-tungsten mixed oxide deposited into titanium dioxide nanotube arrays for ultrahigh rate supercapacitors. ACS Appl. Mater. Interfaces 9, 1869918709 (2017). https://doi.org/10.1021/acsami.7b01871
277. E. Karaca, D. Gökcen, N.Ö. Pekmez, K. Pekmez, Electrochemical synthesis of PPy composites with nanostructured $\mathrm{MnO}_{\mathrm{x}}, \mathrm{CoO}_{\mathrm{x}}, \mathrm{NiO}_{\mathrm{x}}$, and $\mathrm{FeO}_{\mathrm{x}}$ in acetonitrile for supercapacitor applications. Electrochim. Acta 305, 502-513 (2019). https://doi.org/10.1016/j.electacta.2019.03.060

278. C.H. Ng, H.N. Lim, Y.S. Lim, W.K. Chee, N.M. Huang, Fabrication of flexible polypyrrole/graphene oxide/manganese oxide supercapacitor. Int. J. Energy Res. 39, 344-355 (2015). https://doi.org/10.1002/er.3247

279. L. Chen, L.-J. Sun, F. Luan, Y. Liang, Y. Li, X.-X. Liu, Synthesis and pseudocapacitive studies of composite films of polyaniline and manganese oxide nanoparticles. J. Power Sources 195, 3742-3747 (2010). https://doi.org/10.1016/j. jpowsour.2009.12.036

280. J. Kim, H. Ju, A.I. Inamdar, Y. Jo, J. Han, H. Kim, H. Im, Synthesis and enhanced electrochemical supercapacitor properties of $\mathrm{Ag}-\mathrm{MnO}_{2}$-polyaniline nanocomposite electrodes. Energy 70, 473-477 (2014). https://doi.org/10.1016/j.energ y.2014.04.018

281. Z. Su, C. Yang, C. Xu, H. Wu, Z. Zhang et al., Co-electrodeposition of the $\mathrm{MnO}_{2}-\mathrm{PEDOT}$ :PSS nanostructured composite for high areal mass, flexible asymmetric supercapacitor devices. J. Mater. Chem. A 1, 12432 (2013). https://doi. org/10.1039/c3ta13148c

282. Z. Wang, J. Du, M. Zhang, J. Yu, H. Liu et al., Continuous preparation of high performance flexible asymmetric supercapacitor with a very fast, low-cost, simple and scalable electrochemical co-deposition method. J. Power Sources 437, 226827 (2019). https://doi.org/10.1016/j.jpows our.2019.226827

283. P. Asen, S. Shahrokhian, A. Irajizad, One step electrodeposition of $\mathrm{V}_{2} \mathrm{O}_{5}$ /polypyrrole/graphene oxide ternary nanocomposite for preparation of a high performance supercapacitor. Int. J. Hydrog. Energy 42, 21073-21085 (2017). https://doi. org/10.1016/j.ijhydene.2017.07.008

284. M.H. Bai, L.J. Bian, Y. Song, X.X. Liu, Electrochemical codeposition of vanadium oxide and polypyrrole for highperformance supercapacitor with high working voltage. ACS Appl. Mater. Interfaces 6, 12656-12664 (2014). https://doi. org/10.1021/am502630g

285. M.-Y. Zhang, Y. Song, D. Guo, D. Yang, X. Sun et al., Strongly coupled polypyrrole/molybdenum oxide hybrid films via electrochemical layer-by-layer assembly for pseudocapacitors. J. Mater. Chem. A 7, 9815-9821 (2019). https ://doi.org/10.1039/c9ta00705a

286. J.-W. Geng, Y.-J. Ye, D. Guo, X.-X. Liu, Concurrent electropolymerization of aniline and electrochemical deposition of tungsten oxide for supercapacitor. J. Power Sources 342, 980 989 (2017). https://doi.org/10.1016/j.jpowsour.2017.01.029

287. Y. Wang, S. Dong, X. Wu, M. Li, One-step electrodeposition of $\mathrm{MnO}_{2} @ \mathrm{NiAl}$ layered double hydroxide nanostructures on the nickel foam for high-performance supercapacitors. J. Electrochem. Soc. 164, H56-H62 (2016). https://doi. org/10.1149/2.0861702jes

288. Z. Zeng, P. Sun, J. Zhu, X. Zhu, Porous petal-like $\mathrm{Ni}(\mathrm{OH})_{2}-\mathrm{MnO}_{\mathrm{x}}$ nanosheet electrodes grown on carbon fiber 
paper for supercapacitors. Surf. Interfaces 8, 73-82 (2017). https://doi.org/10.1016/j.surfin.2017.04.011

289. B.-X. Zou, Y. Liang, X.-X. Liu, D. Diamond, K.-T. Lau, Electrodeposition and pseudocapacitive properties of tungsten oxide/polyaniline composite. J. Power Sources 196, 48424848 (2011). https://doi.org/10.1016/j.jpowsour.2011.01.073

290. X. Fan, X. Wang, G. Li, A. Yu, Z. Chen, High-performance flexible electrode based on electrodeposition of polypyrrole/ $\mathrm{MnO}_{2}$ on carbon cloth for supercapacitors. J. Power Sources 326, 357-364 (2016). https://doi.org/10.1016/j.jpows our.2016.05.047

291. C.-C. Hu, C.-Y. Hung, K.-H. Chang, Y.-L. Yang, A hierarchical nanostructure consisting of amorphous $\mathrm{MnO}_{2}, \mathrm{Mn}_{3} \mathrm{O}_{4}$ nanocrystallites, and single-crystalline $\mathrm{MnOOH}$ nanowires for supercapacitors. J. Power Sources 196, 847-850 (2011). https://doi.org/10.1016/j.jpowsour.2010.08.001

292. P. Tang, L. Han, L. Zhang, Facile synthesis of graphite/ PEDOT/ $\mathrm{MnO}_{2}$ composites on commercial supercapacitor separator membranes as flexible and high-performance supercapacitor electrodes. ACS Appl. Mater. Interfaces. 6, 10506-10515 (2014). https://doi.org/10.1021/am5021028

293. N. Zhao, H. Fan, M. Zhang, C. Wang, X. Ren et al., Preparation of partially-cladding $\mathrm{NiCo}-\mathrm{LDH} / \mathrm{Mn}_{3} \mathrm{O}_{4}$ composite by electrodeposition route and its excellent supercapacitor performance. J. Alloys Compd. 796, 111-119 (2019). https://doi. org/10.1016/j.jallcom.2019.05.023

294. D.V. Zhuzhelskii, E.G. Tolstopjatova, S.N. Eliseeva, A.V. Ivanov, S. Miao, V.V. Kondratiev, Electrochemical properties of PEDOT/ $/ \mathrm{WO}_{3}$ composite films for high performance supercapacitor application. Electrochim. Acta 299, 182-190 (2019). https://doi.org/10.1016/j.electacta.2019.01.007

295. S.-Q. Wang, X. Cai, Y. Song, X. Sun, X.-X. Liu, VO $\mathrm{V}_{\mathrm{x}}$ $\mathrm{MoO}_{3}$ nanorod composite for high-performance supercapacitors. Adv. Funct. Mater. 28, 1803901 (2018). https://doi. org/10.1002/adfm.201803901

296. G.-F. Chen, Z.-Q. Liu, J.-M. Lin, N. Li, Y.-Z. Su, Hierarchical polypyrrole based composites for high performance asymmetric supercapacitors. J. Power Sources 283, 484-493 (2015). https://doi.org/10.1016/j.jpowsour.2015.02.103

297. J. Yang, C. Yu, X. Fan, S. Liang, S. Li, H. Huang, Z. Ling, C. Hao, J. Qiu, Electroactive edge site-enriched nickel-cobalt sulfide into graphene frameworks for high-performance asymmetric supercapacitors. Energy Environ. Sci. 9, 12991307 (2016). https://doi.org/10.1039/c5ee03633j

298. J. Zeng, J. Liu, S.S. Siwal, W. Yang, X. Fu, Q. Zhang, Morphological and electronic modification of 3D porous nickel microsphere arrays by cobalt and sulfur dual synergistic modulation for overall water splitting electrolysis and supercapacitors. Appl. Surf. Sci. 491, 570-578 (2019). https://doi. org/10.1016/j.apsusc.2019.06.182

299. B.D. Falola, L. Fan, T. Wiltowski, I.I. Suni, Electrodeposition of $\mathrm{Cu}$-doped $\mathrm{MoS}_{2}$ for charge storage in electrochemical supercapacitors. J. Electrochem. Soc. 164, D674-D679 (2017). https://doi.org/10.1149/2.0421712jes

300. B.D. Falola, T. Wiltowski, I.I. Suni, Electrodeposition of $\mathrm{MoS}_{2}$ for charge storage in electrochemical supercapacitors.
J. Electrochem. Soc. 163, D568-D574 (2016). https://doi. org/10.1149/2.0011610jes

301. X. Zhang, J. Gong, K. Zhang, W. Zhu, J.-C. Li, Q. Ding, Allsolid-state asymmetric supercapacitor based on porous cobalt selenide thin films. J. Alloys Compd. 772, 25-32 (2019). https://doi.org/10.1016/j.jallcom.2018.09.023

302. W. Chen, C. Xia, H.N. Alshareef, One-step electrodeposited nickel cobalt sulfide nanosheet arrays for high-performance asymmetric supercapacitors. ACS Nano 8, 9531-9541 (2014). https://doi.org/10.1021/nn503814y

303. K.R. Prasad, K. Koga, N. Miura, Electrochemical deposition of nanostructured indium oxide: high-performance electrode material for redox supercapacitors. Chem. Mater. 16, 18451847 (2004). https://doi.org/10.1021/cm0497576

304. A. Albu-Yaron, C. Lévy-Clément, A. Katty, S. Bastide, R. Tenne, Influence of the electrochemical deposition parameters on the microstructure of $\mathrm{MoS}_{2}$ thin films. Thin Solid Films 361-362, 223-228 (2000). https://doi.org/10.1016/ s0040-6090(99)00838-x

305. W. Deng, X. Feng, Y. Xiao, C. Li, Layered molybdenum (oxy) pyrophosphate $\left(\mathrm{MoO}_{2}\right)_{2} \mathrm{P}_{2} \mathrm{O}_{7}$ as a cathode material for sodium-ion batteries. ChemElectroChem 5, 1032-1036 (2018). https://doi.org/10.1002/celc.201800005

306. B. Wen, N.A. Chernova, R. Zhang, Q. Wang, F. Omenya, J. Fang, M.S. Whittingham, Layered molybdenum (oxy)pyrophosphate as cathode for lithium-ion batteries. Chem. Mat. 25, 3513-3521 (2013). https://doi.org/10.1021/cm401946h

307. C. Masquelier, L. Croguennec, Polyanionic (phosphates, silicates, sulfates) frameworks as electrode materials for rechargeable Li (or Na) batteries. Chem. Rev. 113, 65526591 (2013). https://doi.org/10.1021/cr3001862

308. R. Murugavel, A. Choudhury, M.G. Walawalkar, R. Pothiraja, C.N. Rao, Metal complexes of organophosphate esters and open-framework metal phosphates: synthesis, structure, transformations, and applications. Chem. Rev. 108, 35493655 (2008). https://doi.org/10.1021/cr000119q

309. R. Sahoo, D.T. Pham, T.H. Lee, T.H.T. Luu, J. Seok, Y.H. Lee, Redox-driven route for widening voltage window in asymmetric supercapacitor. ACS Nano 12, 8494-8505 (2018). https://doi.org/10.1021/acsnano.8b04040

310. Y. Yang, H. Hou, G. Zou, W. Shi, H. Shuai, J. Li, X. Ji, Electrochemical exfoliation of graphene-like two-dimensional nanomaterials. Nanoscale 11, 16-33 (2018). https://doi. org/10.1039/c8nr08227h

311. S. Yang, P. Zhang, F. Wang, A.G. Ricciardulli, M.R. Lohe, P.W.M. Blom, X. Feng, Fluoride-free synthesis of twodimensional titanium carbide (MXene) using a binary aqueous system. Angew. Chem. Int. Ed. 57, 15491-15495 (2018). https://doi.org/10.1002/anie.201809662

312. M. Le Thai, G.T. Chandran, R.K. Dutta, X. Li, R.M. Penner, 100k cycles and beyond: extraordinary cycle stability for $\mathrm{MnO}_{2}$ nanowires imparted by a gel electrolyte. ACS Energy Lett. 1, 57-63 (2016). https://doi.org/10.1021/acsenergyl ett. $6 \mathrm{~b} 00029$

313. P. Zhang, F. Wang, S. Yang, G. Wang, M. Yu, X. Feng, Flexible in-plane micro-supercapacitors: progresses and challenges 
in fabrication and applications. Energy Storage Mater. 28, 160-187 (2020). https://doi.org/10.1016/j.ensm.2020.02.029

314. A. Emrani, P. Vasekar, C.R. Westgate, Effects of sulfurization temperature on CZTS thin film solar cell performances. Sol. Energy 98, 335-340 (2013). https://doi.org/10.1016/j.solen er.2013.09.020

315. J.G. Werner, G.G. Rodríguez-Calero, H.D. Abruña, U. Wiesner, Block copolymer derived 3-D interpenetrating multifunctional gyroidal nanohybrids for electrical energy storage. Energy Environ. Sci. 11, 1261-1270 (2018). https:// doi.org/10.1039/c7ee03571c

316. T. Liu, F. Yang, G. Cheng, W. Luo, Reduced graphene oxide-wrapped $\mathrm{Co} 9-\mathrm{xFexS} 8 / \mathrm{Co}, \mathrm{Fe}-\mathrm{N}-\mathrm{C}$ composite as bifunctional electrocatalyst for oxygen reduction and evolution. Small 14, 1703748 (2018). https://doi.org/10.1002/ smll.201703748
317. H. Niu, Y. Zhang, Y. Liu, B. Luo, N. Xin, W. Shi, MOFsderived $\mathrm{Co}_{9} \mathrm{~S}_{8}$-embedded graphene/hollow carbon spheres film with macroporous frameworks for hybrid supercapacitors with superior volumetric energy density. J. Mater. Chem. A 7, 8503-8509 (2019). https://doi.org/10.1039/c8ta11983j

318. X.M. Lin, J.H. Chen, J.J. Fan, Y. Ma, P. Radjenovic et al., Synthesis and operando sodiation mechanistic study of nitrogen-doped porous carbon coated bimetallic sulfide hollow nanocubes as advanced sodium ion battery anode. Adv. Energy Mater. 9, 1902312 (2019). https://doi.org/10.1002/ aenm.201902312

319. R. Kumar, S. Sahoo, E. Joanni, R.K. Singh, R.M. Yadav et al., A review on synthesis of graphene, h-BN and $\mathrm{MoS}_{2}$ for energy storage applications: recent progress and perspectives. Nano Res. 12, 2655-2694 (2019). https://doi.org/10.1007/ s12274-019-2467-8 